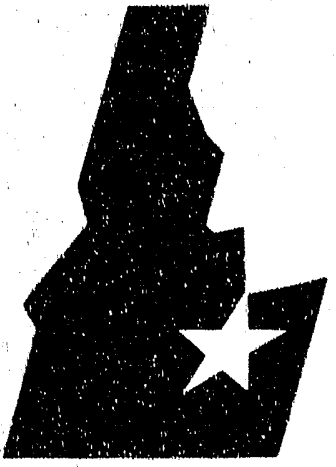

Idaho

National

Engineering

Laboratory

Managed

by the U.S.

Department

of Energy
EGG-NE-10353

ANALYSIS OF TWO SMALL BREAK LOSS-OF-COOLANT EXPERIMENTS IN THE BETHSY FACILITY USING RELAP5/MOD 3

Paul A. Roth

Chul J. Choi

Richard R. Schultz

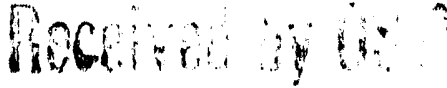

AUC 2 a 19?

Prepared for the

U.S. NUCLEAR REGULATORY COMMISSION

Work pertormed undier

DOE Contract

NO. DE-A. 07.761001570 


\section{NOTICE}

This report was prepared as an account of work sponsored by an agency of the United States Government. Neither the United States Govemment nor any agency chereof, or any of their employees, makes any warranty, expressed or implied, or assumes any legal liability or responsibility for any third party's use, or the results of such use, of any information, apparatus, product or process disclosed in this report, or represents that its use by such third party would not infringe privately owned rights. The views expressed in this report are not necessarily those of the U.S. Nuclear Regulatory Commission. 


\title{
ANALYSIS OF TWO SMALL BREAK LOSS-OF-COOLANT EXPERIMENTS \\ IN THE BETHSY FACILITY USING RELAP5/MOD3
}

\author{
PAUL A. ROTh \\ ChUL J. ChOI' \\ RICHARD R. SCHULTZ \\ Published July 1992 \\ Idaho National Engineering Laboratory \\ EG\&G Idaho, Inc. \\ Idaho Falls, Idaho 83415
}

* Resident Engineer from Korea Atomic Energy Research Institute

Prepared for the Division of Systems Research

Office of Nuclear Regulatory Research

U.S. Nuclear Regulatory Commission, Washington, DC 20555

Under DOE Idaho Field office, Idaho

contract \#DE-AC07-761001570 

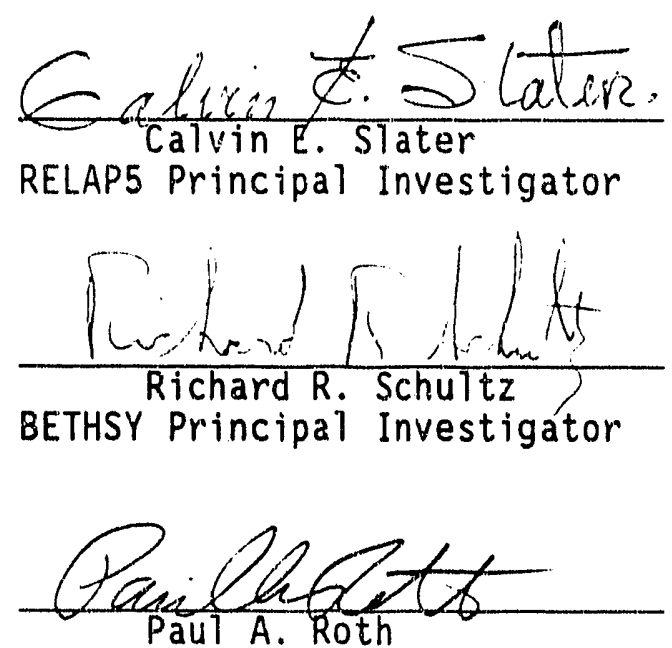

Analysis Principal Author 


\section{ABSTRACT}

Small break loss-of-coolant accident (SBLOCA) data were recorded during tests $9.1 \mathrm{~b}$ and $6.2 \mathrm{TC}$ in the Boucle d'Etudes THermohydrouliques SYsteme (BETHSY) facility at the Centre d'Etudes Nucleares de Grenoble (CENG) complex in Grenoble, France. The data from test $9.1 \mathrm{~b}$ form the basis for the International Standard Problem number 27 (ISP-27). For each test the primary system depressurization, break flow rate, core heat-up, and effect of operator actions were analyzed. Based on the test 9.1b/ISP-27 and 6.2 TC data, an assessment study of the RELAP5/MOD3 version 7 code was performed which included a study of the above phenomena along with countercurrent flow limitation and vapor pull-through. The code provided a reasonable simulation of the various phenomena which occurred during the tests. 


\section{SUMMARY}

Data from tests $9.1 \mathrm{~b}$ and $6.2 \mathrm{TC}$, conducted in the Boucle d'Etudes THermohydrouliques SYsteme (BETHSY) facility in Grenob?e, France, describe the phenomena observed during two smail break loss-of-coolant (SBLOCA) accidents in the facility. Since the two tests were performed from different starting conditions, used different sized break nozzles, and assumed different failures and operator actions, they exhibited somewhat different phenomena. Thus it is interesting and relevant to analyze both tests. The Committee on the Safety of Nuclear Installations (CSNI) of the Organization for Economic Co-operation and Development (OECD) approved test $9.1 \mathrm{~b}$ to be used as the experimental basis for the International standard Problem number 27 (ISP-27).

The BETHSY facility is a $1 / 100$ volume-scaled simulator of a $2775 \mathrm{MW}_{\mathrm{t}}$ 3 loop Framatome pressurized water reactor (PWR). The BETHSY facility has 3 identical loops, with the exception of a pressurizer being mounted in one 10op, and has the same component heights as its Framatome counterpart. BETHSY was designed to be able to study asymmetric phenomena which can occur in a large number of accident scenarios. Hot legs and cold legs were constructed to preserve the pipe length to root pipe diameter scaling between the reference plant and BETHSY.

Test $9.1 \mathrm{~b} /$ ISP-27 involved a $0.5 \%$ (2 inch) cold leg break without available high pressure safety injection. Initially the core operated at $10 \%$ scaled power while the pumps ran at full scaled flow. Reactor scram and a lengthy pump coastdown were used. An operator action was simulated by depressurizing the secondary when core thermocouples detected significant heat up. The experiment continued through accumulator injection and low pressure safety injection (LPSI). No nitrogen was injected into the system. Auxiliary feedwater was used to maintain the secondary level above the top of the steam generator $U$-tubes. This test showed several major phenomena: (a) single- and two-phase flow through a break nozzle, (b) pump operation during two-phase flow, (c) primary and secondary system depressurization, (d) natural circulation and reflux cooling, (e) loop seal clearing, (f) core boiloff, (g) accumulator injection, and (h) LPSI injection. 
Test 6.2 TC involved a $5.0 \%$ ( 6 inch) cold leg break without available high or low pressure safety injection. Initially the core operated at 10 $\%$ scaled power and the pumps ran at reduced flow to obtain a realistic primary temperature distribution. Reactor scram was followed by a rapid shutdown of the primary pumps. Accumulator injection began and was terminated before nitrogen entered the system. The transient was terminated when unmitigated core heat up began. No auxiliary feedwater was used but the $U$-tubes remained covered. This test showed several major phenomena: (a) single- and two-phase flow through a break nozzle, (b) primary system depressurization, (c) natural circulation and reflux cooling, (d) 10op seal clearing, (e) core boiloff, and ( $f$ ) accumulator injection.

The objectives of the $9.1 \mathrm{~b} / 1 \mathrm{SP}-27$ and 6.2 TC test analysis efforts were to (i) gain greater understanding of the phenomena which occur during a small break loss-of-coolant accident, and (ii) assess the RELAP5/MOD3 version 7 code using these data. Objective (i) was reached by evaluating the time progression of several critical parameters for which experimental data were gathered during the tests. Objective (ii) was reached by constructing a RELAP5/MOD3 model of the BETHSY facility and performing calculations of the tests $9.1 \mathrm{~b} /$ ISP-27 and 6.2 TC using the initial and boundary conditions defined by the BETHSY experimenters.

The data analysis of test $9.1 \mathrm{~b} / \mathrm{ISP}-2.7$ showed that this test experienced: (a) a long period of two-phase flow from the break with liquid entrainment and vapor puli-through, (b) a considerable core heat up during boiloff, (c) a single loop seal to clear twice during the transient and (d) the effective use of a delayed accident management procedure, depressurizing the secondary, to prevent core clad temperatures from exceeding safety limits for this very small break.

Analysis of test 6.2 TC showed: (a) a moderately fast primary system depressurization, (b) 10op seal clearing, and (c) counter-current flow limitation causing liquid holdup in the steam generator $U$-tubes.

Following the data analysis, the RELAP5/MOD3 version 7 code assessment was conducted. Using a model with 269 volumes and 276 junctions, the two tests were simulated following the same scenario that occurred during the tests. The RELAP5/MOD3 simulations of the two tests showed reasonable 
agreement with experimental data. The emergency core cooling mixer (ECCMIX) component was found to be inappropriate for use with the $0.5 \%$ break input deck but acceptable for use with the $5.0 \%$ break input deck. A mismatch between the calculated and measured primary inventory distributions at various times during the two transients indicates a likely problem with the interphase drag mode1. An error was identified in the counter-current flow limitation (CCFL) model which has led to a code correction that will appear in RELAP5/MOD3 version 8. Further assessment is required to define the code's secondary modeling capability. 


\section{CONTENTS}

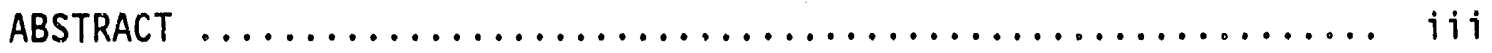

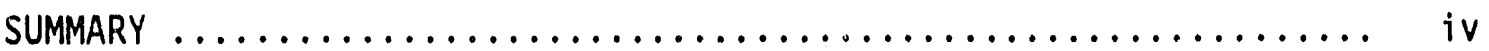

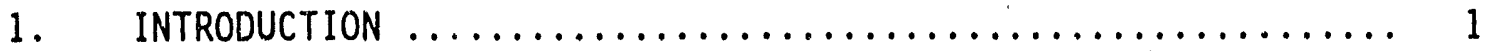

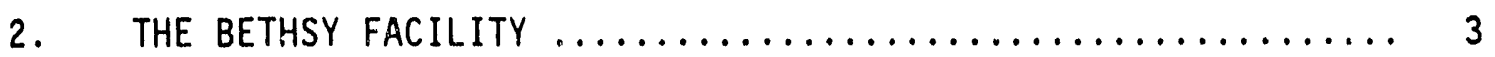

3. EXPERIMENTAL OBSERVATIONS $\ldots \ldots \ldots \ldots \ldots \ldots \ldots \ldots \ldots \ldots \ldots$

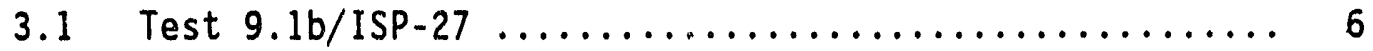

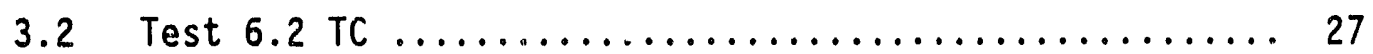

4. RELAP5 $/ M O D 3$ CALCULATIONS $\ldots \ldots \ldots \ldots \ldots \ldots \ldots \ldots \ldots \ldots \ldots \ldots$

4.1 Code and Model $\ldots \ldots \ldots \ldots \ldots \ldots \ldots \ldots \ldots \ldots \ldots, \ldots \ldots \ldots$

4.2 Test 9.1b/ISP-27 Calculation versus Experiment

Comparison ............................. 49

4.3 Test 6.2 TC Calculation versus Experiment Comparison .. 67

5. OBSERVATIONS AND CONCLUSIONS $\ldots \ldots \ldots \ldots \ldots \ldots \ldots \ldots \ldots$

6. REFERENCES $\ldots \ldots \ldots \ldots \ldots \ldots \ldots \ldots \ldots \ldots \ldots \ldots \ldots \ldots \ldots \ldots$

\section{FIGURES}

1. BETHSY facility ............................ 4

2. BETHSY test $9.1 \mathrm{~b} / \mathrm{ISP}-27$ break nozzle $\ldots \ldots \ldots \ldots \ldots \ldots \ldots$

3. BETHSY test $9.1 \mathrm{~b} /$ ISP-27 core power curve $\ldots \ldots \ldots \ldots \ldots \ldots$

4. BETHSY test $9.1 \mathrm{~b} / \mathrm{ISP}-27$ pump speed curve $\ldots \ldots \ldots \ldots \ldots \ldots \ldots 11$

5. BETHSY test 9.1b/ISP-27 primary and secondary system

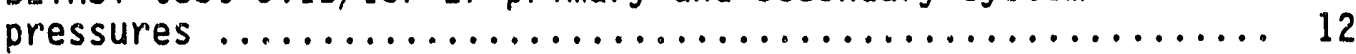

6. BETHSY test 9.1b/ISP-27 primary and secondary system pressures for the first 100 seconds ................... 13

7. BETHSY test $9.1 \mathrm{~b} /$ ISP-27 pressurizer differential pressure for the first 100 seconds ........................... 14

8. BETHSY test $9.1 \mathrm{~b} / \mathrm{ISP}-27$ differential pressure on the downflow side of the loop seals in the 3 loops. One plot shows all three loops together while the other 3 plots show them individually

9. BETHSY test $9.1 \mathrm{~b} /$ ISP-27 vessel collapsed liquid level ...... 18 
10. BETHSY test $9.1 \mathrm{~b} / \mathrm{ISP}-27$ accumulator mass inventory $\ldots . . . .19$

11. BETHSY test 9.1b/ISP-27 core clad temperatures at various elevations above the bottom of the core ................ 21

12. BETHSY test $9.1 \mathrm{~b} / \mathrm{ISP}-27$ core clad temperatures at various elevations above the bottom of the core during the heatup period

13. BETHSY test $9.1 \mathrm{~b} / \mathrm{I}$ 'SP-27 maximum core clad temperature ..... 23

14. BETHSY test 9.1b/ISP-27 cold leg void fractions. One plot shows all three loops together while the other 3 plots show them individually

15. BETHSY test $9.1 \mathrm{~b} / \mathrm{ISP}-27$ cold leg void fraction between

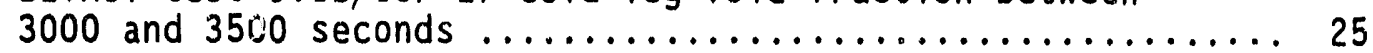

16. BETHSY test $9.1 \mathrm{~b} / \mathrm{ISP}-27$ break mass flow rate $\ldots \ldots \ldots \ldots \ldots 26$

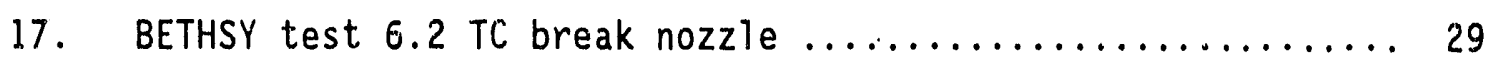

18. BETHSY test 6.2 TC core power curve $\ldots \ldots \ldots \ldots \ldots \ldots \ldots \ldots$

19. BETHSY test 6.2 TC primary and secondary system pressures ... 31

20. BETHSY test 6.2 TC primary and secondary system pressures

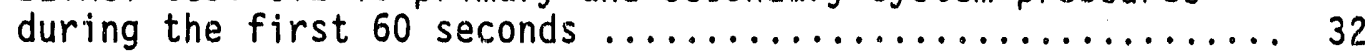

21. BETHSY test 6.2 TC pressurizer differential pressure ...... 34

22. BETHSY test 6.2 TC differential pressure in the downflow side of the loop seals .......................... 35

23. BETHSY test 6.2 TC differential prosure in the downflow side of the loop seals during the first 200 seconds ....... 36

24. BETHSY test 6.2 TC vessel collapsed liquid level ......... 38

25. BETHSY test 6.2 TC core clad temperatures at various elevations above the bottom of the core ............... 39

26. BETHSY test 6.2 TC core clad temperatures at various elevations above the bottom of the core from 250 to

27. BETHSY test 6.2 TC integrated mass injected by the

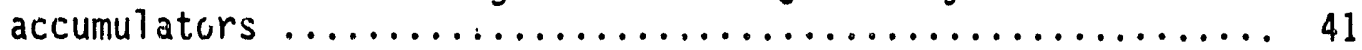

28. BETHSY test 6.2 TC break mass $i$ ow rate $\ldots \ldots \ldots \ldots \ldots \ldots . \ldots 42$

29. RELAP5 model nodalization for the BETHSY facility ........ 46

30. BETHSY test 9.1b/ISP-27 primary pressure comparison between experiment and RELAP5/MOD3 calculation ............... 52 
31. BETHSY test $9.1 \mathrm{~b} /$ ISP-27 secondary pressure comparisen between experiment and RELAP5/MOO3 calculation ............

32. BETHSY test $9.1 \mathrm{~b} /$ ISP-27 broken cold leg void fraction comparison between experiment and RELAP5/MOD3 calculation ...

33. BETHSY test 9.1b/ISP-27 broken cold leg void fraction comparison between experiment and RELAP5/MOD3 calculation

34. BETHSY test $9.1 \mathrm{~b} / \mathrm{ISP}-27$ break mass flow rate comparison between experiment and RELAP5/MOD3 calculation ............

35. BETHSY test $9.1 \mathrm{~b} / \mathrm{ISP}-27$ time integrated break mass flow rate comparison between experiment and RELAP5/M003

calculation

36. BETHSY test 9.1b/ISP-27 core collapsed liquid level comparison between experiment and RELAP5/MOD3 calculation ... 60

37. BETHSY test 9.1b/ISP-27 peak core clad temperature comparison between experiment and RELAP5/MOD3 calculation ...

38. BETHSY test 9.1b/ISP-27 differential pressure in the downflow side of loop 2 loop seal comparison between

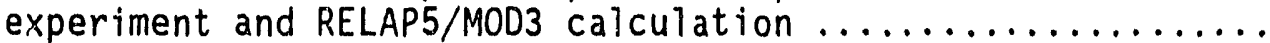

39. BETHSY test 9.1b/ISP-27 differential pressure in the downflow side of loop 3 loop seal comparison between experiment and RELAP5/MOD3 calculation

40. BETHSY test 9.1b/ISP-27 downcomer mass flow rate comparison between experiment and RELAP5/MOD3

calculation

41. BETHSY test 9.Ib/ISP-27 REI.AP5/MOD3 calculated void

fractions in the vicinity of the break ............... 66

42. BETHSY test 6.2 TC break mass flow rate comparison between experiment and RELAP5/MOD3 calculation ................. 70

43. BETHSY test 6.2 TC primary system pressure comparison between experiment and RELAP5/MOD3 calculation ........... 71

44. BETHSY test 6.2 TC secondary system pressure comparison between experiment and RELAP5/MOD3 calculation .......... 72

45. BETHSY test 6.2 TC integrated accumulator mass injection comparison between experiment and RELAP5/M0D3 calculation ... 74

46. BETHSY test 6.2 TC differential pressure in the downflow side of a typical loop seal comparison between experiment

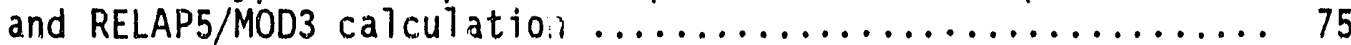

47. BETHSY test 6.2 TC primary fluid inventory comparison between experiment and RELAP5/MOD3 calculation ........... 7 
48. BETHSY test 6.2 TC core collapsed liquid level comparison between experiment and RELAP5/MOD3 calculation ............ 7

49. BETHSY test 6.2 TC differential pressure in the upflow side of a typical U-tube comparison between experiment and RELAP5/MOD3 calculation

50. BETHSY test 6.2 TC rod clad temperature at $1.628 \mathrm{~m}$ above the bottom of the core comparison between experiment and RELAP5/MOD3 calculation

51. BETHSY test $6.2 \mathrm{TC}$ rod $\mathrm{clad}$ temperature at $3.6 \mathrm{~m}$ above the bottom of the core comparison between experiment and

52. BETHSY test 6.2 TC RELAP5/MOD3 calculation typical vaporization rates at the point of accumulator injection

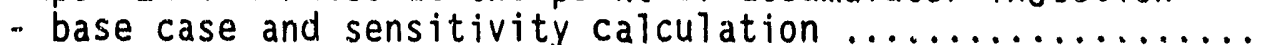

53. BETHSY test 6.2 TC core collapsed 1 iquid level comparison between experiment and two RELAP5/MOD3 calculations .........

54. BETHSY test 6.2 TC RELAP5/MOD3 calculated dimensionless vapor flux versus dimensionless liquid flux - selected points in time

\section{TABLES}

1. Initial conditions for BETHSY test $9.1 \mathrm{~b} /$ ISP-27 ........ 7

2. Major events observed during BETHSY test $9.1 \mathrm{~b} /$ ISP $-27 \ldots \ldots .10$

3. Initial conditions for BETHSY test 6.2 TC ............ 28

4. Chronology of BETHSY test 6.2 TC $\ldots \ldots \ldots \ldots \ldots \ldots \ldots \ldots \ldots$

5. Major events during BETHSY test 6.2 TC $\ldots \ldots \ldots \ldots \ldots \ldots . \ldots 33$

6. Code assessment comparison descriptors $\ldots \ldots \ldots \ldots \ldots \ldots \ldots . \ldots 4$

7. Comparison of experimental and calculated initial conditions for BETHSY test 9.1b/ISP-27 .............. 49

8. Comparison of experimental and calculated chronology for

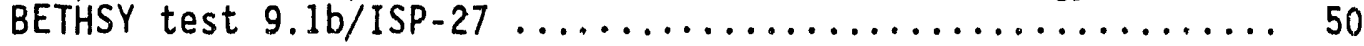

9. Observed ranges for vapor pull-through/liquid entrainment ... 67

10. Comparison of experimental and calculated initial conditions for BETHSY test 6.2 TC

11. Comparison of experimental and calculated chronology for BETHSY test 6.2 TC 


\section{ANALYSIS OF TWO SMALL BREAK LOSS-OF-COOLANT EXPERIMENTS IN THE BETHSY FACILITY USING RELAP5/MOD3}

\section{INTRODUCTION}

The work presented herein assesses the advanced thermal-hydrauilic RELAP5/MOD3 version 7 code' $^{\prime}$ using small break loss-of-cnolant accident (SDLOCA) data from a scaled pressurized water reactor (PWR) test facility. This assissment will be used in conjunction with other code assessments based on separate effects data, integral systems effects ata, and plant operational transient data, currently being done in the Iriternaticnal Code Assessment and Applications Progra ${ }^{2}$, to produce a comprehensive evaluation of the RELAP5/MOD3 code's capabilities and limits of applicability.

The SBLOCA data were recorded in the Boucle d'Etudes THermohydrouliques SYsteme (BETHSY) facility ${ }^{3}$. BETHSY is located at the Centre d'Etudes Nucleares de Grenoble (CENG) in Grenoble, France and is a 1/100-volume scaled, three-10op simulation of a French Framatome, Ltd., three-loop commercial power plant.

The data are comprised of two sets: (a) test 9.lb (which became International Standard Problem number 27, ISP-27): a $0.5 \%$ (.old leg break without high pressure safety injection (HPSI) but with secondary auxiliary feed water (AFW), and (b) test 6.2 TC: a $5.0 \%$ cold leg break with neither HPSI nor AFW. Tests 9.IB/ISP-27 and 6.2 TC were conducted $4,6,8$ in December and September of 1989 respectively.

Some of the phenomena which can occur during a SBLOCA are: (a) vapor pull-through and liojid entrainment at the break, (b) single-phase natural circulation, (c) two-phase natural circulation, (d) reflux-condenser mode circulation, (e) loop seal clearing, (f) liquid holdup in the steam generator U-tubes due to counter-current flow limitation (CCFL) and interphase drag, and $(g)$ core uncovery and boiloff. Several of these phenomena are not well understood and code models to simulate them need further assessment. 
The BETHSY facility is well suited to study asymmetric phenomena during a SBLOCA. Furthermore, the behavior of the 1/100-scale BETHSY factlity is of interest from a scaling perspective with respect to the behavior of other scaled facilities.

In the remainder of this report Section 2 describes the BEIHSY facility, Section 3 describes the experimental findings from test 9.1b/ISP. 27 and test $6.2 \mathrm{TC}$, and Section 4 compares the RELAP5/MOD3 calculations with the experimental data. The results of the analyses are discussed in sectir. 5. 


\section{THE BETHSY FACILITY}

The BETHSY facility ${ }^{3,10}$ (see Figure 1) is a $1 / 100$ volumetrically scaled model, with 1:1 elevation scaling, of a 900 MWe Framatome three 1oop PWR designed to simulate most PWR accident situations of interest while minimizing the distortions of relevant physical phenomena. Because BETHSY has three equaliy sized loops that differ only in the possible break geometries and in the presence of a pressurizer in loop 1, the facility is ideal to investigate asymmetric phenomena which can occur in a large number of accident scenarios. Hot legs and cold legs were built to preserve the pipe length to root pipe diameter sca?ing between the reference plant and BETHSY.

The primary coolant system consists of a pressure vessel and three identical loops (except loop 1 includes the pressurizer). The pressure vessel contains an electrically heated core and a single pipe externa? dowrcomer. Each primary coolant Toop is equipped with an active pump and an active sieam generator. The cylindrical core is composed of 428 heated rods and 2 s guide thimbles simulating $17 \times 17$ fuel assemblies. It also models the internal structures and leakage paths of the reference PWR vessel. Each primary coolant pump has the capability of operating at scaled nominal conditions. Each steam generator has 34 inverted $U$-tubes of the same radial dimensions and heights as those of the reference steam generator. The pressurizer is equipped with six electrical heater rods, normal and auxiliary spray circuits, and a relief circuit. The secondary coolant system is composed of three steam generators, steam lines, a spray condenser, and main and auxiliary feedwater systems.

The BETHSY safety injection systems have the same capabilities as the ieference PWR with some enhancements for sensitivity studies. There are a high pressure safety injection (HPSI) system, accumulators, and a low pressure safety injection (LPSI) system. The break system consists of a break nozzle and a discharge line including spool pieces and blowdown tanks. A trace heating system is installed to compensate for unavoidable heat losses to the environment that are approximately $100 \mathrm{~kW}$ (primary and secondary) at nominal conditions. 


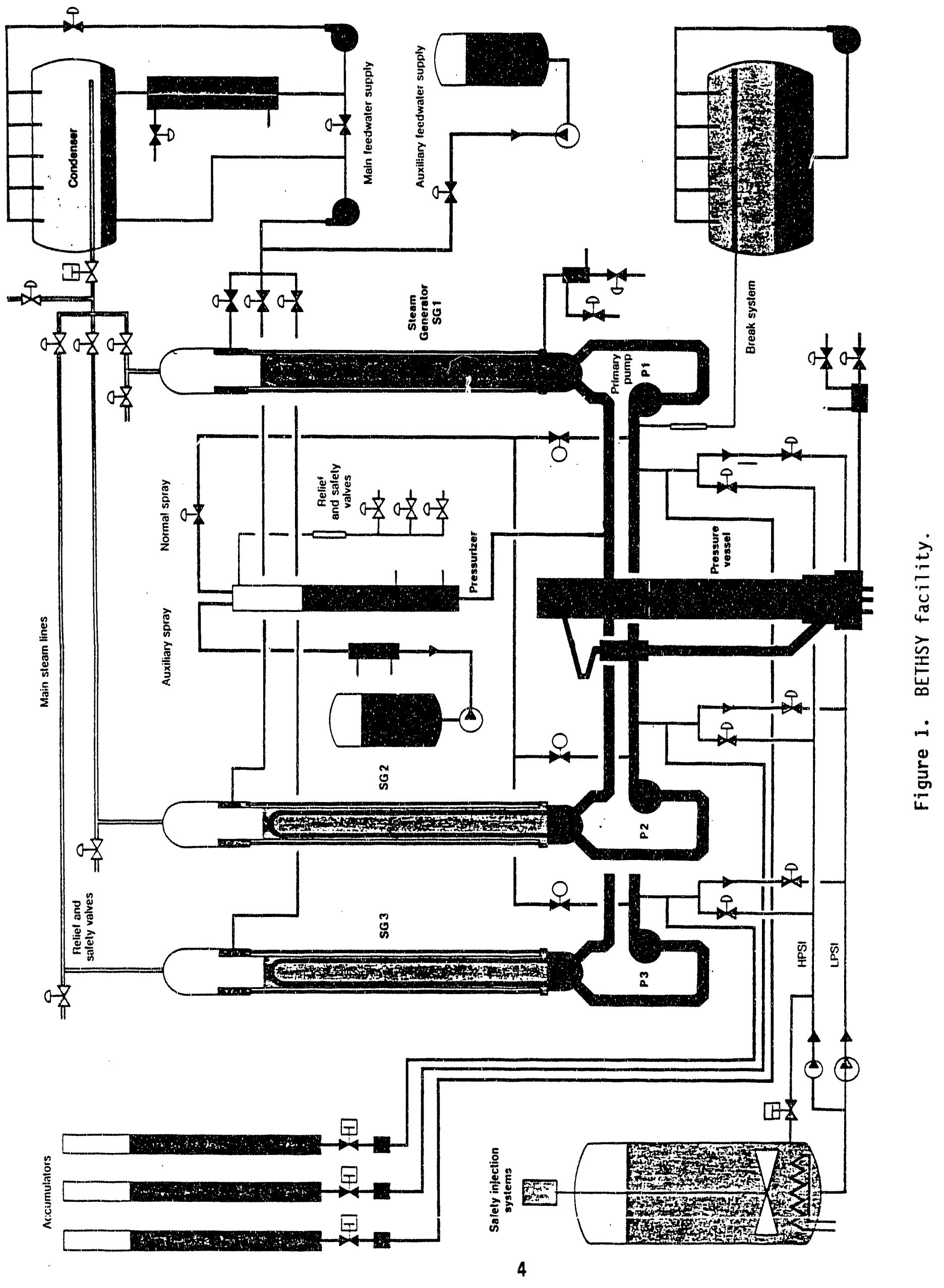


BETHSY is designed to operate at the reference PWR operating pressure and temperatures. However, the electric core can operate at a maximum fower of only $3 \mathrm{MW}$ ( $10 \%$ of rated scaled power). Thus in order to simulate full power steady state initial operating conditions of the reference PWR there is a tradeoff between simulating full scaled flow and a normal temperaiure distribution. If full flow is chosen (as in test 9.1b/ISP-27) the temperature difference across the core is much less than in an actual PIJR. In order to obtain a realistic temperature distribution (as was done in test 6.2 TC) the flow must be reduced which will distort the normal pressure distribution.

The facility is instrumented with 16 pressure transducers in such locations as the steam generator steam domes, the pressurizer, the core outlet, the hot and cold leg spool pieces and the accumulators. Hot leg spool pieces are located approximately $1.0 \mathrm{~m}$ from the vessel in each hot leg. Cold leg spool pieces are located approximately $0.4 \mathrm{~m}$ from the vessel in each cold leg. The spool pieces contain temperature measurements, void fraction measurements, and differential pressure measurements. There are also 122 differential pressure transducers. They are located throughout the loop piping, in the vessel, in the steam generator secondary, and minimally on the primary side of the steam generator $U$-tubes. There are 24 turbine meters for measuring volumetric flow rates which are used to determine the flows in the vessel downcomer, steam generator feed water lines, and steam generator steam lines, as well as several other locations. Thermocouples (224) are used for measuring the temperature of the primary and secondary fluid at a variety of points in the system. They are generally distributed adequately to give the data needed for analysis except in the vicinity of the bypass around the core and on the primary side of the steam generators. In these areas it would have been helpful to have more temperature information. There are 444 thermocouples which are used to measure structure temperatures; 297 of these measure heater rod cladding temperatures. A total of 18 gamma densitometers are distributed between each of the hot leg spool pieces and cold leg spool pieces where they are used to measure the fluid void fraction. The data acquisition system has 1056 channels with a maximum sampling rate of $2 \mathrm{~Hz}$. 


\section{EXPERIMENTAL OBSERVATIONS}

The following subsections describe the two BETHSY tests which have been analyzed, and the experimental findings.

\subsection{Test $9.1 \mathrm{~b} / \mathrm{ISP}-27$}

This test $t^{4.6}$ was a $0.5 \%$ SBLOCA. At the beginning of the test the pumps were operating at full rated scaled flow (corresponding to a downcomer mass flow rate $=150 . \pm 5 \mathrm{~kg} / \mathrm{s}$ and a pump speed of $2940 \pm 30 \mathrm{rpm}$ ) and the core heat was $10 \%$ of rated scaled power $(2857 \pm 30 \mathrm{~kW})$. The pressurizer pressure was $15.51 \pm 0.09 \mathrm{MPa}$. The pressurizer spray and relief circuits were not used during the test. A more complete listing of initial. conditions appears in Table 1.

The scenario for the test can be divided into 10 major events. They are: (a) at time equals zero the break was opened, (b) when the pressurizer pressure reached $13.1 \mathrm{MPa}$ the reactor trip signal was generated but, since the initial reactor power was $10 \%$ of nominal, the core power began its reduction 17 seconds later, (c) when the pressurizer pressure reached 11.9 $M P a$ the safety injection (SI) signal was generated but since HPSI was assumed to have failed the only response to this signal was to shut off the main feedwater and bypass the turbine, (d) 30 seconds after the SI signal auxiliary feedwater was turned on, (e) 300 seconds after the SI signal the pump coastdown was simulated by controlling the pump speed to follow a designated coastdown curve which reduced the pump speed to zero over a time period of 600 seconds, (f) when the maximum core cladding temperature reached $723.15 \mathrm{~K}$ an emergency operator action was simulated by initiating a rapid depressurization of the secondary (referred to as the ultimate procedure - UP), (g) when the pressurizer pressure reached $4.2 \mathrm{MPa}$ accumulator injection began on the two intact loops, ( $h$ ) when the pressurizer pressure reached $1.5 \mathrm{MPa}$ the accumulators were isolated, (i) when the pressurizer pressure reached $0.91 \mathrm{MPa}$ LPSI injection began, $(j)$ when stable conditions for startup of the residual heat removal system (RHRS) were achieved the test was terminated. The stable RHRS startup conditions used for this test were: (i) core outlet temperature less than 
Table 1. Initial conditions for BETHSY test 9.1b/ISP-27.

\begin{tabular}{lr}
\hline \multicolumn{1}{c}{ Parameter } & Value \\
Core power (kW) & $2857 \pm 30$ \\
Pressurizer pressure (MPa) & $15.51 \pm 0.09$ \\
Pressurizer level (m) & $4.02 \pm 0.1$ \\
Pump speed (rpm) & $2940: 30$ \\
Downcomer mass flow rate (kg/s) & $150 \pm 5$ \\
Core inlet temperature (K) & $559.90 \pm 4$ \\
Core outlet temperature (K) & $566.35 \pm 4$ \\
Primary system mass with & \\
pressurizer (kg) & $1940 \pm 40$ \\
Secondary system pressure (MPa) & $6.91 \pm 0.04$ \\
Secondary steam generator level (m) & $13.45 \pm 0.05$ \\
$\begin{array}{l}\text { Secondary mass inventory per } \\
\text { steam generator (kg) }\end{array}$ & $820 \pm 30$ \\
Feed water temperature (K) & \\
Feed water flow rate per steam & \\
generator (kg/s) & \\
Bypass flow: downcomer to upper & \\
head (\% of total loop flow) & \\
Core bypass flow: lower plenum to \\
upper plenum (\% of downcomer flow) \\
$\begin{array}{l}\text { Trace heating (kW) } \\
\text { Pump cooling circuits heat loss } \\
\text { per pump (kW) }\end{array}$ \\
\hline
\end{tabular}

$450.15 \mathrm{~K}$, (ii) pressurizer pressure less than $2.5 \mathrm{MPa}$, (iii) saturation margin at the core outlet greater than $20 \mathrm{~K}$.

The boundary conditions for the test were: (a) the break nozzle (see Figure 2) was horizontal, connected to the side of the cold leg just downstream of the pump outlet flange, and perpendicular to the cold leg axis, (b) the pressurizer was connected through the surge 7 ine to the broken loop (hot leg 1) and did not activate any of the spray, relief, or heate: systems after the opening of the break, (c) the core power followed the scram curve shown in Figure 3 , (d) the pump coastdown followed the curve 


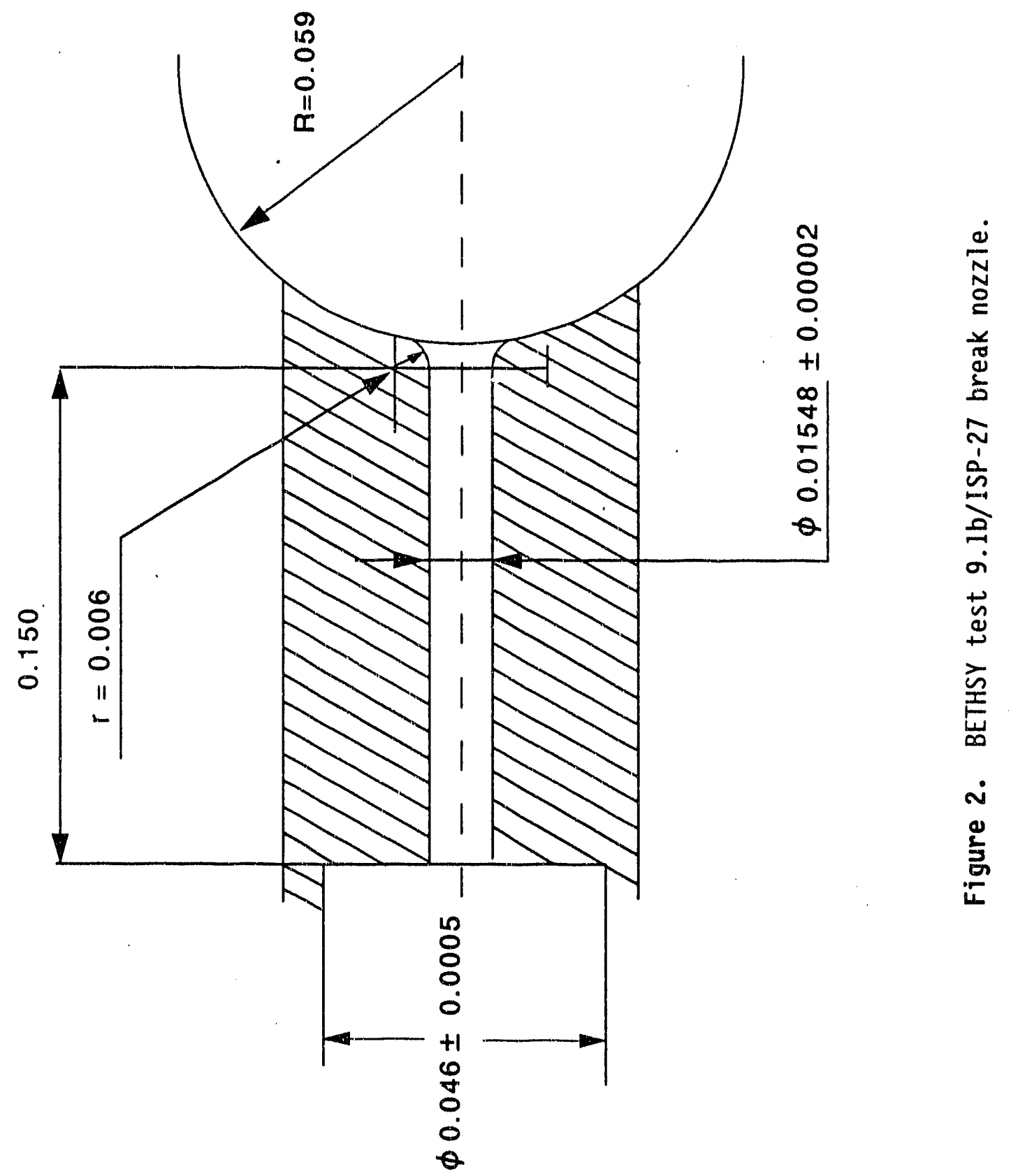




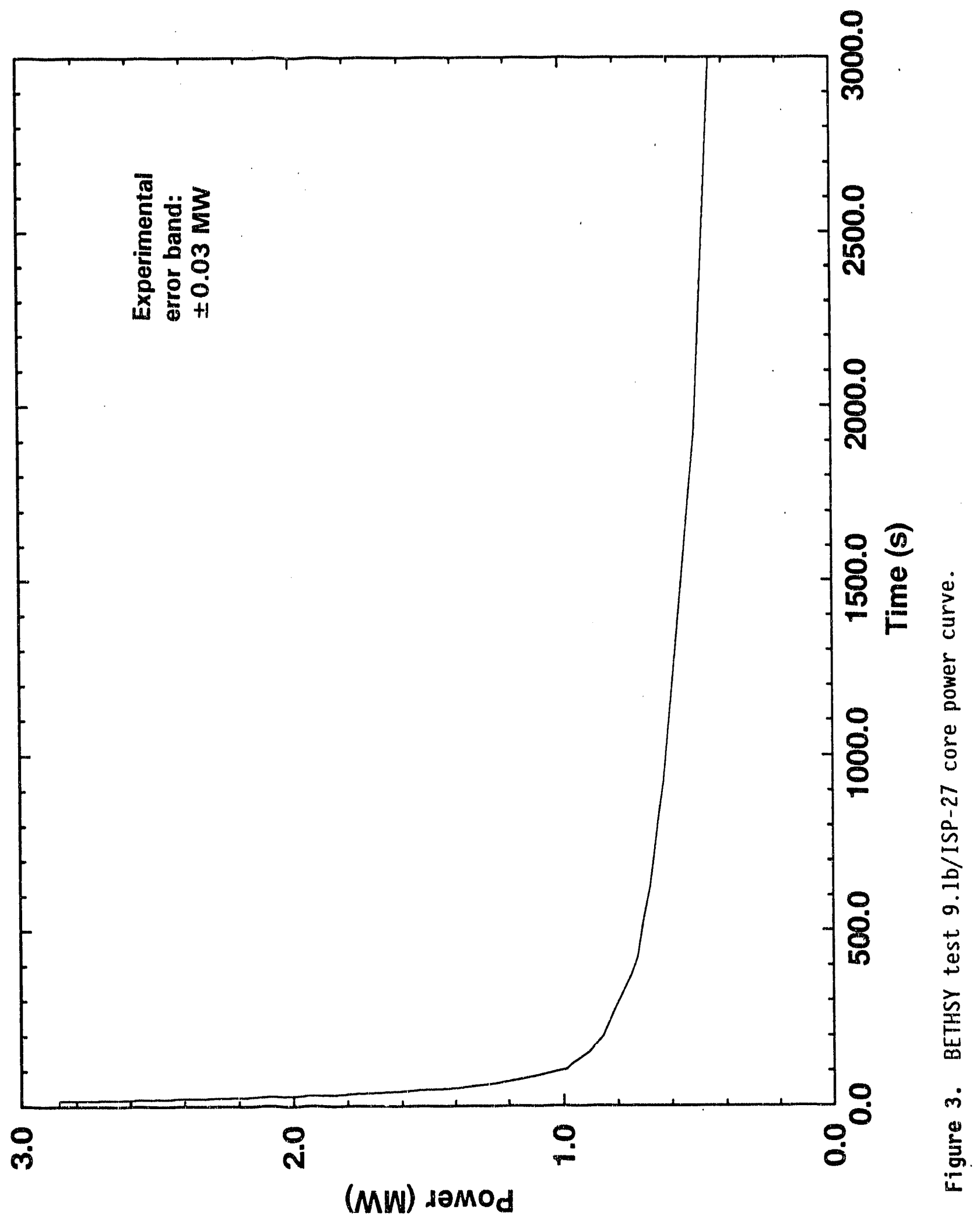


shown in Figure 4 , (e) before the SI signal the three steam generator secondary pressures remained constant at $6.91 \mathrm{MPa}$ but after the SI signal the pressure boundary condition became $7.03 \mathrm{MPa}$ until the UP, (f) specific auxiliary feedwater flow control schemes were followed before and after the UP, (g) the trace heating was on at constant power until the beginning of accumulator injection after which it was turned off.

The major events and the times they were observed during the test are summarized in Table 2. A plot of the observed experimental pressurizer pressure and a typical secondary pressure are shown in Figure 5 . The details of the first 100 seconds of the depressurization are shown in Figure 6. Primary system depressurization began as soon as the break opened. The pressure decline was relatively slow until the pressurizer emptied at about 50 s (see Figure 7). Then a steep decline began and continued until the primary pressure approached the secondary pressure.

Table 2. Major events observed during BETHSY test 9.1b/ISP-27.

Event

Scram signal (pressurizer pressure $=13.1 \mathrm{MPa}$ )

SI signal (pressurizer pressure $=11.9 \mathrm{MPa}$ )

Core power decay start

Auxiliary feedwater on

Pump coastdown start

End of pump coastdown

Two-phase discharge at the break

Start of first core level depression

First loop seal clearing

Start of second core level depression

UP initiation

Accumulator injection start

Primary mass inventory minimum

Second loop seal clearing

Maximum core heatup

Accumulator isolation

LPSI startup

End of test
Time $(s)$

41
54
58
82
356
971
1340
1830
1944
2180
2562
2962
2970
3040
3053
3831
5177
8330

For the conditions of this test, with the steam generator secondary level always above the top of the $U$-tubes and a very small break size, the energy lost through the break was considerabiy less than the energy lost 


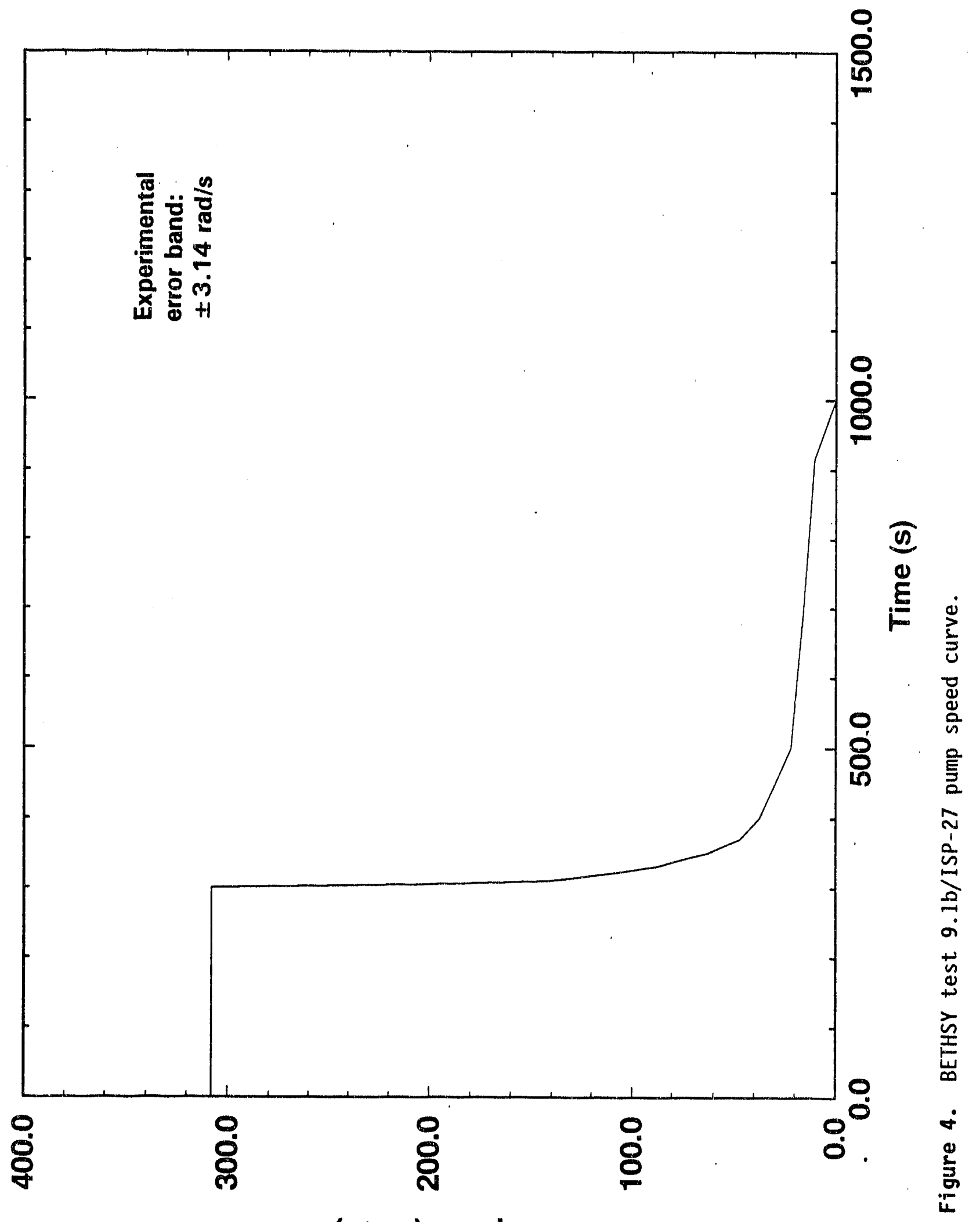

(s/pe.) pəəds 


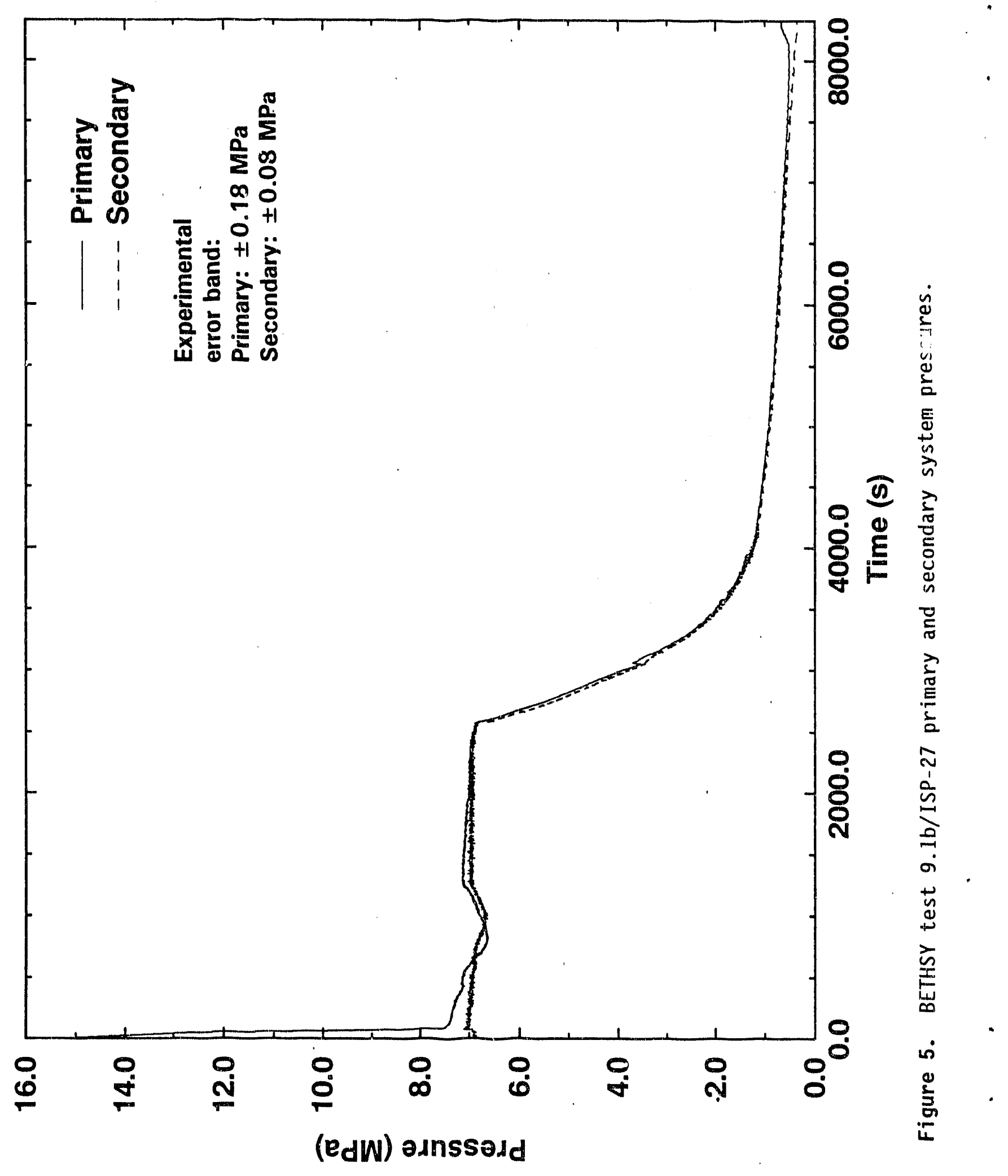




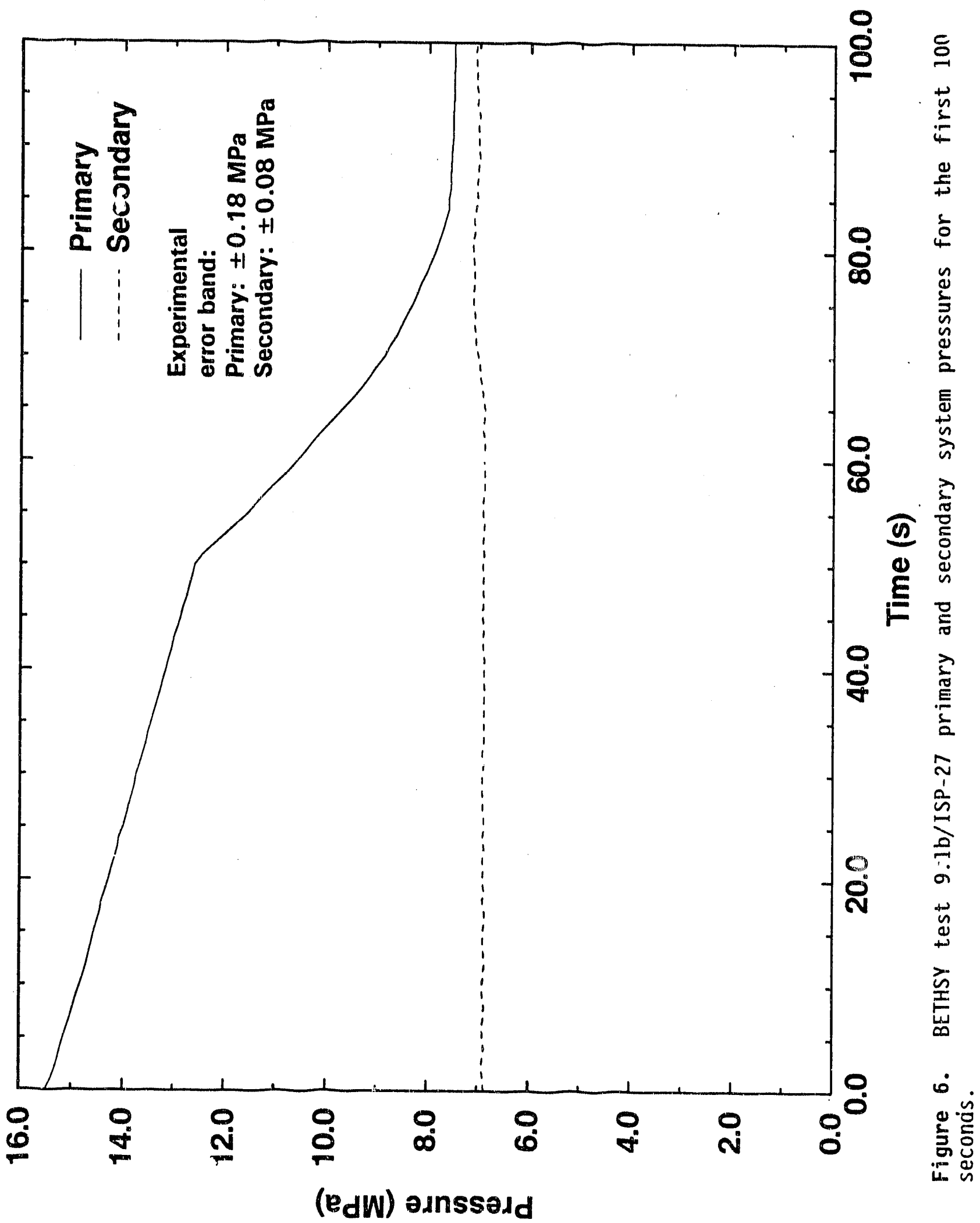




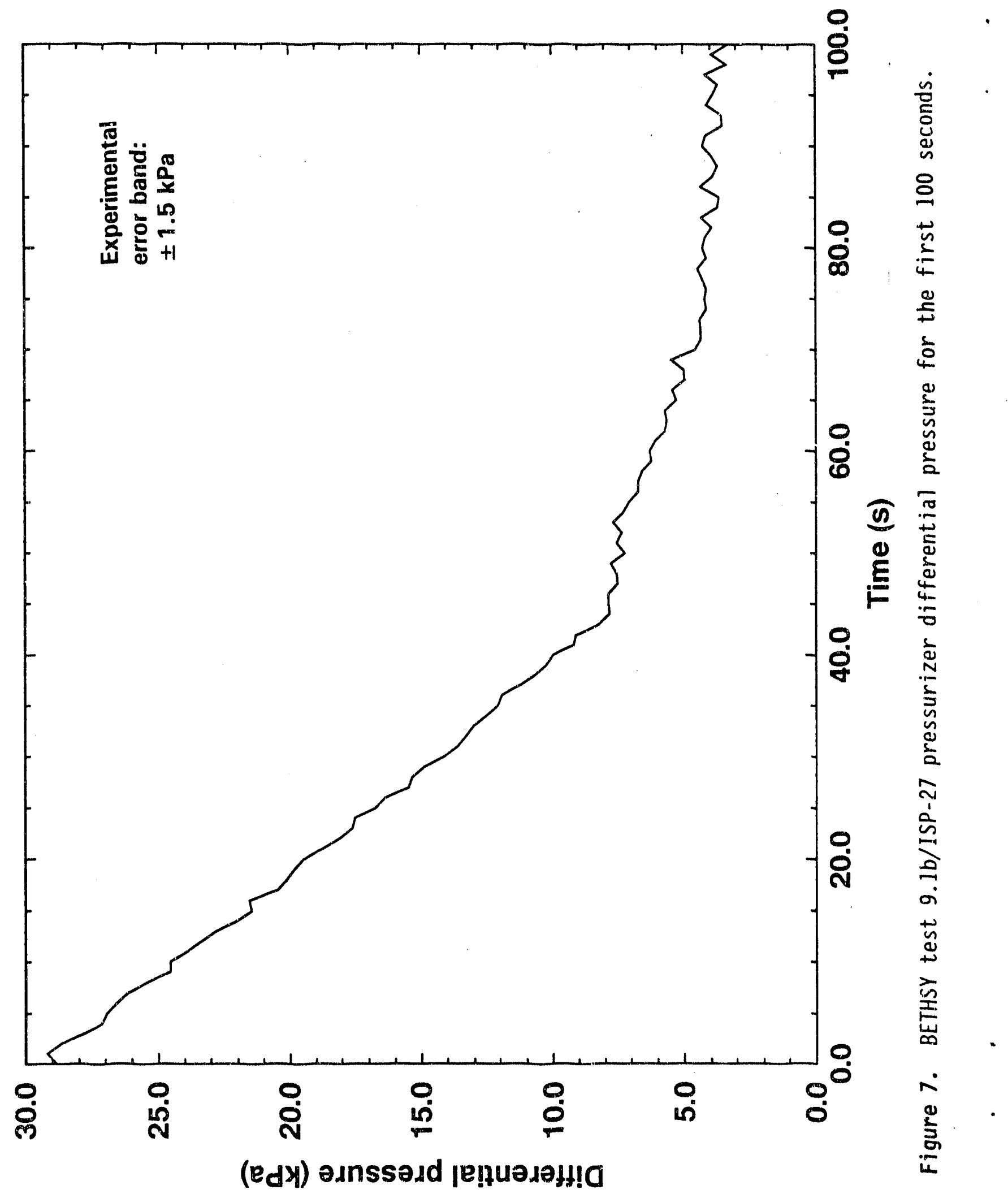


through the steam generators. Therefore the temperature of the primary remained slightiy above the secondary temperature. For the majority of the transient, after about 80 seconds, the primary hot legs and the secondaries were saturated, thus the primary pressure remained slightly above the secondary pressure. There was a brief dip in both primary and secondary pressure between 500 and 1200 seconds. This dip was caused by an accumulation of subcooled auxiliary feedwater in the steam generator risers. Thus during this time the primary was actually transferring heat to subcooled liquid and the primary pressure fell below the secondary pressure.

When the ultimate procedure was initiated (2562 seconds), a valve opened which connected the manifold for the 3 steam generator steam 7 ines to the atmosphere through an orifice. A fairly rapid secondary depressurization occurred which was closely followed by the primary pressure except that, at the time of maximum core heatup when the accumulator water just reached the hot core ( 3053 seconds), there was a small increase in primary pressure due to increased steam production. The primary pressure continued to follow the secondary pressure until LPSI flow exceeded the break flow for a long enough time to cause the upper plenum, hot legs, and upflow side of the $U$-tubes to refill such that the primary pressure increased.

Figure 8 shows the differential pressure over the downflow side of the three loop seals. The three traces are shown together and individually for improved clarity. There was an initial discrepancy between the differential pressure readings for loops 1 and 2 and that for loop 3 . The cause of the discrepancy is uncertain but an instrumentation error is suspected. It does not appear to affect the data beyond the initial part of the transient. The plot for loop 2 shows that this loop seal cleared twice, once at 1944 seconds and once at 3040 secorlds. The first loop seal clearing occurred as a direct consequence of the slow depressurization and mass loss from the primary system. The second loop seal clearing occurred after the UP and after the accumulator flow refilled the loop seals. It is not known why the loop 2 loop seal cleared instead of either of the other loop seals. The geometry of the loops has been checked and no significant deviation was found. However a temperature difference as small as $2 \mathrm{~K}$ between intermediate legs could result in asymmetric loop seal clearing. 

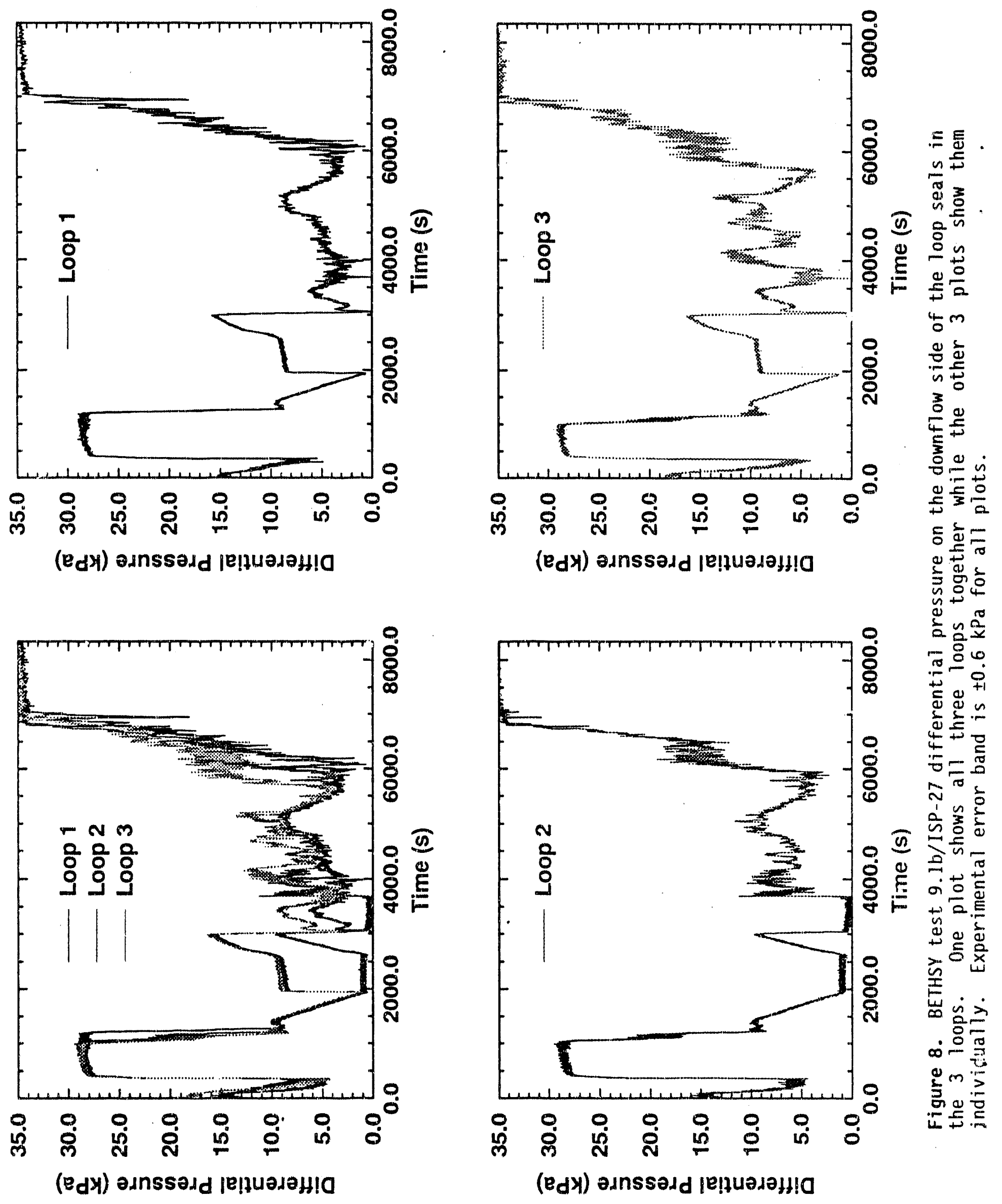
Figure 9 shows the collapsed liquid level in the vessel. Note that, while the pumps are running during the first 971 seconds of the transient, the data are not valid since the fluid velocity head increases the reading beyond the range of the instrumentation. Zero level for this measurement was $0.4 \mathrm{~m}$ above the bottom of the lower plenum. The theoretical maximum value for this measurement, which would be measured if the core was full of liquid without any void, was $5.81 \mathrm{~m}$. The heated part of the core goes from level $1.764 \mathrm{~m}$ to $5.420 \mathrm{~m}$. At approximately 1000 seconds the fluid in the core consisted of saturated liquid with some void present. The core level began to decline steeply about 200 seconds before the first loop seal clearing. This depression was due to a simple loss of primary inventory through the break. When the loop seal cleared, at 1944 seconds, the water from the loop seal raised the level in the vessel.

The vessel level remained high for about 200 seconds when another level depression began. This depression was caused by low system inventory and boiloff from the core. This second level depression was deep in that the collapsed level falls below $2.0 \mathrm{~m}$. (The swollen level was measured to be approximately $0.5 \mathrm{~m}$ higher.) Thus a large part of the upper core was dry and experienced heatup. This heatup led to the initiation of the UP at 2562 seconds and the resulting depressurization led to accumulator injection at 2962 seconds. The loop seal in loop 2 beyan to refill after the UP. The loop seal cleared shortly after the beginning of accumulator injection at 3040 seconds and refilled the core. At the end of the transient the L.PSI flow had filled the core with subcooled liquid thus raising the collapsed level to its theoretical maximum.

Figure 10 shows the inventory in the two active accumulators, connected to loops 2 and 3 . The injection was fairly steady except for a short interruption from about 3050 seconds to about 3100 seconds. This interruption occurred just after the second loop seal clearing and was probably caused when cold accumulator liquid and loop seal liquid reached the core and created a surge of vapor. The excess vapor which was generated pressurized the system slightly and shut off the accumulator flow. The slight rise in primary pressure is also visible in Figure 5 at about 3050 seconds. 


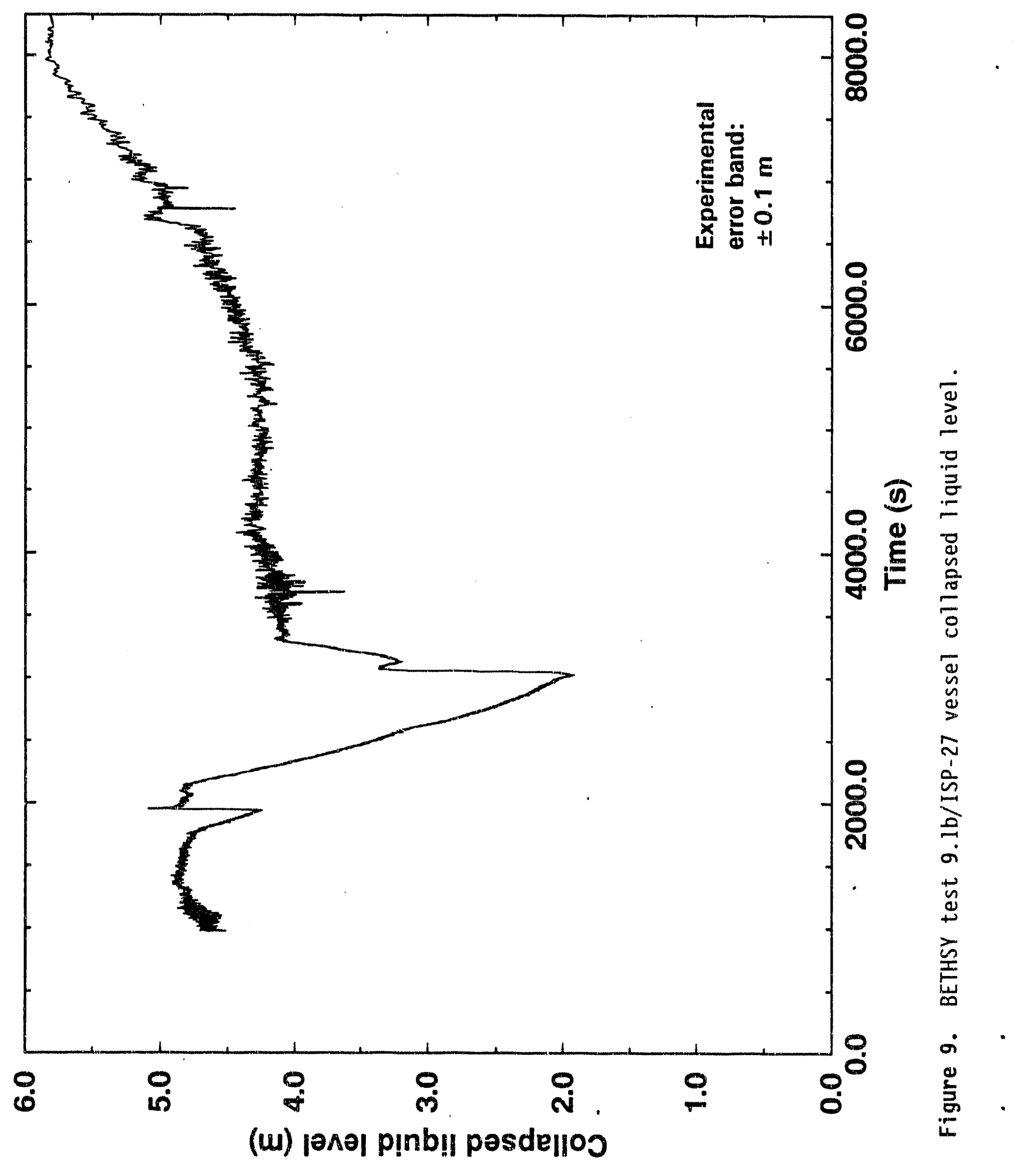




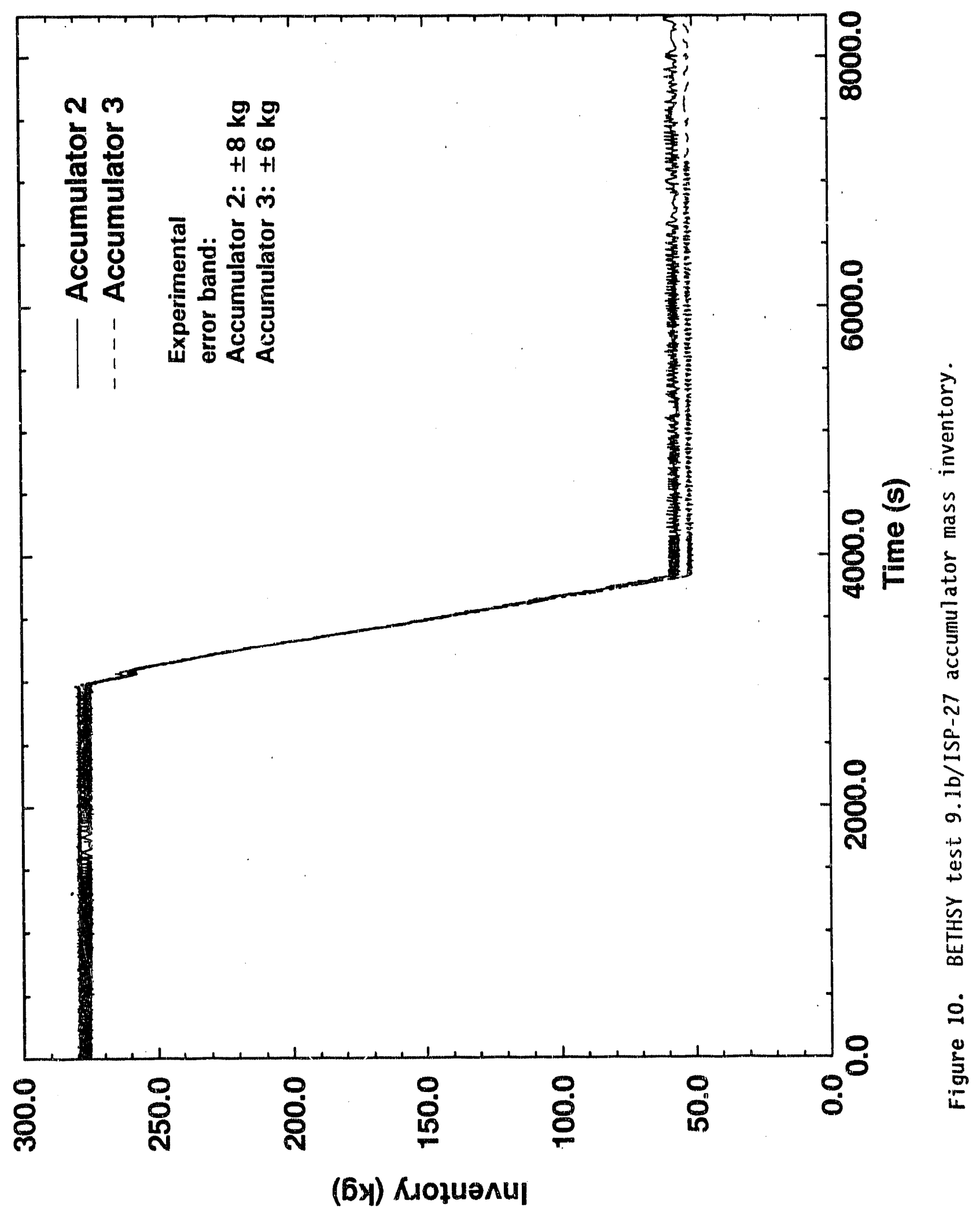


Figure 11 shows the clad temperatures at various elevations above the bottom of the core. A closer look at the heatup is given in Figure 12. A very slight heatup occurred at the highest elevation between 1900 and 1950 seconds. This corresponded with the first core level depression just before the first loop seal clearing. The major core heatup occurred during the core boiloff between 2200 and 3100 seconds. It can be seen that the highest elevations heat up first and are followed successively by the lower elevations. After the initial heat up, reflux liquid from the hot legs cooled the upper elevations so that the lowest elevation heated last and achieved the highest temperature of this sample. Figure 13 shows the result of taking the maximum of all the core thermocouples at each data sampling time.

Figure 14 shows the void fractions measured in the spool piece in each loop cold leg. The three traces have been shown together and individually for improved clarity. Downward pointing spikes are evident in the trace for loop 2 at the time of each loop seal clearing (1944 and 3040 seconds). The low point of void fraction at about 3800 seconds coincides with accumulator isolation. The drop in void fraction around 5700 seconds corresponds to the beginning of LPSI.

Given the \pm 0.05 error band, the three void fraction measurements only deviated significantly beyond measurement error between 3000 and 3500 seconds. Figure 15 shows a closer view of this time span. There was a high void in loop 1, somewhat lower void in loop 3, and the lowest void of the three occurred in loop 2. This asymmetric behavior is logical because the break was located in the loop 1 cold leg which did not have any safety injection so its void fraction was high. Loop 3 had no break and had safety injection from the accumulator so its void fraction was lower. Loop 2 was similar to Loop 3 but, since its loop seal was cleared during this time, the water which was condensing on the downflow side of the steam generator $U$. tubes was also being passed into the cold leg.

Figure 16 shows the mass flow rate from the break. The flow rate was high initially because of the high primary system pressure. The pressure and the break flow leveled off at the same time. At about 1300 seconds the break flow rate dropped because the flow became two-phase. There was an increase in fiow rate around 3800 seconds which corresponded to the lower 


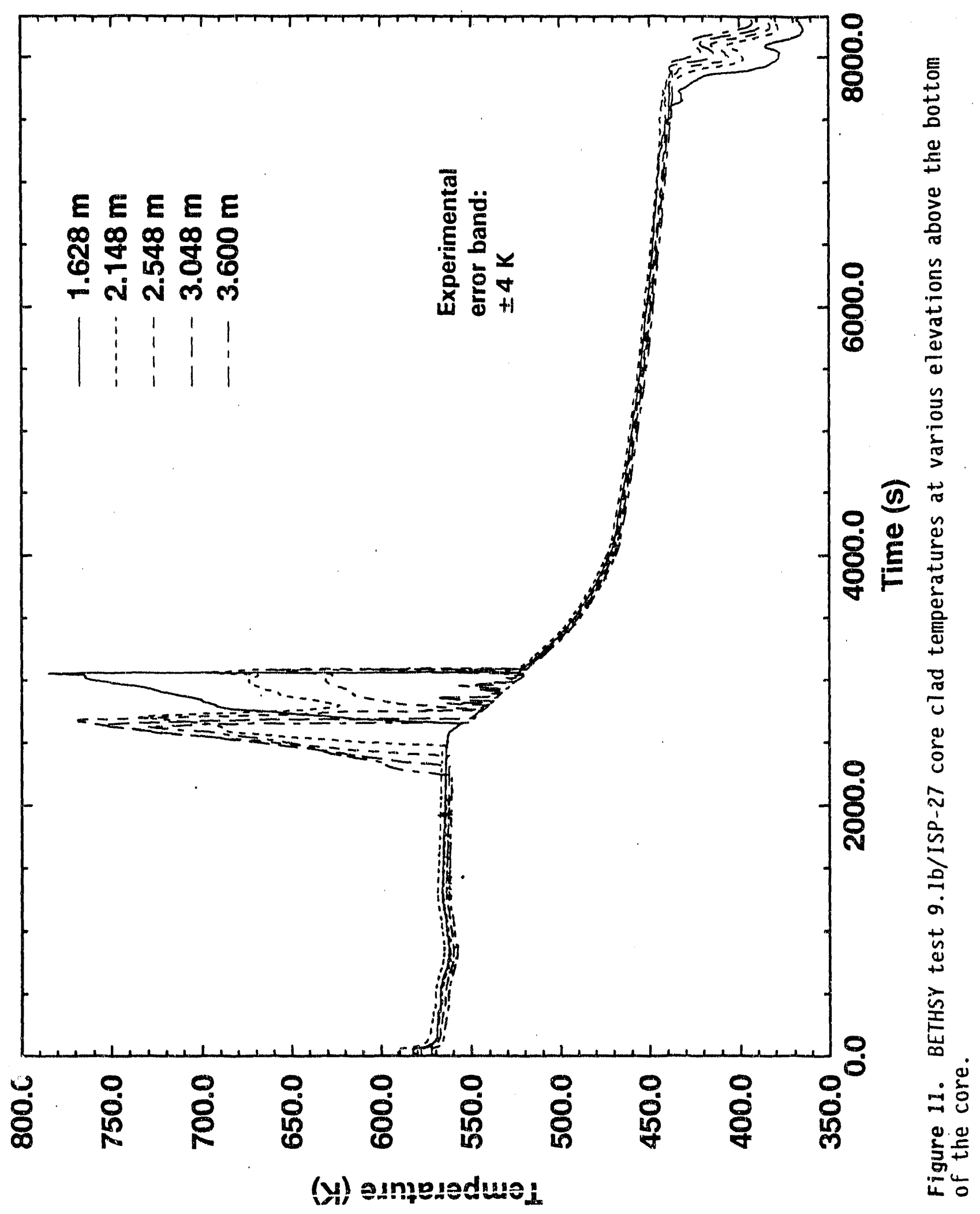




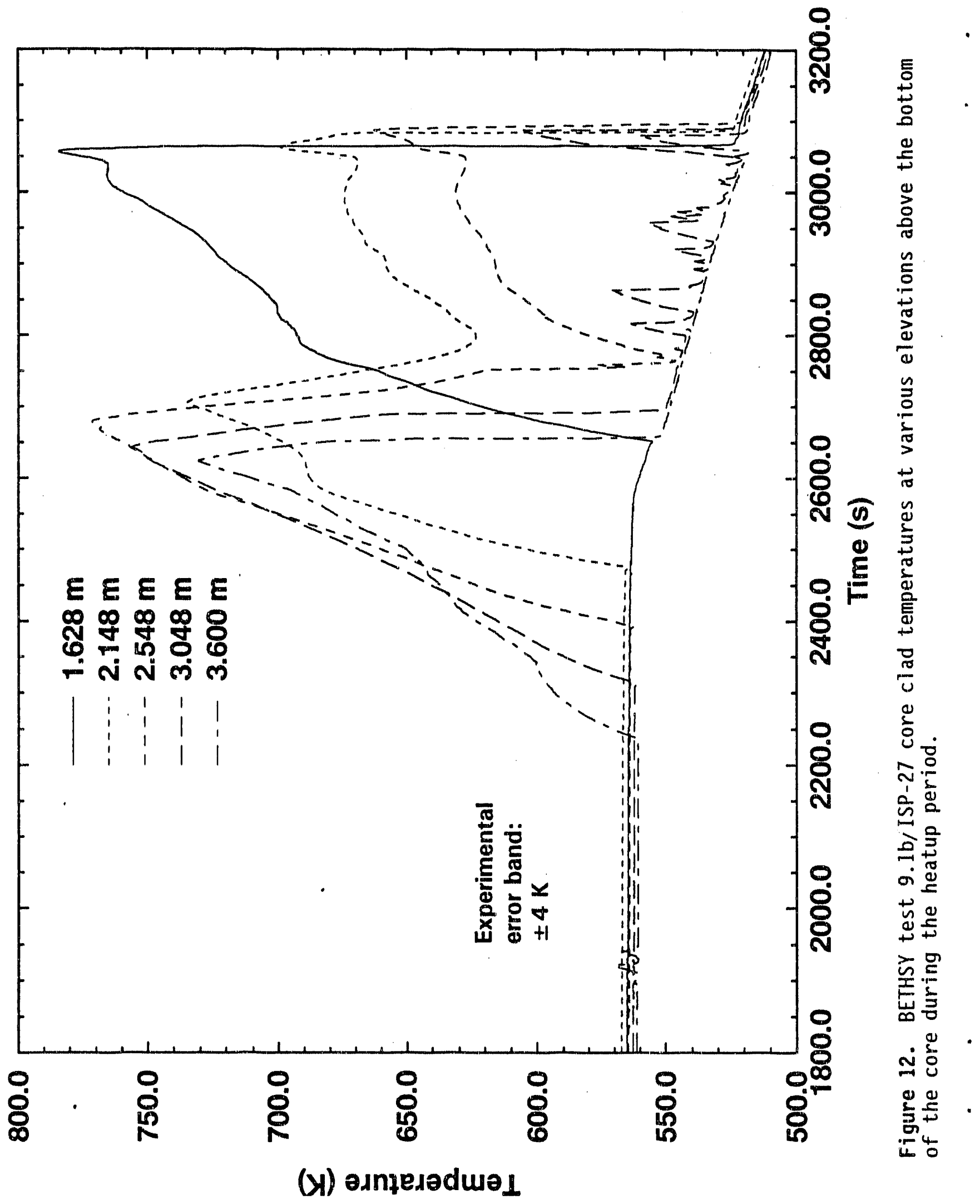




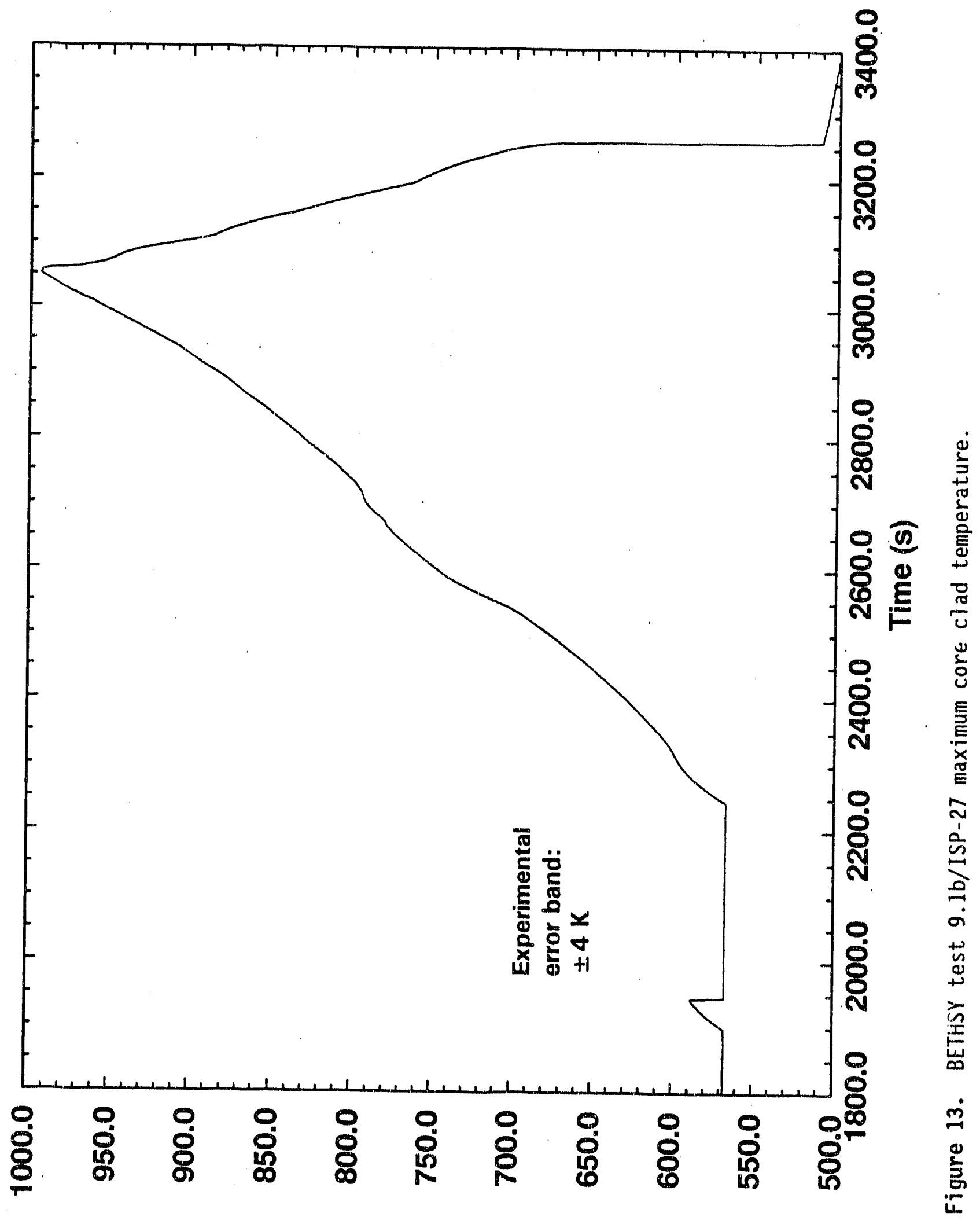

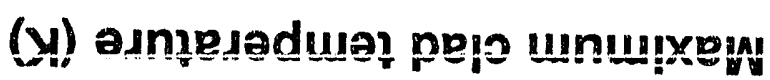



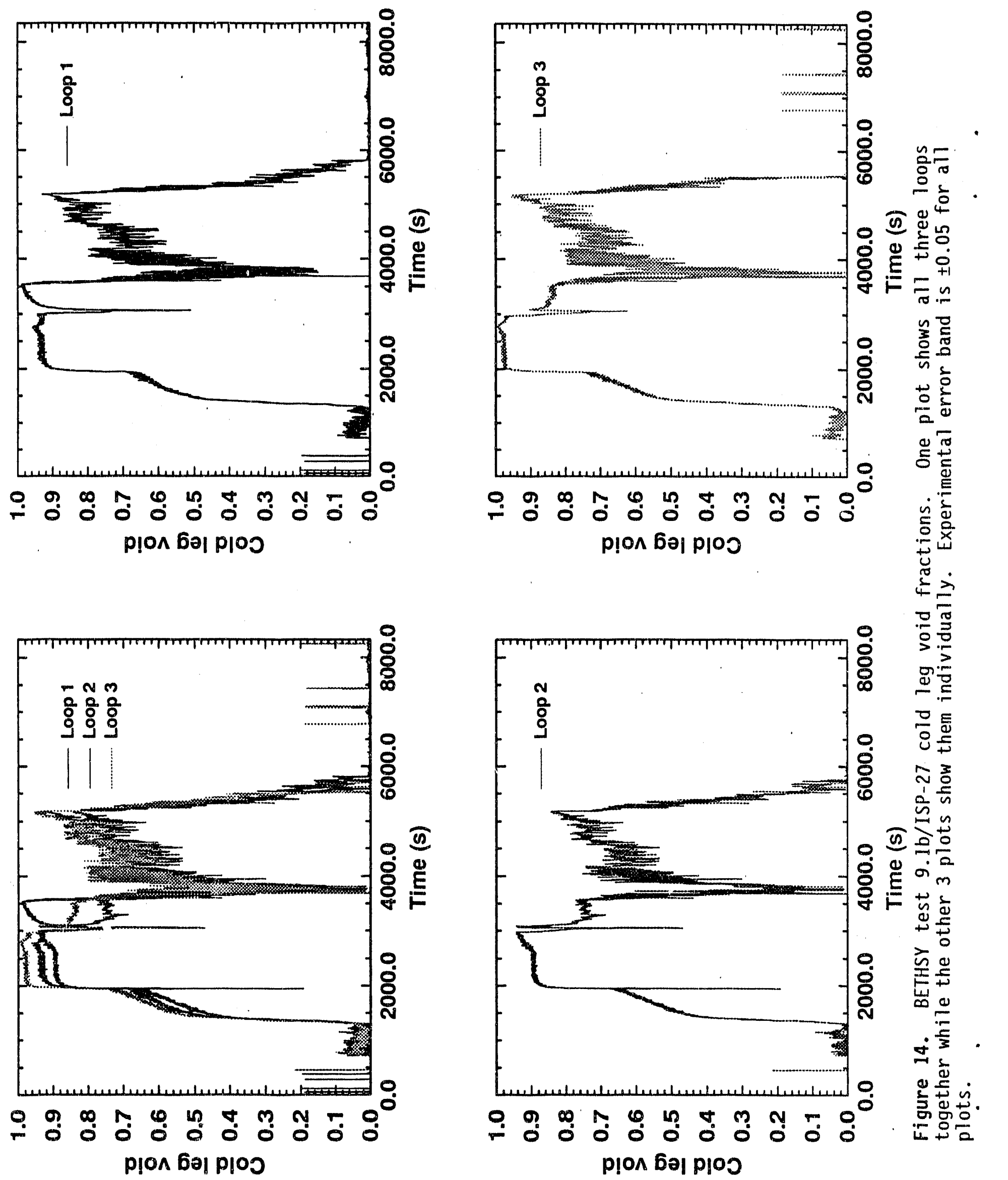


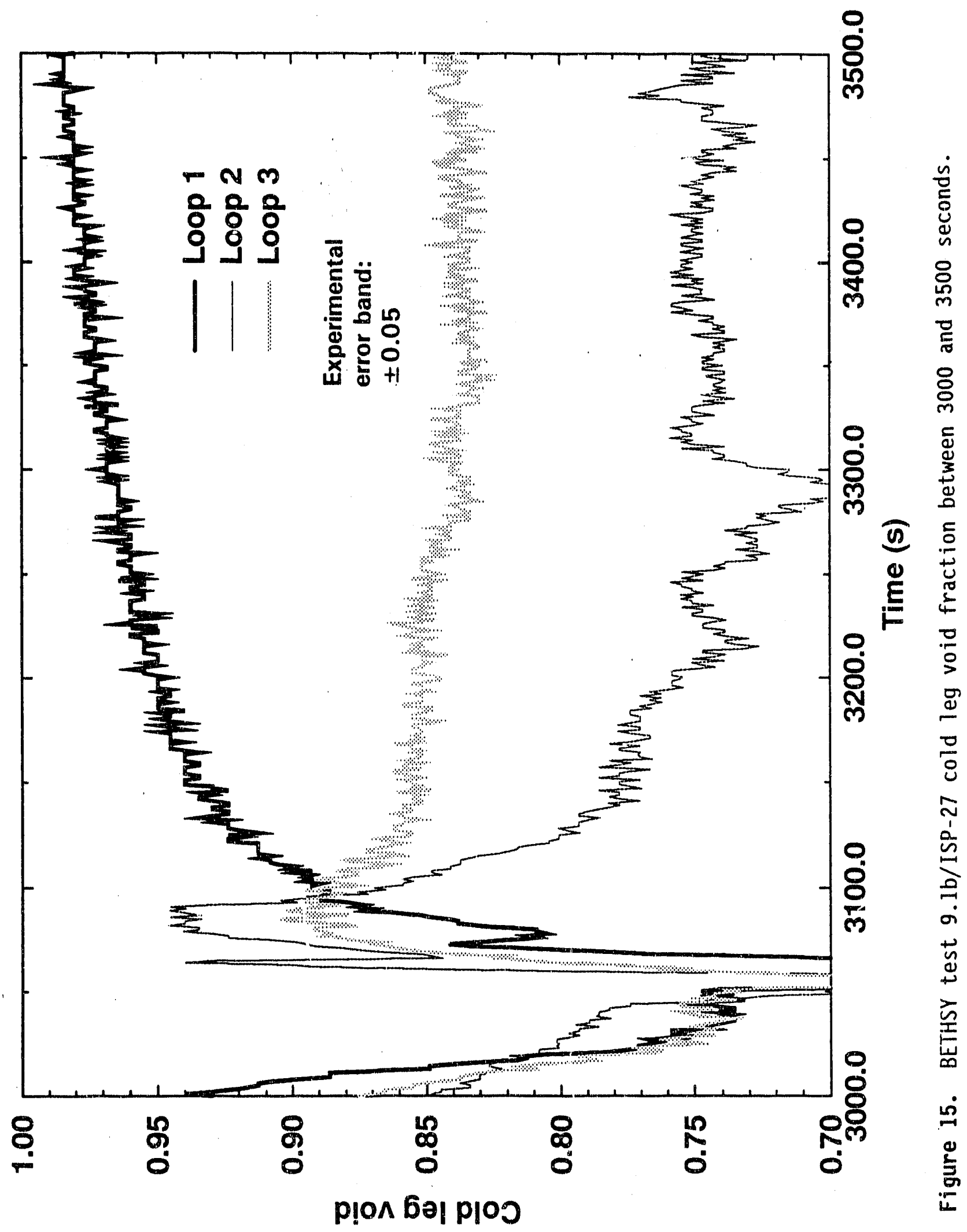




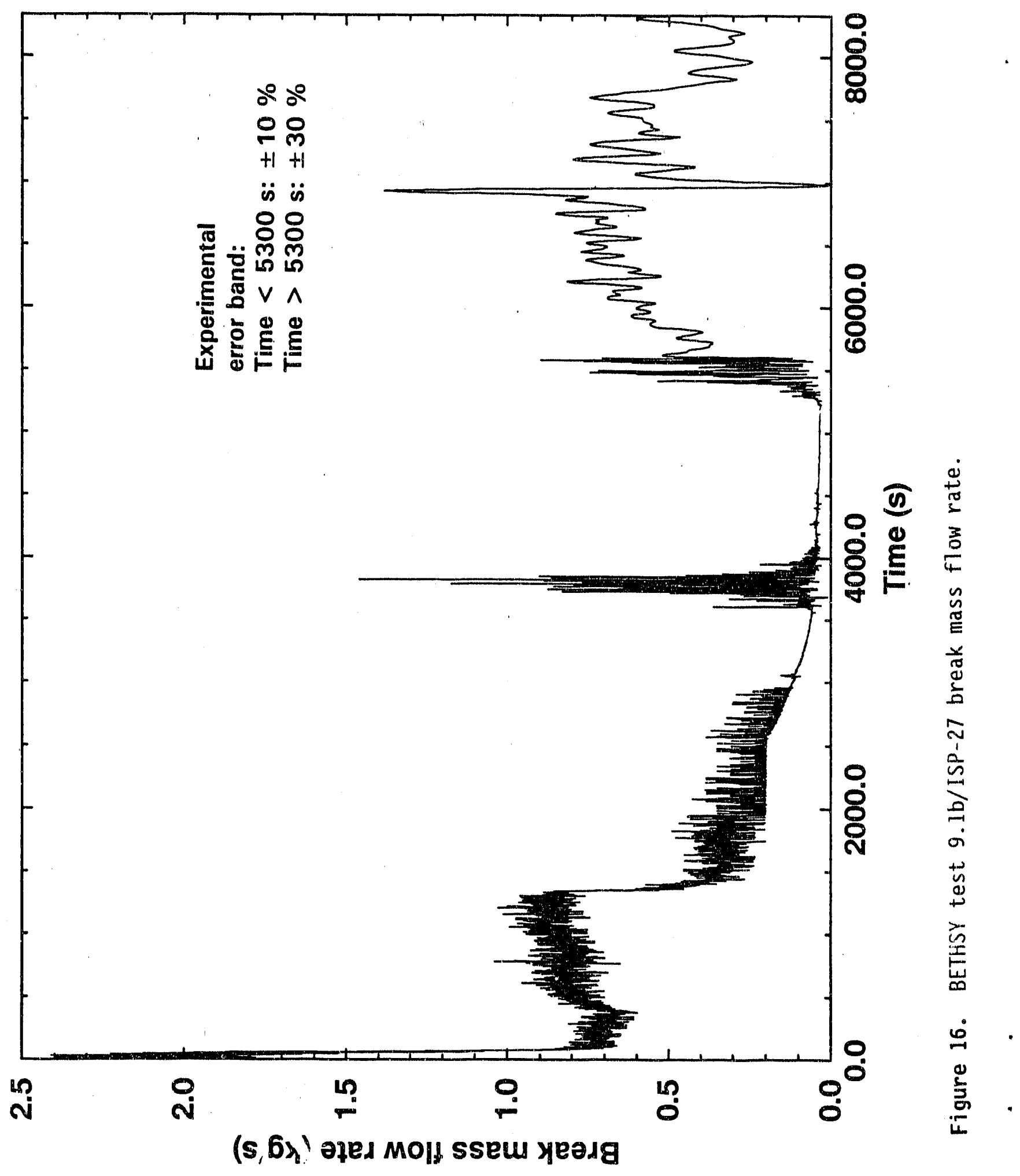


cold leg void fraction found in loop 1 due to accumulator injection. Then the flow remained fairly low until LPSI injection refilled the cold legs at abolit 5500 seconds which increased the liquid discharged from the break and thus increased the mass flow rate.

\subsection{Test 6.2 TC}

This test $t^{0,7}$ was a $5.0 \%$ SBLOCA. At the beginning of the test, the pumps were running at a reduced speed (approximately $238 \mathrm{rpm}$ ) in order to give a realistic temperature distribution around the primary system with the low core power (which could not exceed $10 \%$ of rated scaled power). The temperature difference between the inlet and outlet of the core was $31 \mathrm{~K}$. The pressurizer pressure was $15.38 \pm 0.15 \mathrm{MPa}$. The pressurizer spray and relief circuits were not used during this test. This test also used a smaller orifice in the bypass between the upper head and the downcomer in order that the bypass flow would be $0.28 \%$ of the sum of the three loop flows. (In test $9.1 \mathrm{~b} /$ ISP-27 the bypass carried $2 \%$ of the flow.) A more complete listing of initial conditions appears in Table 3.

The scenario for the test is shown in the chronology of Table 4 . This test was different from test $9.1 \mathrm{~b} /$ ISP -27 because the main feedwater was shut off and the turbine bypass occurred when the scram occurred rather than when the SI signal was generated. Also, no auxiliary feedwater was used during the test and no LPSI was used.

The boundary conditions for this test were similar to those for test 9.1b/ISP-27 except that: (a) the break nozzle was larger (see Figure 17), (b) the core power was controlled to follow the JAERI conservative curve (see Figure 18) rather than the curve used for test $9.1 \mathrm{~b} / \mathrm{ISP}-27$, (c) the pumps were stopped (pump speed $=0$ ) at the scram signal rather than coasting down, and (d) the trace heating was shut off when the break was opened.

The major events and the times they were observed during the test are summarized in Table 5. A plot of the pressurizer pressure and a typical secondary pressure are shown in Figure 19. The details of the first 60 seconds of the depressurization are shown in Figure 20. Primary system 
Table 3. Initial conditions for BETHSY test 6.2 TC

\begin{tabular}{lc}
\multicolumn{1}{c}{ Parameter } & Value \\
\cline { 2 - 2 } Core power (kW) & $2863 \pm 30$ \\
Pressurizer pressure (MPa) & $15.38 \pm 0.15$ \\
Pressurizer level (m) & $7.45 \pm 0.2$ \\
Pump speed (rpm) & $238 \pm 6$ \\
Core inlet temperature (K) & $557.15 \pm 4$ \\
Core outlet temperature (K) & $588.15 \pm 4$ \\
Primary system mass with & \\
pressurizer (kg) & $1984 \pm 50$ \\
Secondary system pressure (MPa) & $6.84 \pm 0.07$ \\
Secondari steam generator level (m) & $11.1 \pm 0.5$ \\
Feed water temperature (K) & $523.15 \pm 4$ \\
Feed water flow rate per steam & 0.55 \\
generator (kg/s) & \\
Bypass flow: downcomer to upper & \\
head (\% of total loop flow) & 0.28 \\
Environmental heat loss (kW) & 54.82 \\
\hline
\end{tabular}

Table 4. Chronology of BETHSY test 6.2 TC

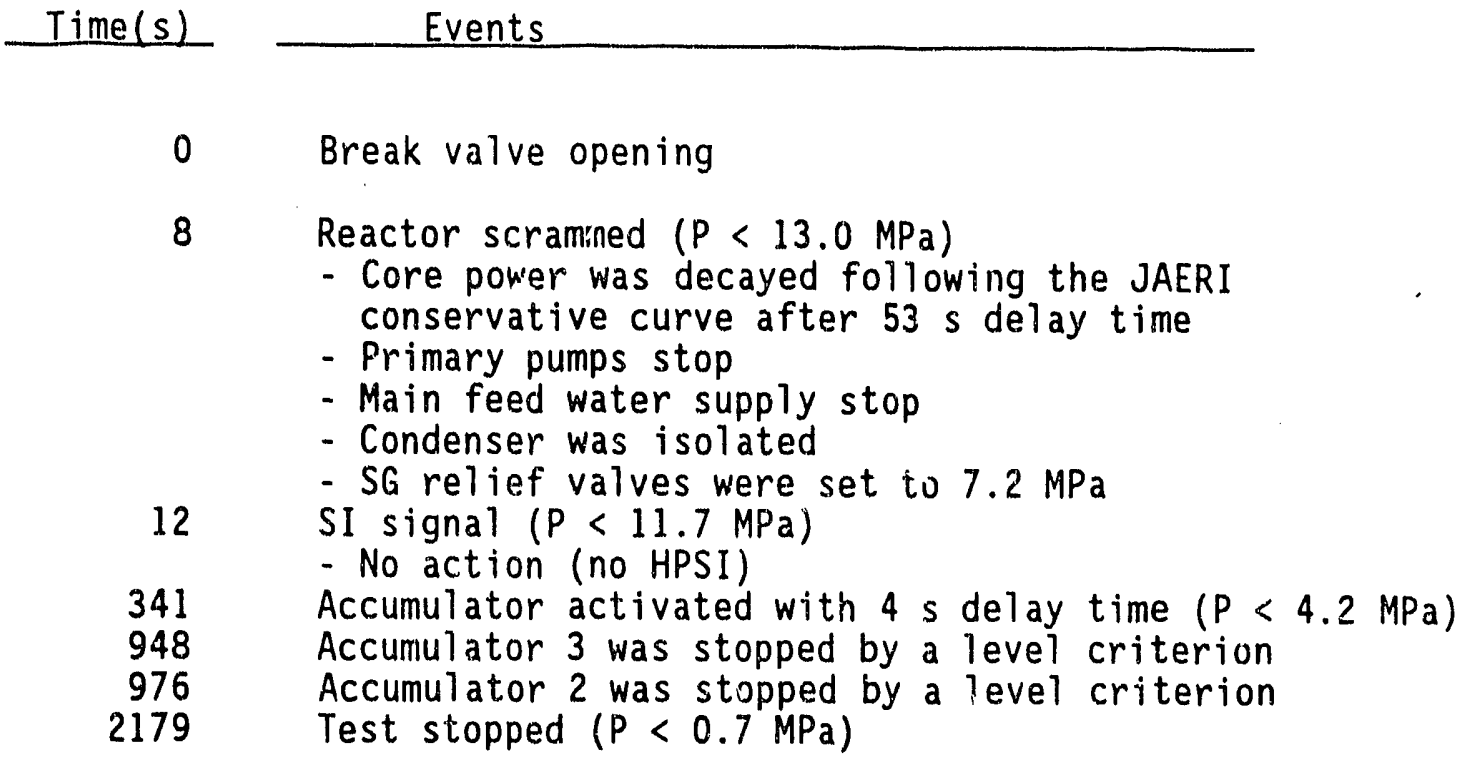




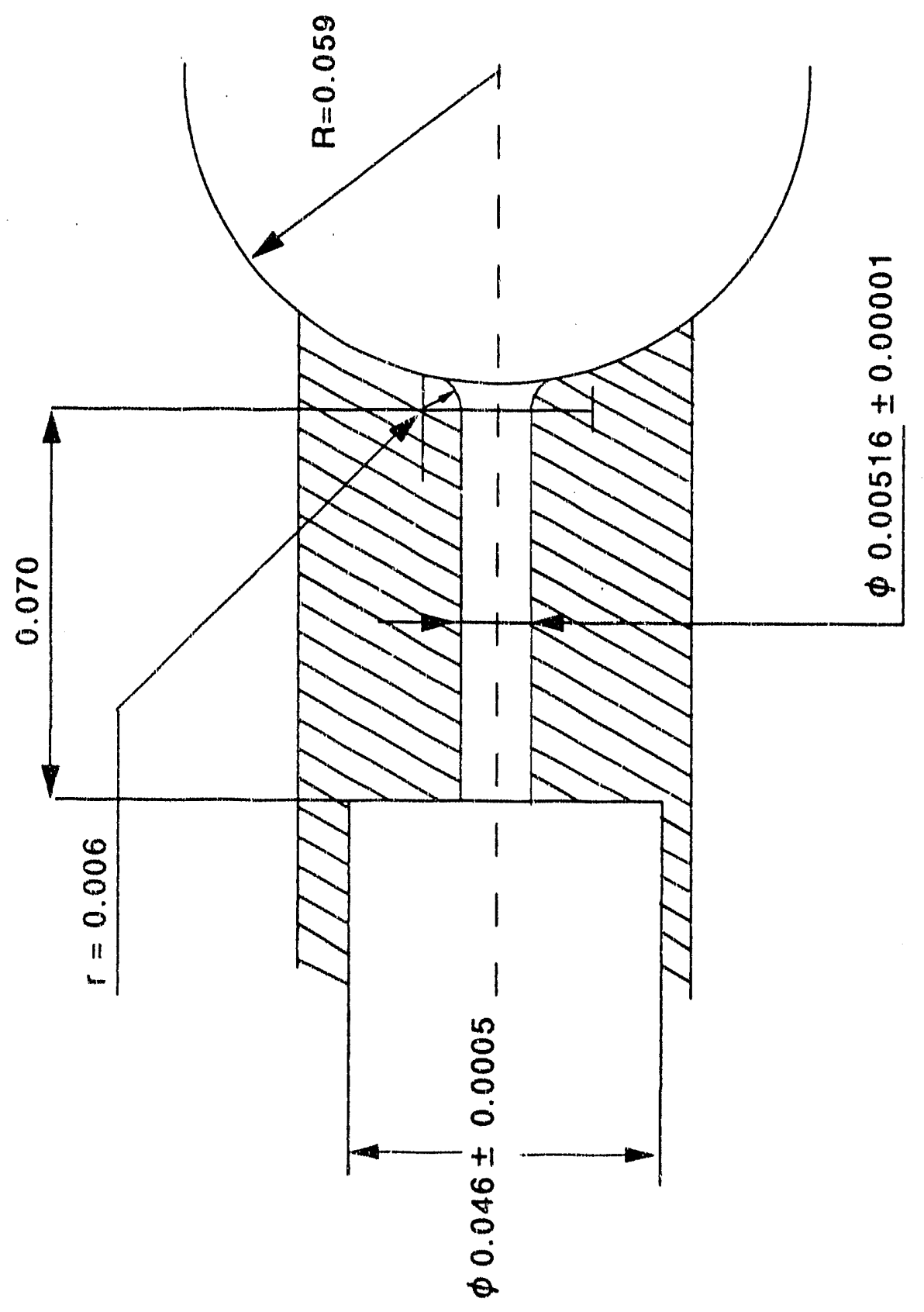

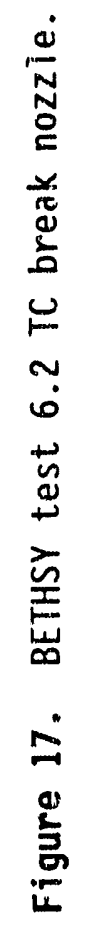




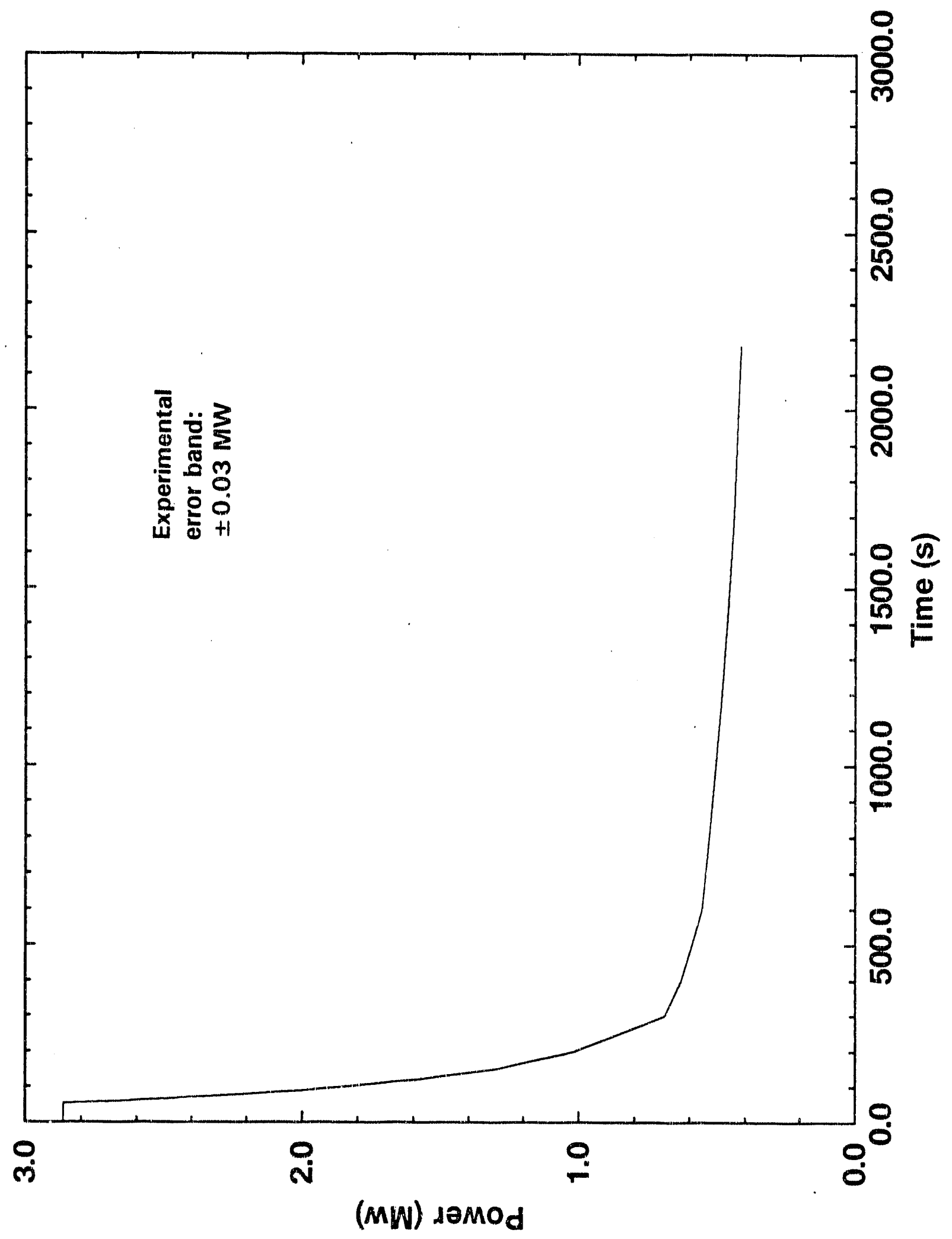

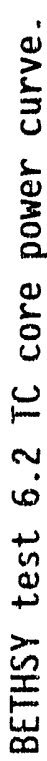

$\infty$

疍 


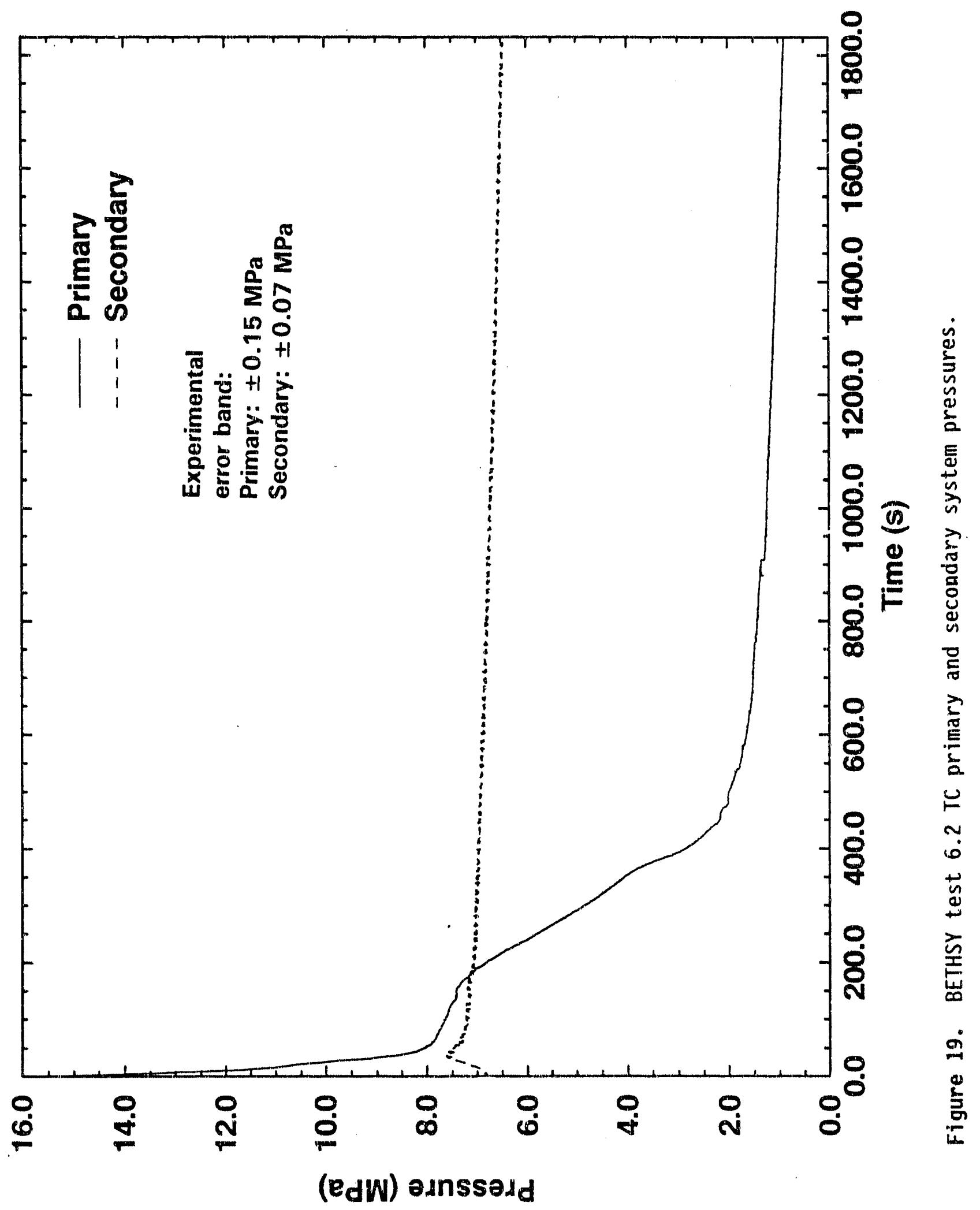




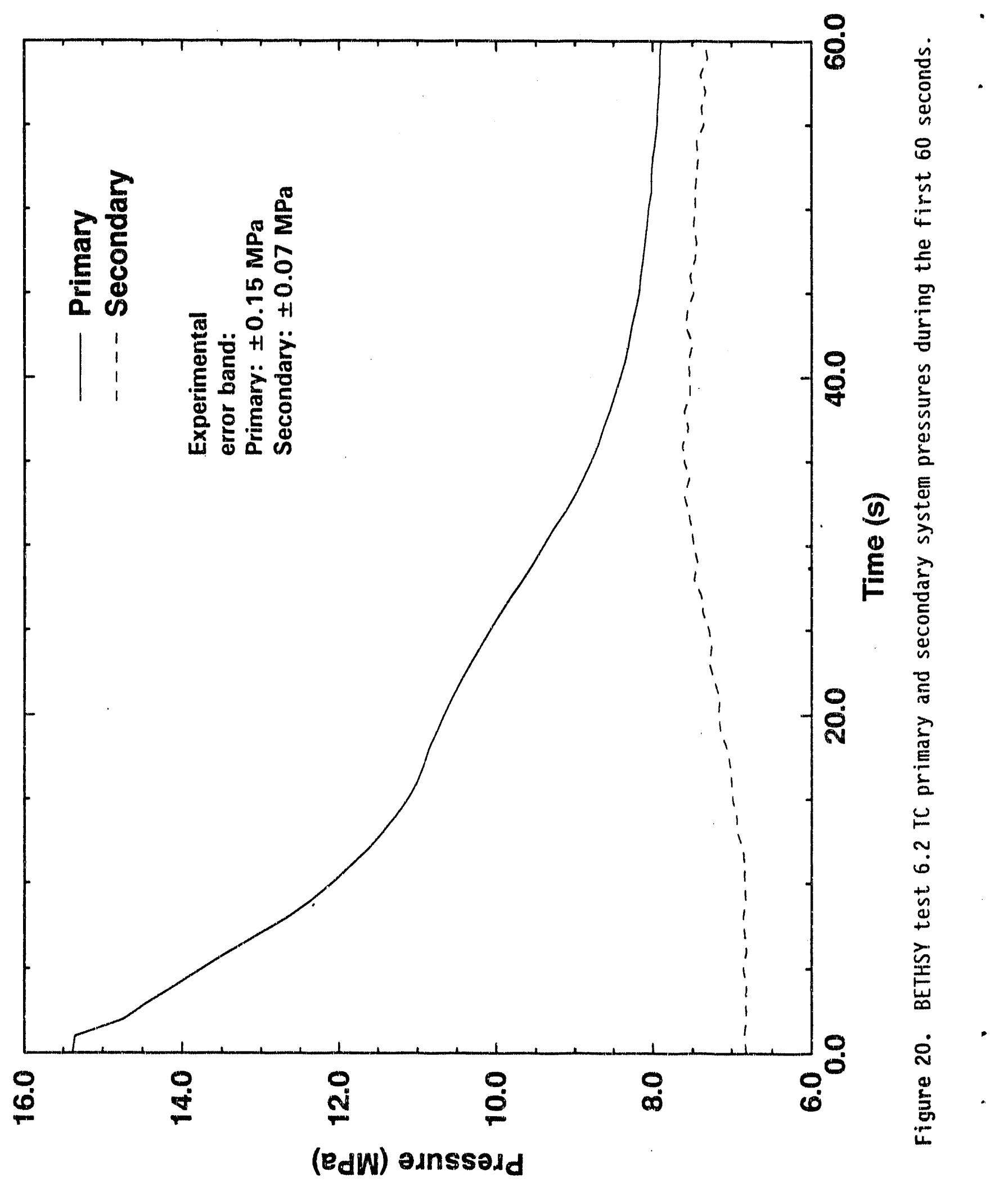


Table 5. Major events during BETHSY test 6.2 TC.

\begin{tabular}{lc} 
Events & Time (s) \\
\cline { 2 - 2 } Scram Signal & 8 \\
SI Signal & 12 \\
Loop Seal Clearing & 134 \\
First Core Uncovery Minimum Leve1 & 137 \\
Primary/Secondary Pressure Reversal & 172 \\
Second Core Uncovery Minimum Leve1 & 345 \\
Loop 2 Accumulator Injection & $345-948$ \\
Loop 3 Accumulator Injection & $345-976$ \\
End of Test & 2179
\end{tabular}

depressurization and pressurizer draining began as soon as the break opened. The pressurizer emptied (see Figure 21) during approximately the first 20 seconds of the transient while the primary pressure only took about 40 seconds to approach the secondary pressure. These events occurred much more quickly during this transient than during test $9.1 \mathrm{~b} /$ ISP -27 because the break was much larger.

The larger break size in this test had an even more striking influence on the primary pressure profile. The primary pressure exceeded the secondary pressure for about 100 seconds after which the secondary pressure was higher. This occurred in this transient because the larger break size carried more energy away from the primary than was transferred from the primary to the secondary. Thus the primary pressure was not tied to the secondary pressure as it was in test 9.1b/ISP-27. The secondary levels decreased by 1 meter or less during the first 200 seconds and then remained steady with the tops of the $U$-tubes still covered. Without any feedwater and with little or no steam flowing out, the secondary system remained saturated and the pressure fell very slowly due to energy transferred to the primary and the environment. The primary system remained saturated but since it was losing a great deal of energy through the break, the pressure fell steadily. As the pressure decreased, the energy lost through the break was reduced until it became nearly equal to the energy being produced in the core.

Figures 22 and 23 show the differential pressure measured on the downflow side of the three intermediate leg loop seals. All three loop seals cleared at about 135 seconds and did not refill. 


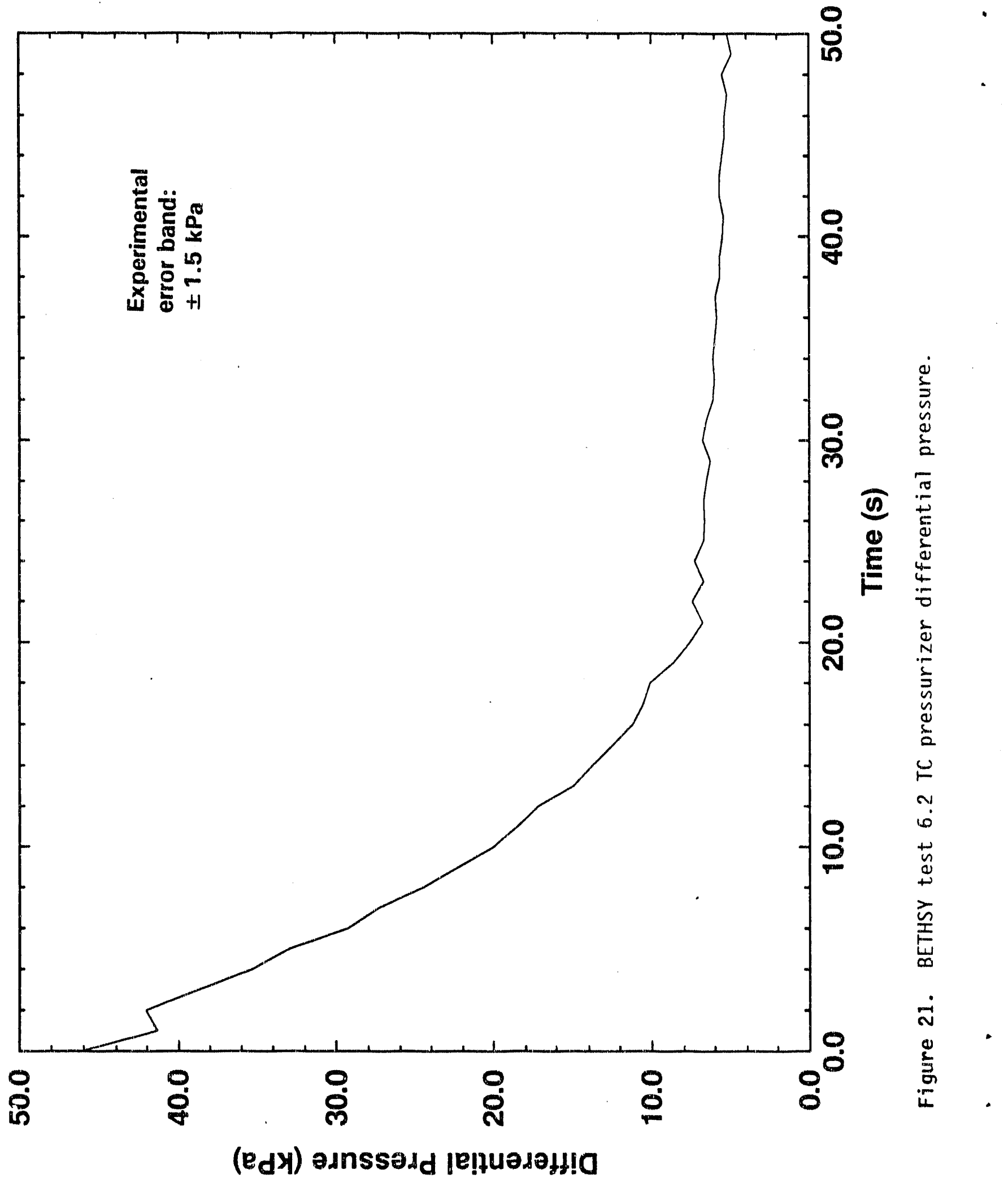




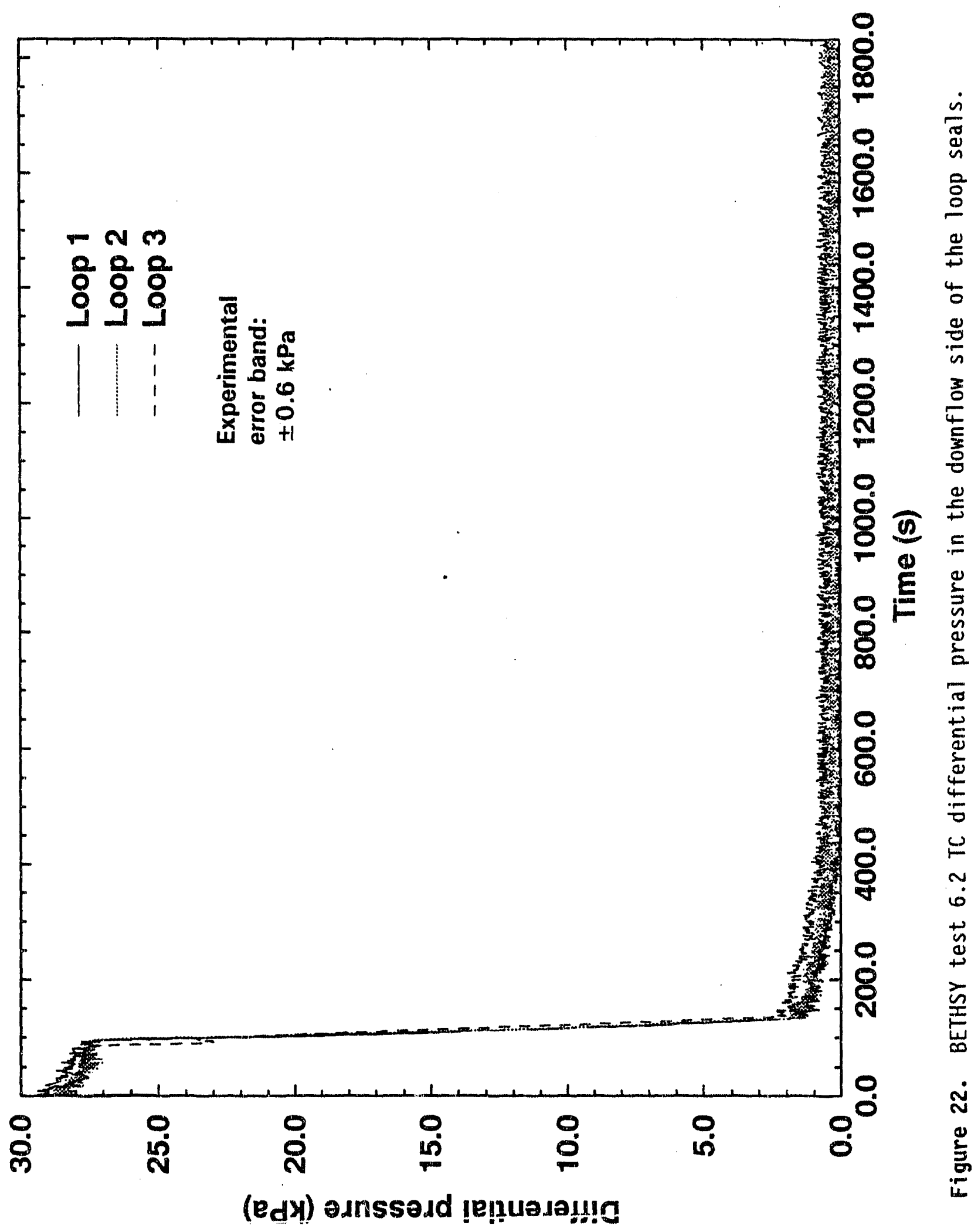




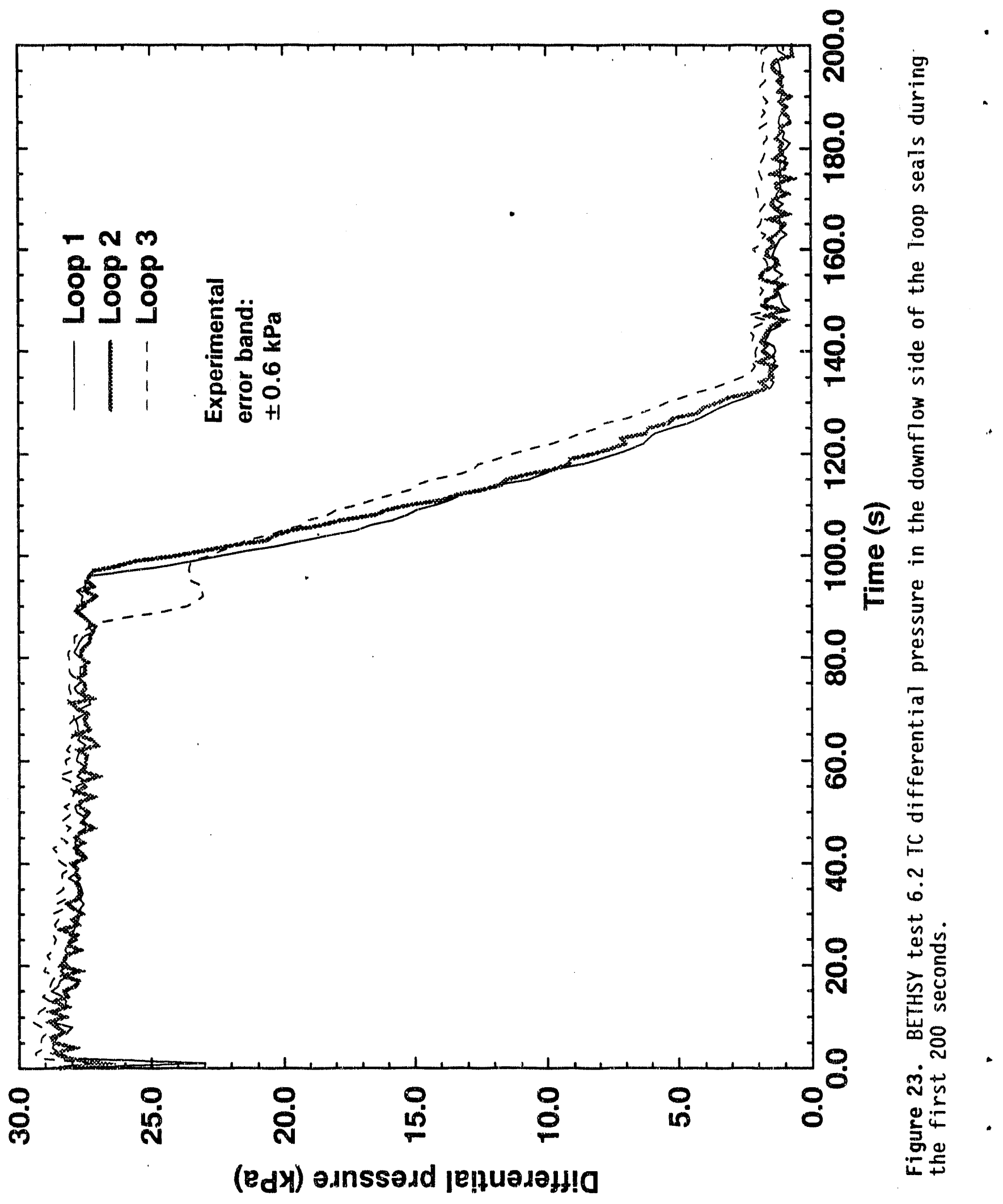


Figure 24 shows the collapsed liquid level in the vessel. Zero level for this measurement was at the bottom of the heated section of the core. There was a deep level depression just before loop seal clearing (137 s), a second minor depression just before accumulator injection (345 s), and a final depression beginning after the termination of accumulator injection at about 1600 seconds which was associated with the overall 10s: of primary inventory.

Figure 25 shows the clad temperatures at various elevations above the bottom of the core. This set of thermocouples indicates that the upper part of the core heated up toward the end of the transient. However, a closer look provided by Figure 26 verifies that there was a slight heatup at the top of the core in association with the first core level depression that occurred just before loop seal clearing.

Figure 27 shows the integrated mass injected from each 'ccumulator. The injection ran very smoothly from initiation at 345 seconds to termination at about 950 seconds.

Figure 28 shows the break mass flow rate. The trace has a simi.lar shape to the primary pressure trace in Figure 19 since break flow was strongly governed by the pressure. However, the flow rate dropped somewhat more quickly than the pressure. This was caused by the flow from the break becoming two-phase and thus reducing the amount of mass lost through the break. 


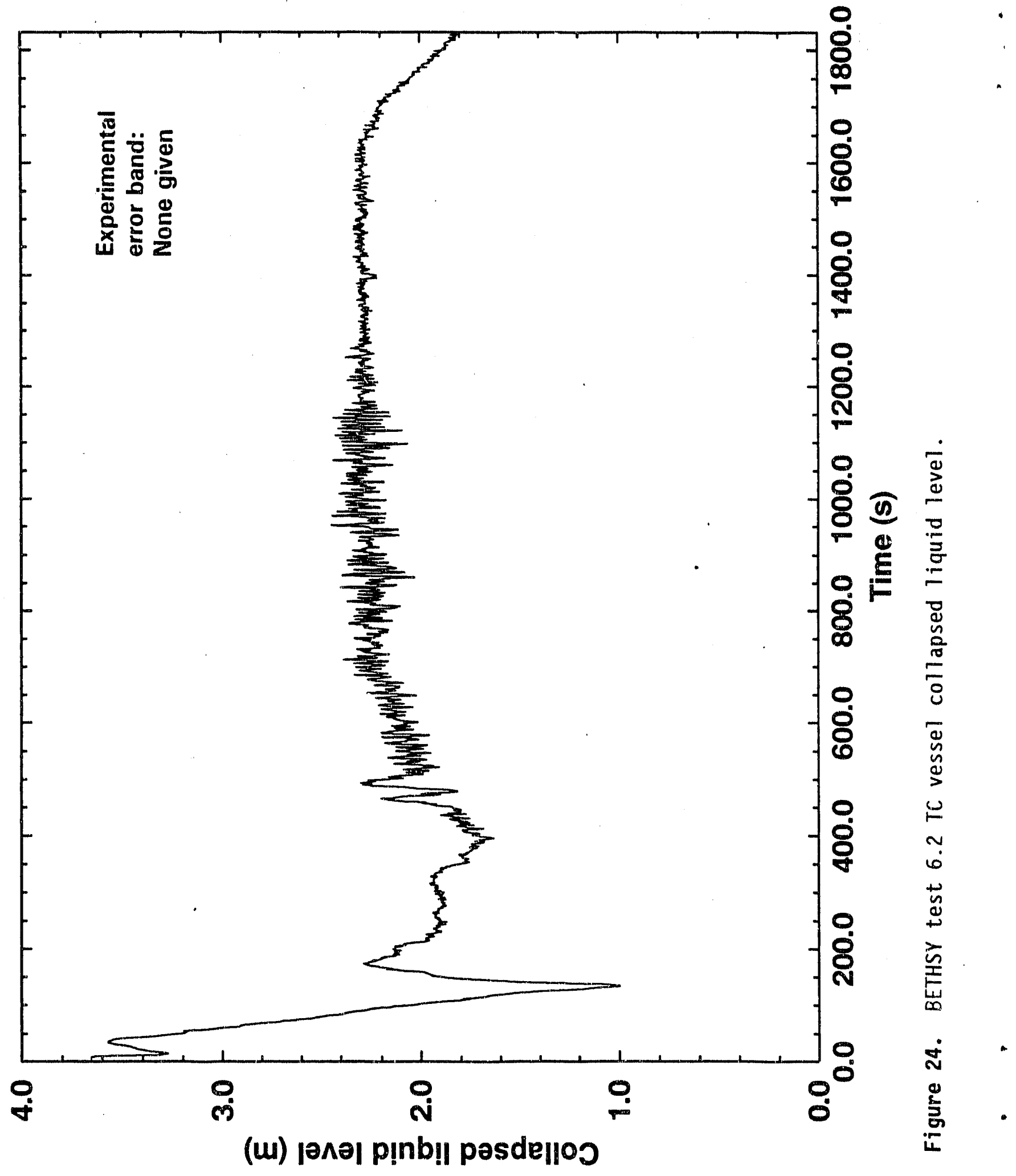




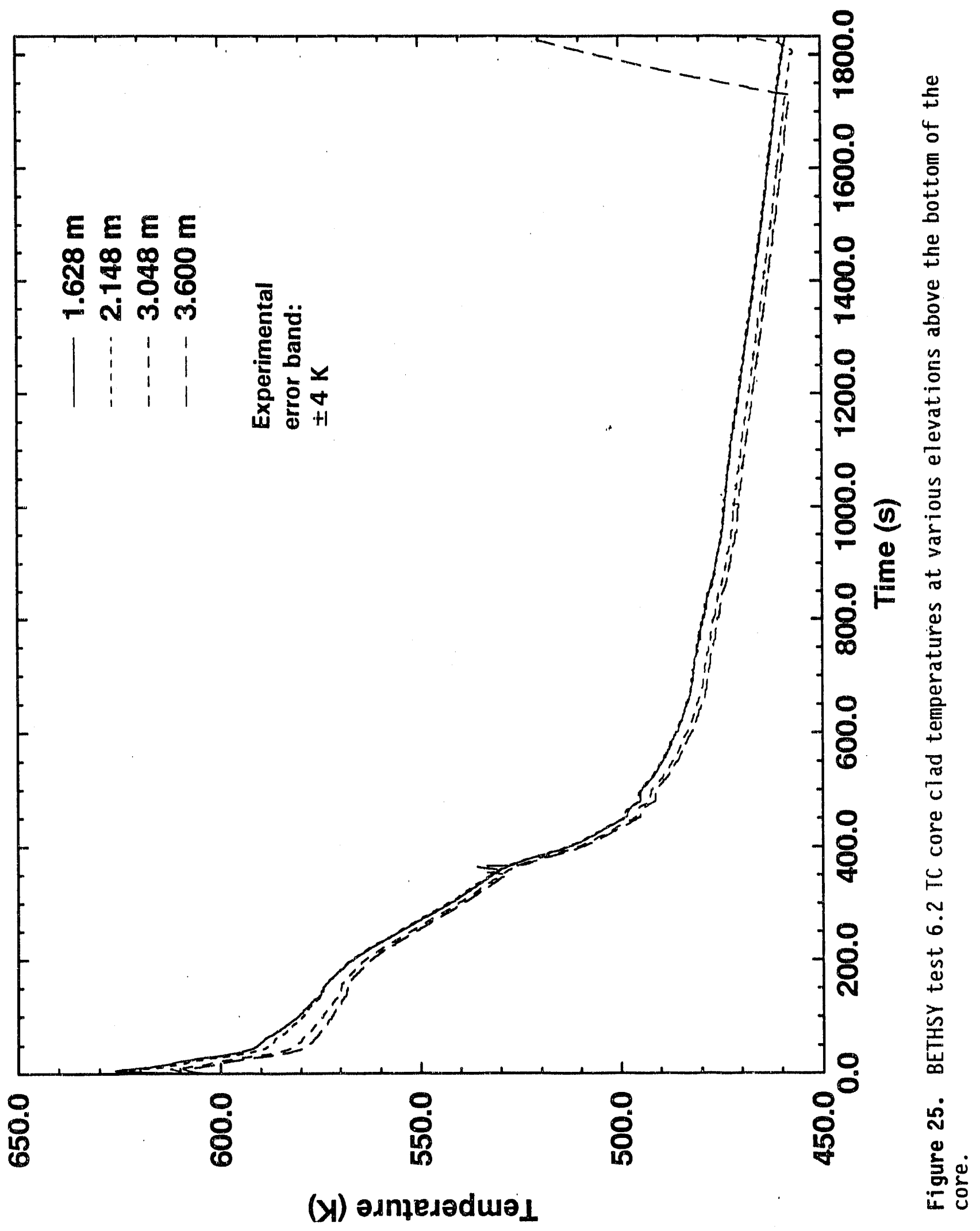




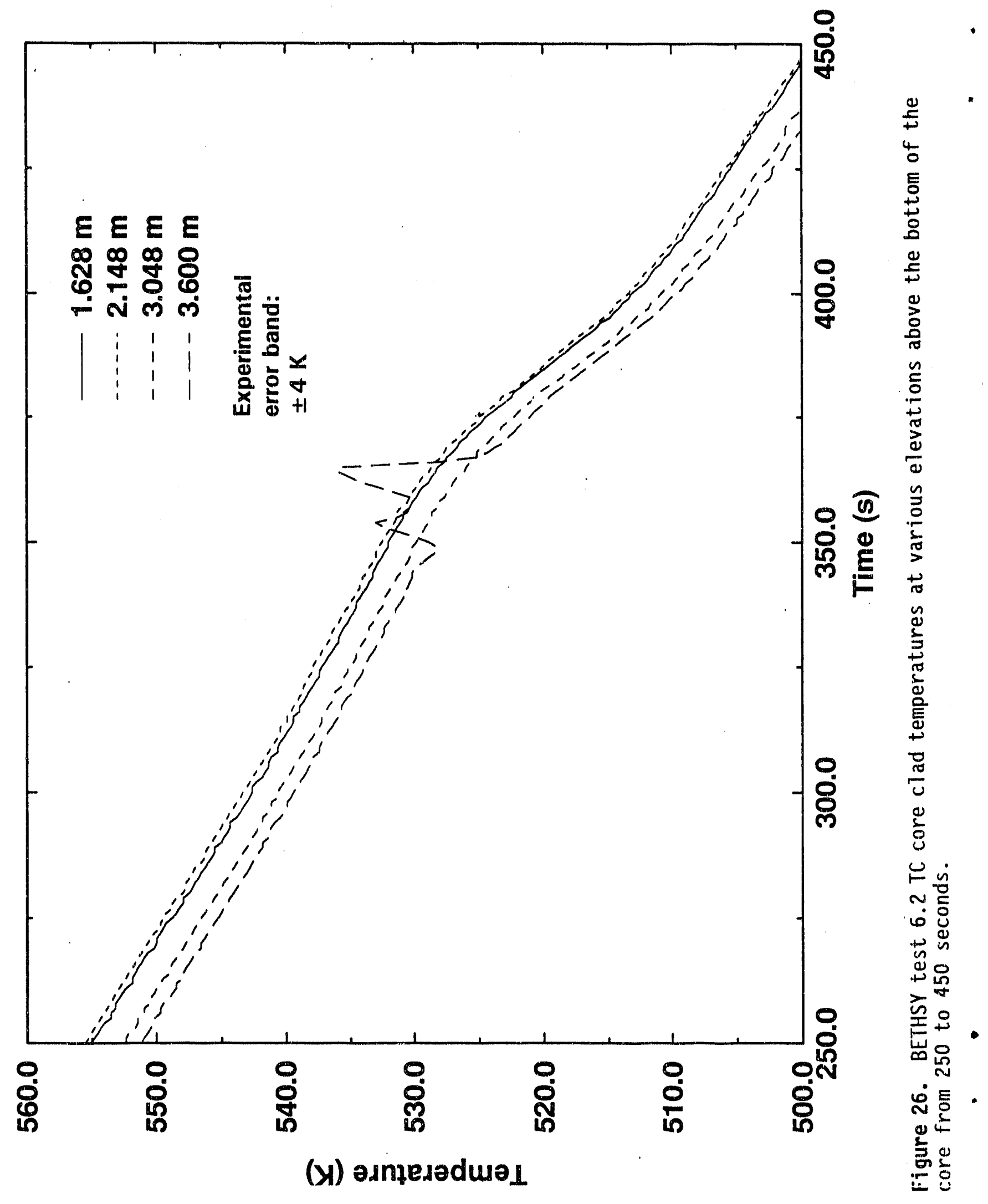




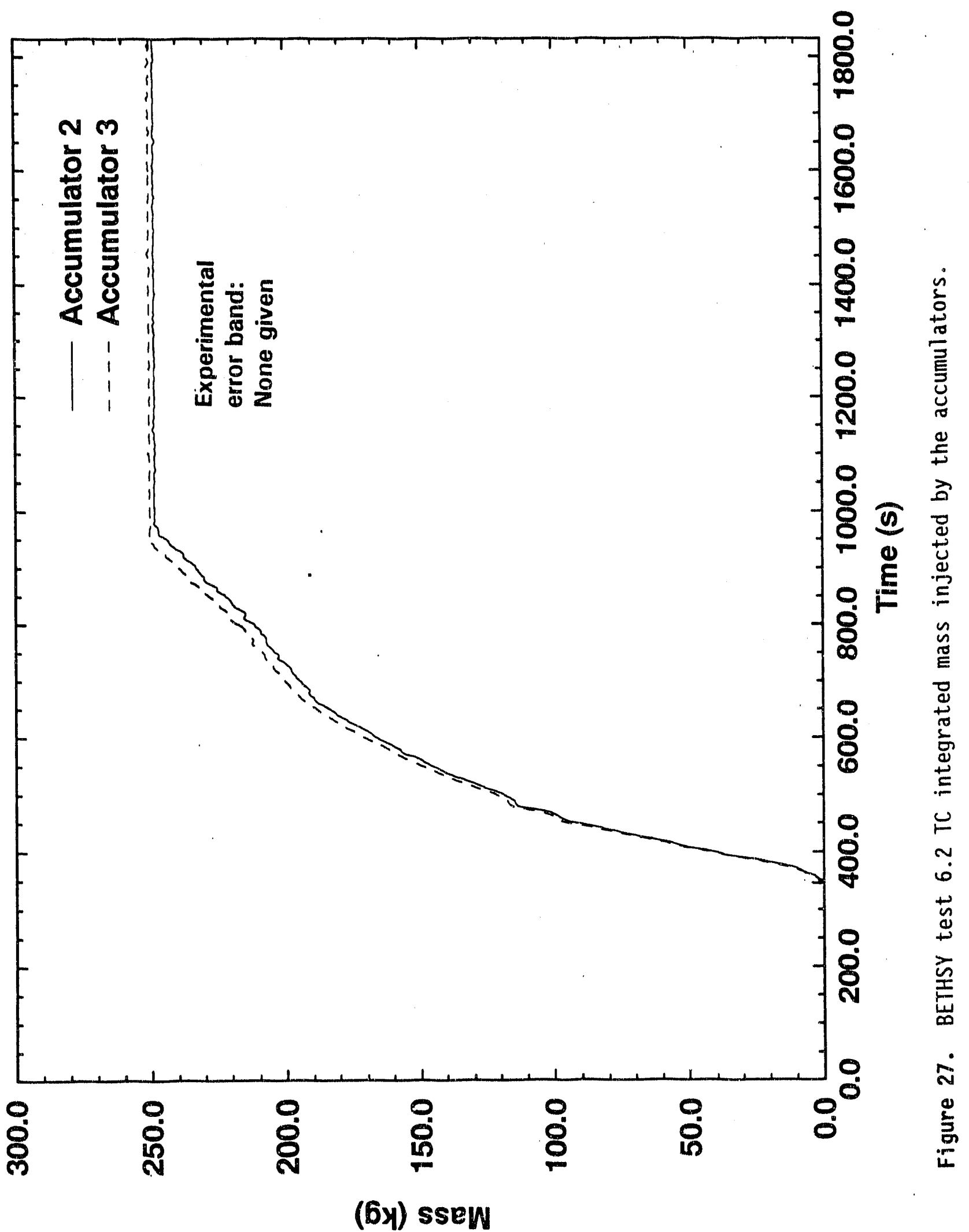




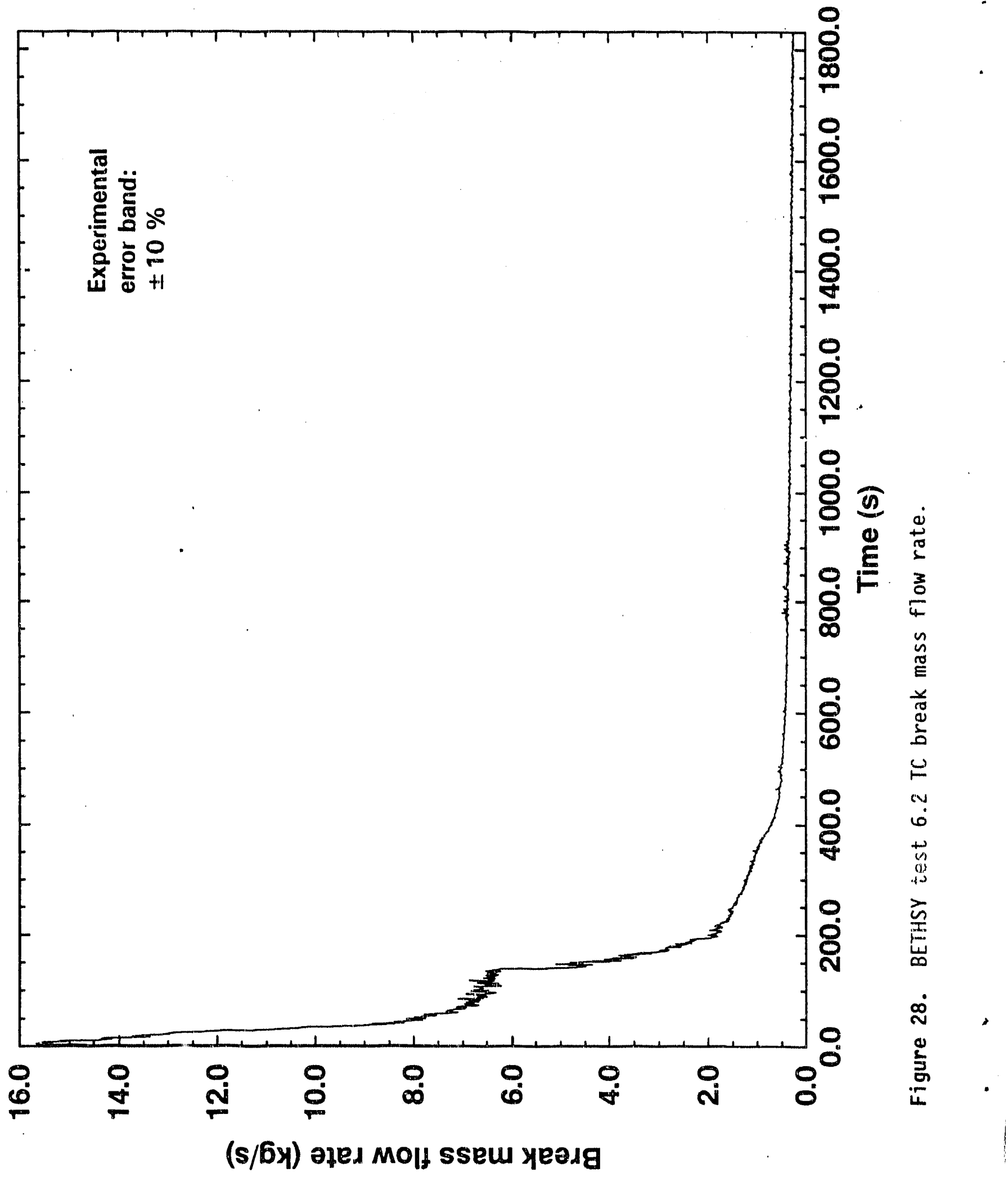




\section{RELAP5/MOD3 CALCULATIONS}

The first of the following subsections des ribes the RELAP5/MOD3 version 7 code and the BETHSY model nodalization which was developed for thes? studies. The next two subsections compare the results of the calculations with the experimental data for each test. The comparisons between the calculations and experiments are qualitatively labeled as excellent, reasonable, or minimal based on the qualifier descriptions given in Table 6 .

\subsection{Code and Model}

The RELAP5/MOD3 COde' is the latest modification in a lengthy series of codes developed to provide best-estimate predictions of postulated accidents and transients in light water reactor systems. The code features a two-phase, two-fluid nonequilibrium hydrodynamic model with many generic component models and special process models. The hydrodynamic model in the code utilizes a six equation formulation which solves the system of equations: (a) phasic mass sum, (b) phasic mass difference, (c) phasic momentum sum, (d) phasic momentum difference, (e) liquid energy, and (f) vapor energy. It also utilizes a constitutive package which solves for: (a) wall heat transfer, (b) interphase mass transfer, (c) interphase drag, and (d) wall friction which is linked to the two-fluid model through a common flow regime definition.

In January, 1990 an initial frozen version of RELAP5/MOD3 (version 5in5) was released to members of the International Code Assessment Program (ICAP). The participants in this program returned their comments to the code developers at Idaho National Engineering Laboratory and a series of new code versions were produced to address the various comments. A new version of MOD3 is planned for release in October, 1992. The analyses reported here were performed using unreleased versions of RELAP5/MOD3 version 7 . The analysis of test $9.1 \mathrm{~b} / \mathrm{ISP}-27$ was performed with an interim version of MOD3 version $7 \mathrm{q}$. The analysis of test 6.2 TC was performed with a different but very similar version of $\mathrm{MOD3}$ - version 70. 
Table 6. Code assessment comparison descriptors.

Descriptor

Definition

Excellent An appropriate descriptor when the code exhibits no deficiencies in modeling a given behavior. Major and minor phenomena and trends are predicted correctly. The calculated results are judged by the analyst to be close to the data with which a comparison is being made. If the uncertainty of the data has been identified and made available to the analyst the calculation will, with few exceptions, lie within the uncertainty band of the data. The code may be used with confidence in similar applications. Neither code models nor the facility noding model requires examination or change.

Reasonable An appropriate descriptor when the code exhibits deficiencies, but the deficiencies are minor; that is, the deficiencies are acceptable because the code provides an acceptable prediction of the test. All major trends and phenomena are predicted correctly. Differences between the test and calculated traces of parameters identified as important by the analyst are greater than those deemed necessary for excellent agreement. If uncertainty data are available, the calculation frequently will lie outside the uncertainty band. However, the analyst believes that the discrepancies are insufficiently large to require a warning to potential users of the code in similar applications. The assessment analyst believes that the correct conclusions about trends and phenomena would be reached if the code were used in similar applizations. The code models and/or facility noding model should be reviewed to see whether improvements can be made.

Minimal An appropriate descriptor when the code exhibits deficiencies and the deficiencies are significant; that is, the deficiencies are such that the code provides a prediction of the test that is only conditionally acceptable. Some major trends or phenomena are not predicted correctly whereas others are predicted correctly. Some RELAP5-calculated values lie far outside the uncertainty band of the data with which a comparison is being made. The assessment analyst be? ieves that incorrect conclusions about trends and phenomena might be reached if the code were used in similar applications. The analyst believes that certain code models and/or the facility noding model must be reviewed, corrections made, and a limited assessment of the revised code or input models made before the code can be used with confidence for similar applications. A warning should be issued to the RELAP5 user community that the user applying the code in similar applications risks drawing incorrect conclusions. This warning should stay in force until the identified review, modification, and limited assessment activities are completed and the resultant characterization descriptor is "reasonable" or better. 
RELAP5/MOD3 versions 70 and $7 q$ are virtually the same but they differ in several ways from version $5 \mathrm{~m} 5$, the earlier official release version of MOD3: (a) the accumulator model was made isotherma1, (b) the umbrella limit on subcooled liquid interfacial heat transfer was turned off, (c) a temperature discontinuity in interphase mass transfer was smoothed, (d) coding causing calculational differences between machines was fixed, (e) mass error problems were improved with corrections to interphase drag and vertical stratification, (f) for metastable states the liquid superheat was limited to $50 \mathrm{~K}$, and (g) an error in the volume velocity when a time step is repeated was fixed.

It was of particular interest in this study, to examine the performance of the new models added to MOD2 to create MOD3. Some of the more important of these are: (a) the counter-current flow limitation (CCFL) model, (b) the vapor pull-through/liquid entrainment model, (c) a revised critical heat flux (CHF) model, (d) the ECCMIX component, (e) junction-based interphase friction, and ( $f$ ) a revised choking model. The use of these models in this study and their performance will be discussed in the following two subsections.

The nodalization of the BETHSY facility" used for the two studies was very similar (see figure 29). The vessel was modeled with 16 cells in the core and a single-pipe external downcomer. The elevations of the divisions between the cells in the core and the divisions between the cells in the loop seals were made the same. All three primary coolant loops were modeled individually with their connected steam generators and accumulators. The pressurizer and the break were modeled connected at the proper points in loop 1. The pumps were each modeled with the incorporated weir. All metal mass in contact with the primary and secondary systems was modeled. For test 6.2 TC the losses to the environment were modeled while, for test $9.1 \mathrm{~b} /$ ISP-27, those structures were assumed to be insulated. The model for test $9.1 \mathrm{~b} /$ ISP-27 included systems to represent the LPSI, AFW, and UP blowdown systems which were not included in the model for test 6.2 TC because they were not used during that test. 


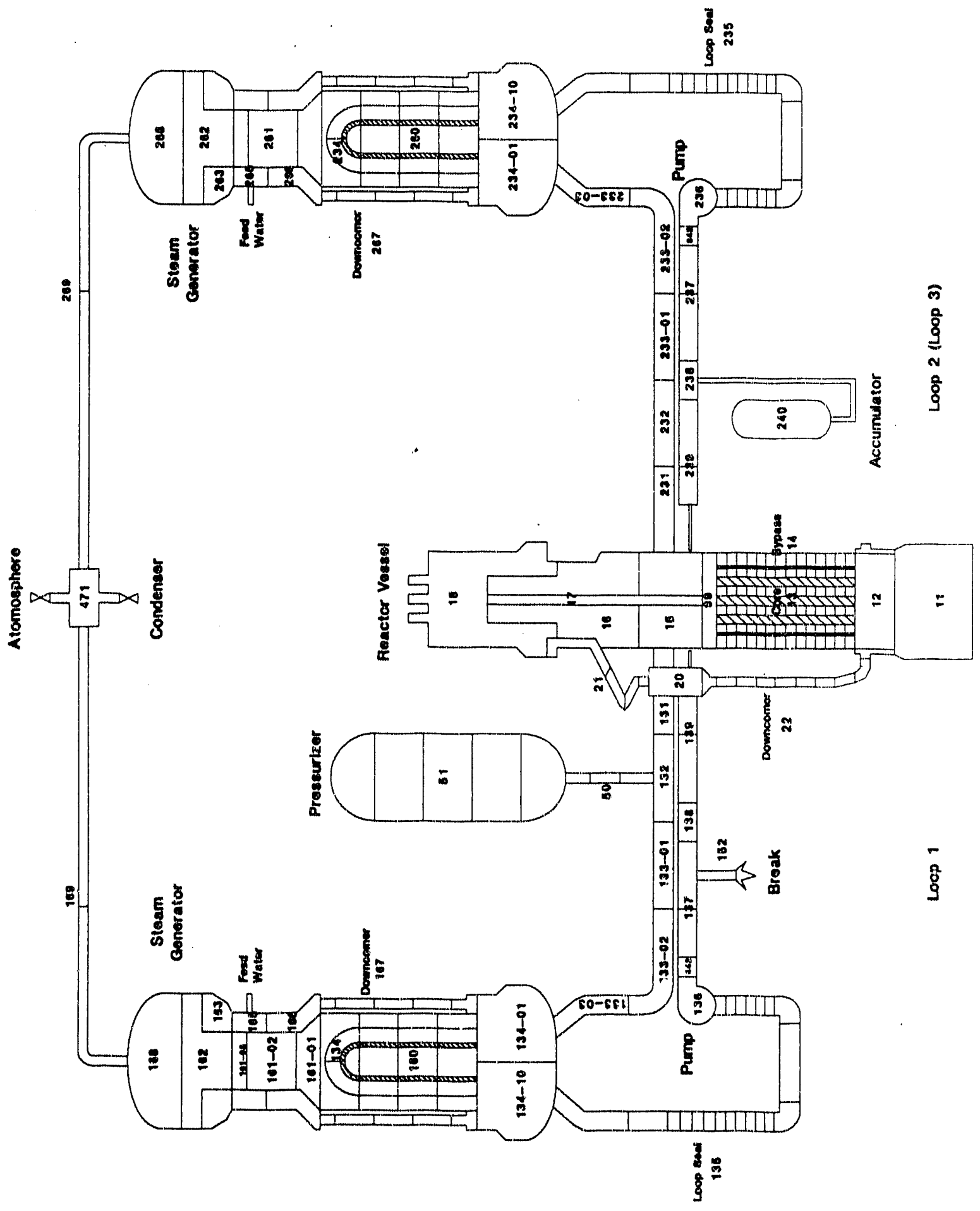

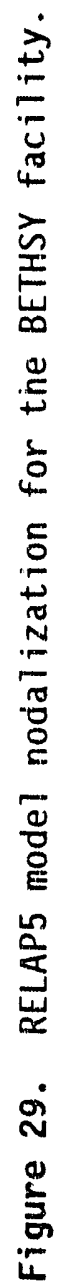


Since the analysis of test 9.16 was done in the framework of the ISP27 it was performed in a "blind" manner. Thus very few test data were made available initially. One piece of information that was released, however, was that only one loop seal cleared and it was the loop seal in loop 2. It was suggested, for consistency, that analysts force the loop 2 loop seal to be the one to clear. In order to do this, the model for this test was altered to raise the elevation of the bottom of loop seal 2 by 1 pipe diameter.

The break nozzle for each test required careful modeling in order to get the correct flow for the given upstream conditions. Data were provided'2 which described the mass flux through each nozzle as a function of inlet conditions. A model of each nozzle was then developed. The smaller break nozzle, used for test $9.1 \mathrm{~b} /$ ISP-27, could not be modeled with a single choked junction because no single set of discharge coefficients could be found which would give the correct flow under all conditions. Therefore, for test $9.1 \mathrm{~b} / \mathrm{ISP}-27$, it was necessary to use a model of the rivzzle which specified discharge coefficients on choking junctions at each end of a short volume representing the nozzle. For test 6.2 TC the nozzle had a large diameter so there was not as great a change in pressure from one end to the other. Thus it was possible to model this case using a single volume with a choking junction at the outlet and a normal junction at the inlet.

In each case, modeling flow through the small volume of the nozzle, would require the use of a very small time step so that the courant limit would not be passed. It would be unacceptable to use a very small time step to simulate these two very lengthy transients because it would require too much computer time. Thus a change was made in the size of the volume used to model the nozzle. The Courant limit for the rest of the model was found to be about 30 times greater than the original Courant limit of the nozzle. Thus, in order to bring the nozzle limit into the same range, its length was multiplied by 30 . Then, in order to avoid distorting the pressure drop in the nozzle cell, the hydraulic diameter was also multiplied by a factor of 30. All other dimensional information remained the same as the actual nozzle. The result was a model of the nozzle that had 30 times the volume but was accurate otherwise. Since the nozzle volume was so small anyway, 
30 times it was still insignificant. Additionally, the nozzle volume did not really play a part in the transient. The only requirement was to provide an accurate model of the flow lost through the break and that was assured by comparison between the calculated nozzle data and the provided experimental nozzle data.

The accumulator model provided by the code was used to model the BETHSY accumulators connected to loops 2 and 3 in test $9.1 \mathrm{~b} / \mathrm{ISP}-27$. The vapor pul1-through/liguid entrainment model was used at the junction to the break nozzle. The new capabilities of the CHF model were applied in the core region and in the steam generator boiler region. The model for test 9.1b/ISP-27 used the CCFL model at the junctions between the steam generator plena and the $U$-tubes but the CCFL model was not used for the base case model of test $6.2 \mathrm{TC}$.

The ECC mixer component was tested for use at the junction between the accumulator injection line and the cold leg. The RELAP5/MOD3 implementation of this component was designed specifically to solve a problem with insufficient condensation occurring on the ECC flow during a large break LOCA. When this component was tested in the model for test 9.1b/ISP-27 it was found that an excessive amount of condensation occurred and caused the code to fail. Without using the ECC mixer component the results for test 9.1b/ISP-27 appeared to be valid so the component was not included in the final model. When this component was tested in the model for test 6.2 TC, it resulted in a slight increase in condensation but otherwise seemed to have little effect. Thus the base case model did not include the ECC mixer component while the sensitivity case model did.

A close examination of the nodalization of the loop seal in Figure 29 will show that a larger than usual number of cells were used in the vertical sections. This was done because, during the development of the deck, it was found that the code did not properly represent the draining of a vertical pipe. It was found that void was passed into the cell beneath the cell with the level much sooner than was physically reasonable. Thus in order to minimize this effect and obtain more accurate timing for the clearing of the loop seals, a large number of cells was used. 


\subsection{Test 9.1b/ISP-27 Calculation versus \\ Experiment Comparison}

The initial conditions of test 9.1b/ISP-27 were well matched by the calculation as shown in Table 7. The division of the downcomer mass flow between the core and the core bypass differs between the calculation and the experiment. The magnitude of the core bypass flow was not given in the information for the blind ISP and the geometrical information was not

Table 7. Comparison of experimental and calculated initial conditions for BETHSY test 9.1b/ISP-27.

\begin{tabular}{|c|c|c|}
\hline Parameter & Experimental & Calculated \\
\hline Core power $(\mathrm{kW})$ & $2857 \pm 30$ & 2864.0 \\
\hline $\begin{array}{l}\text { Pressurizer pressure (MPa) } \\
\text { Pressurizer Tevel (m) }\end{array}$ & $\begin{aligned} 15.5 .1 & \pm 0.09 \\
4.08 & \pm 0.1\end{aligned}$ & $\begin{array}{r}15.50 \\
4.08\end{array}$ \\
\hline $\begin{array}{l}\text { Pump speed (rpm) } \\
\text { Downcomer mass flow rate }(\mathrm{kg} / \mathrm{s})\end{array}$ & $\begin{aligned} 2940 & \pm 30 \\
150 & \pm 5\end{aligned}$ & $\begin{array}{r}2940.1 \\
150.6\end{array}$ \\
\hline $\begin{array}{l}\text { Core inlet temperature }(K) \\
\text { Core outlet temperature }(K)\end{array}$ & $\begin{array}{l}559.90 \pm 4 \\
566.35 \pm 4\end{array}$ & $\begin{array}{l}561.1 \\
564.6\end{array}$ \\
\hline $\begin{array}{l}\text { Primary system mass with } \\
\text { pressurizer }(\mathrm{kg})\end{array}$ & $1940 \pm 40$ & 1939.0 \\
\hline $\begin{array}{l}\text { Secondary system pressure (MPa) } \\
\text { Secondary steam generaror level (m) } \\
\text { Secondary mass inventory per } \\
\text { steam generator }(\mathrm{kg})\end{array}$ & $\begin{aligned} 6.91 & \pm 0.04 \\
13.45 & \pm 0.05 \\
820 & \pm 30\end{aligned}$ & $\begin{array}{r}6.91 \\
13.42 \\
796.0\end{array}$ \\
\hline $\begin{array}{l}\text { Feed water temperature }(\mathrm{K}) \\
\text { Feed water flow rate per steam } \\
\text { generator }(\mathrm{kg} / \mathrm{s})\end{array}$ & $\begin{array}{l}491.15 \pm 2.0 \\
0.525 \pm 0.04\end{array}$ & $\begin{array}{r}491.15 \\
0.538\end{array}$ \\
\hline $\begin{array}{l}\text { Bypass flow: downcomer to upper } \\
\text { head ( } \% \text { of total loop flow) }\end{array}$ & 2.0 & 2.0 \\
\hline $\begin{array}{l}\text { Core bypass flow: lower plenum to } \\
\text { upper plenum ( } \% \text { of downcomer flow) }\end{array}$ & 5.0 & 2.0 \\
\hline $\begin{array}{l}\text { Trace heating (kW) } \\
\text { Pump cooling circuits heat loss } \\
\text { per pump (kW) }\end{array}$ & $\begin{array}{r}107.5 \pm 2 \\
25.0\end{array}$ & $\begin{array}{l}0.0 \\
0.0\end{array}$ \\
\hline
\end{tabular}


sufficient to clearly define this value. It is not expected that this discrepancy has much influence on the results. There is a significant difference between calculated and experimental core inlet temperature. However, there is reason to question the given experimental core inlet temperature. A heat balance across the core was performed using the data from the ISP including the listed core inlet temperature. This balance found that the core would have to produce $75.3 \%$ more energy to yield the given temperature difference across the core. However : he given experimental core inlet and outlet temperature were changed to match the calculated values, the balance was reasonable. Finally, there is a difference between the powers shown for the external circuits. For simplicity the contribution from trace heating was assumed to be balanced exactly by the heat losses from the system and the pump cooling heat loss was assumed to be trivial.

A comparison of the chronology of major events in the experiment and the calculation is shown in Table 8 . There is excellent agreement between

Table 8. Comparison of experimental and calculated chronology for BETHSY test $9.1 \mathrm{~b} / \mathrm{ISP}-27$.

Events

Scram signal

SI signal

Core power decay start

Auxiliary feedwater on

Pump coastdown start

End of pump coastdown

Two-phase discharge at the break

start of first core level depression

First loop seal clearing

Start of second core level depression

UP initiation

Accumulator injection start

Primary mass inventory minimum

Second loop seai clearing

Maximum core heatup

Accumulator isolation

LPSI startup

ind of test

Experiment Calculation

41

54

58

82

356

971

1340

1830

1944

2180

2562

2962

2970

3040

3053

3831

5177

8330
36.0

53.6

53.0

82.0

353.6

969.6

920.0

2057

2357

2371

2756

3161

3260

3186

3212

4125

5728

8661 
the experiment and the calculation until the start of two-phase discharge at the break. This occurs earlier in the calculation than in the experiment. Since the onset of two-phase discharge at the break causes a reduction in mass flow and an increase in the depressurization rate, the timing of the other events in the calculation are wrong by various amounts depending on how they are affected by primary inventory and primary pressure.

A plot comparing the values of primary pressure found in the experiment with the calculated value is shown in Figure 30 . The dip in primary pressure between 500 and 1200 seconds which appeared in the experiment was not simulated in the calculation. This problem is a consequence of the blind nature of the test analysis. The data provided for the secondary boundary conditions of the ISP-27 was not sufficiently accurate to simulate this pressure dip. Figure 31 shows that the corresponding secondary pressure dip was also not simulated for the same reason. In both figures the delay in the timing of the pressure drop associated with the UP is evident. The cause of this delay will be described below. If the delay were not present, the comparison would be excellent. As it is, the comparison is reasonable. Toward the end of the transient it appears that the calculation is predicting a slightly higher pressure than found in the experiment. This could be due to the fact that the calculation did not take into account the heat losses to the environment.

Figure 32 shows the experimental and calculated void in the broken cold leg. In the experimental data, the value of the void, considering the experimental error of \pm 0.05 , remained at zero until 1300 seconds. A closer view, in Figure 33 , shows that the calculated value departed from zero void at about 800 seconds. It then rose to about 0.3 where it remained unti? about 1500 seconds. This behavior differs considerably from the behavior in the experiment. For this parameter, the comparison agreement is minimal.

During the time between the first loop seal clearing and the drop in void associated with accumulator injection, 1944-3550 s for the experiment and 2357-3650 s for the calculation, the void fraction was very close to 


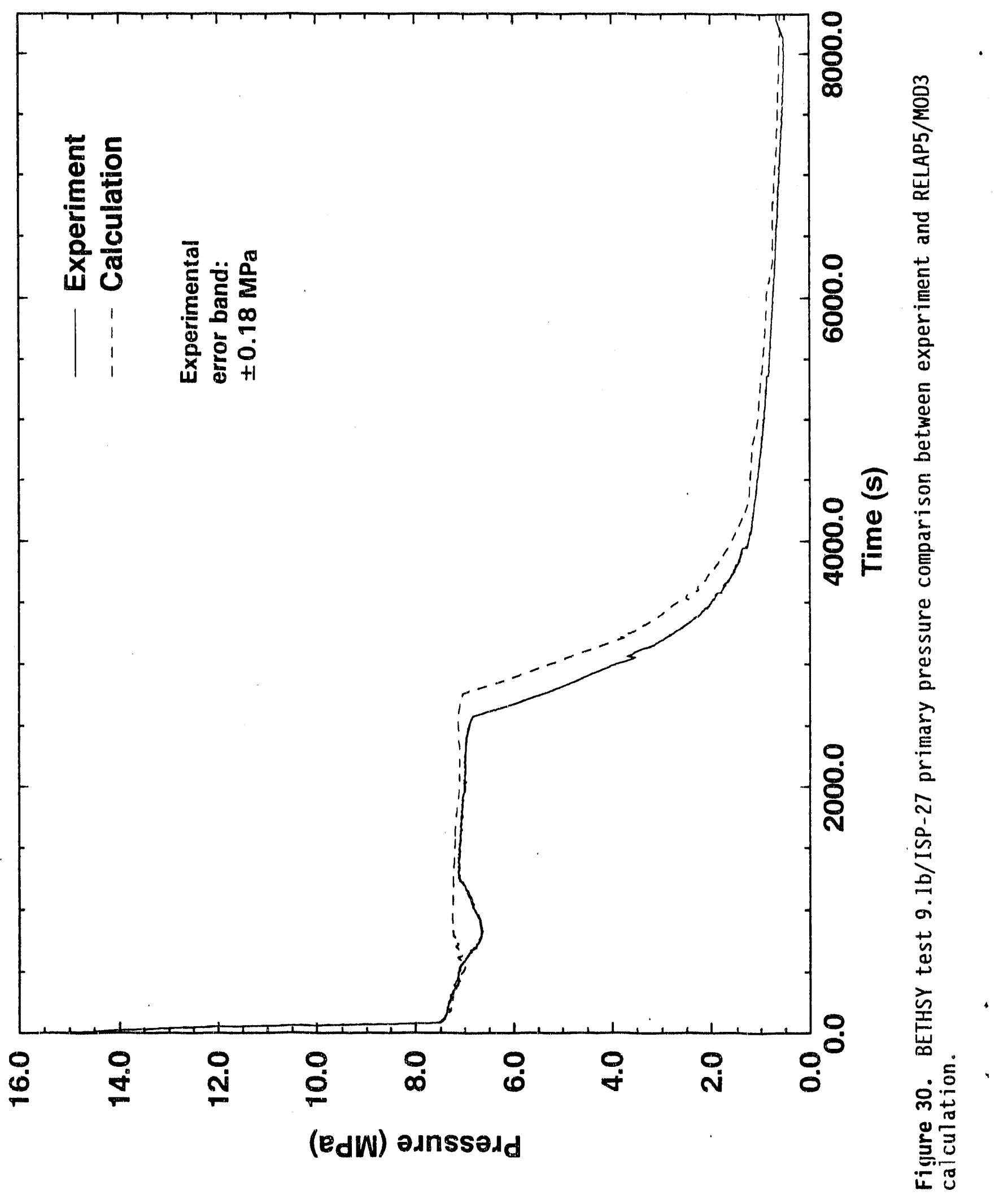




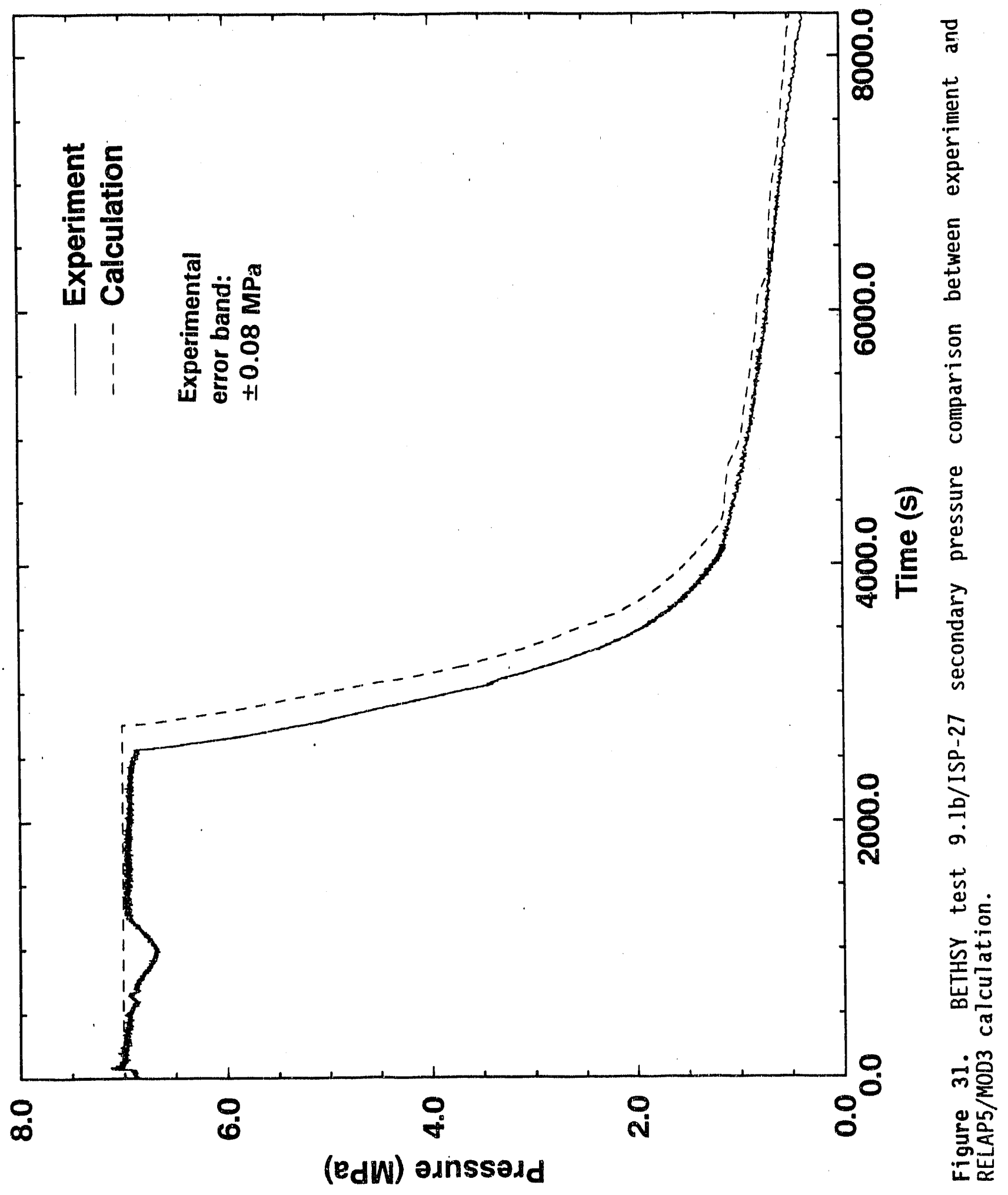




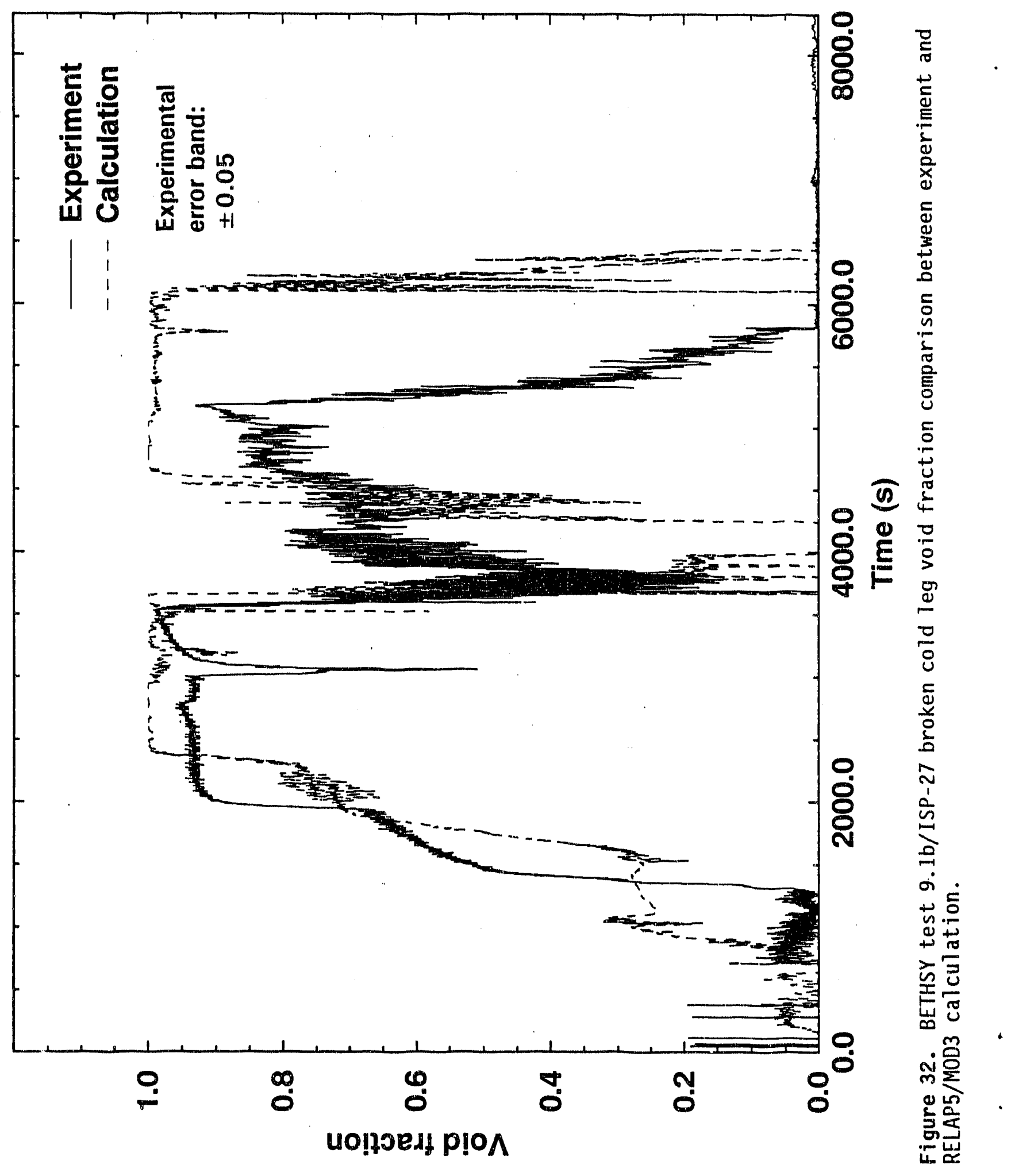




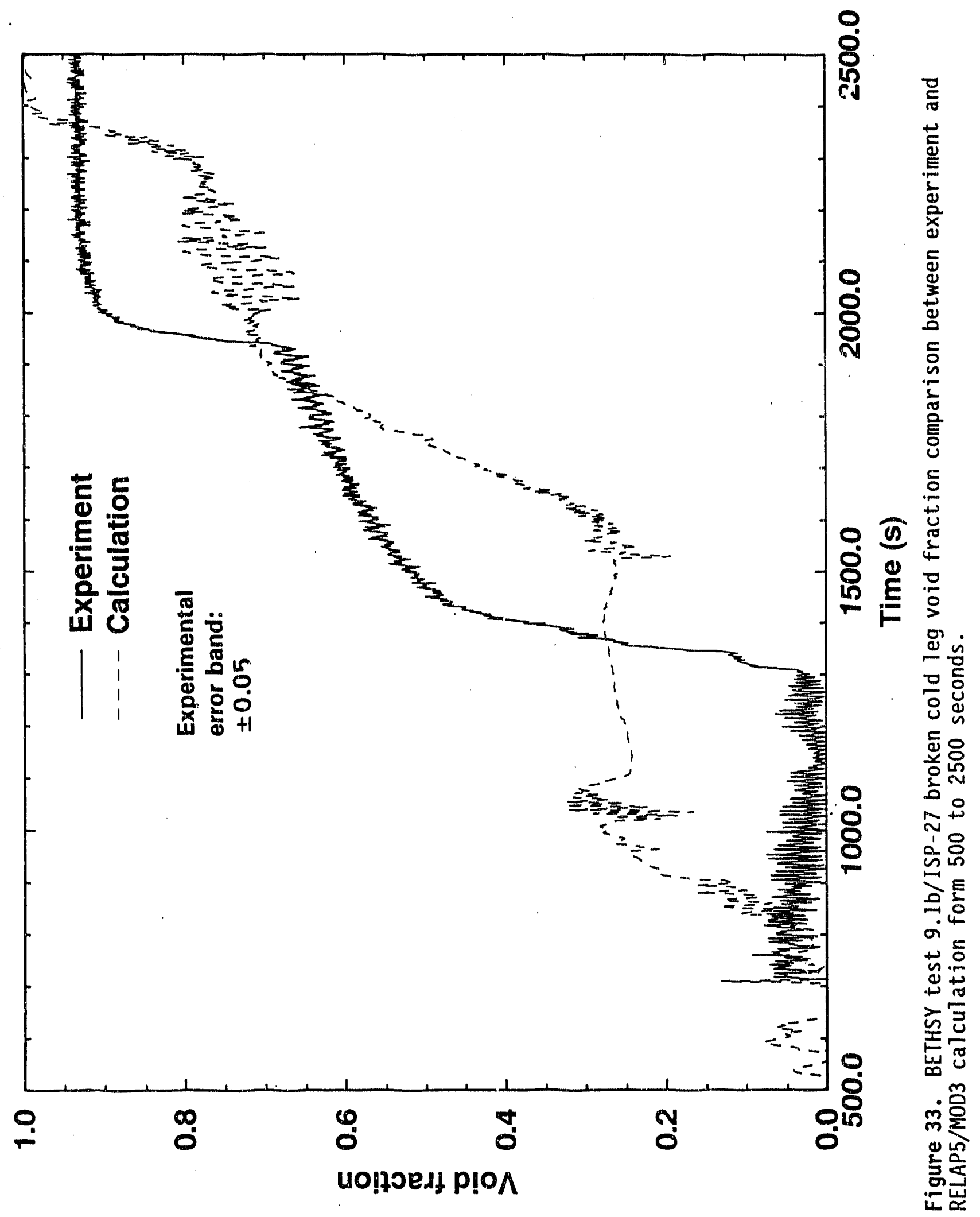


one. However, although the calculated void was somewhat higher than found in the experiment, it was only slightly beyond experimental error. During this time span, both traces showed the drop in void associated with the second loop seal clearing. Then, between accumulator isolation and the time when LPSI refilled the cold leg, the calculated void again rose to nearly one. During this time span, the experimental value remained significantly lower.

Figure 34 shows the effect that the early appearance of void in the broken cold leg had on the break mass flow rate. Both calculation and experimentai flow rates were similar until 800 seconds when, due to the lowered void in the cold leg, the calculation flow rate dropped. The experimental flow rate did not drop until 1300 seconds when the experimental cold leg void rose above zero. The remaining events which are evident on the plot of experimental break mass flow rate are also evident on the plot of the calculated flow rate but are shifted by various amounts depending on how they were affected by the primary pressure and primary inventory. Once consideration is made for these time shifts, the agreement of the magnitude of the calculated mass flow rate appears to be reasonable in comparison with the experiment. This conclusion is also in agreement with the results shown in Figure 35 for time integrated break niass flow.

Considerable effort has been exerted to determine the cause and remedy for the early appearance of void in the broken leg. Several sensitivity calculations have been performed using nodalizations with smailer nodes throughout the region from the cold leg through the bypass and the upper head. Other calculations examined the effect of modifying the secondary pressure boundary condition to match the data, eliminating the use of the CCFL model, and changing the pump model. Recently, and additional sensitivity calculation was performed. This calculation made a slight change in the model of the junctions to and from the guide tube volume (volume 17 in Figure 29). The new model used a homogeneous junction velocity calculation instead of a non-homogeneous one. This had the effect of locking the vapor and liquid velocities together. This effectively disables the function of the vertical stratification model which could be performing improperly during the time that the void is being transferred to the broken cold leg erroneous ly. Preliminary analysis of the results from this new calculation show that it represents the void in the broken leg properly. Purther analyssis is underway, but these results might point to 


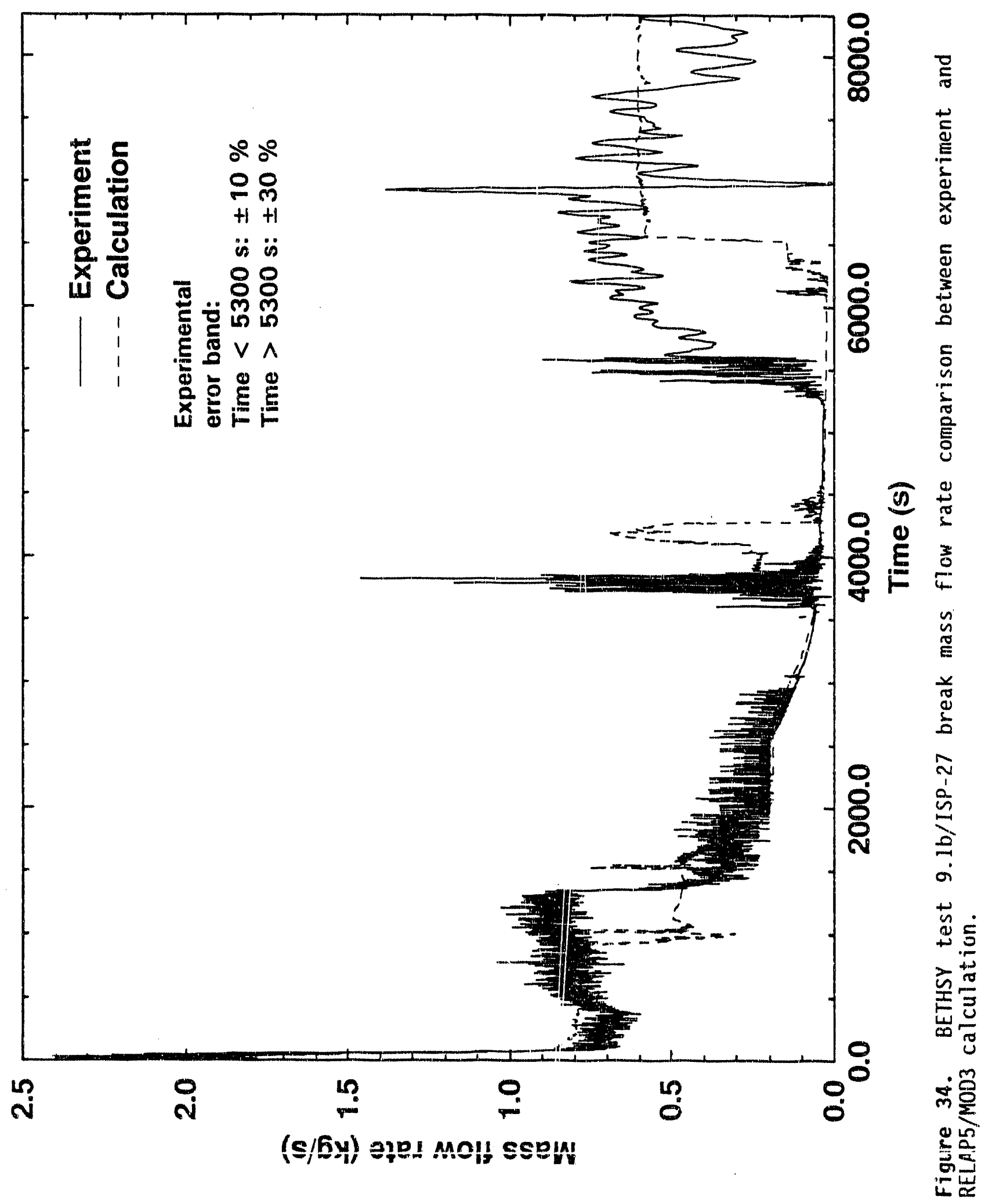




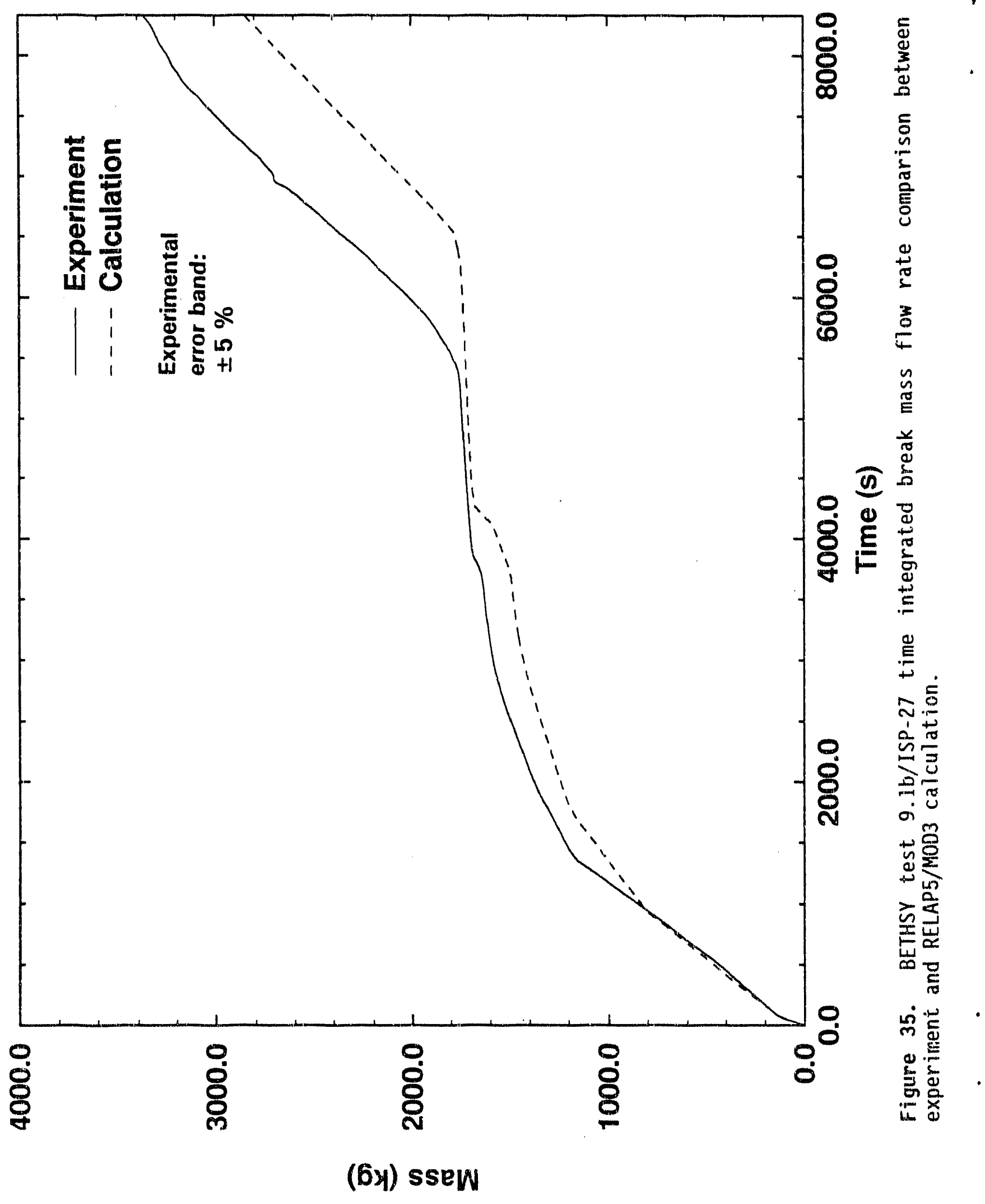


a problem in ore of several possible models in RELAP5/MOD3. These models include: (a) the vertical stratification model, (b) the interphase drag model, and (c) the solution technique that donors void from one cell to another.

The collapsed core level comparison plot is shown in Figure 36 . The core level depression was shifted in time for reasons already discussed. otherwise the agreement is reasonable up to about 7000 seconds when the experiment showed the presence of significantly more liquid in the core than was shown in the calculation. It appears that the distribution of the primary inventory was not well represented by the calculation. The interphase drag model could be responsibie for this discrepancy.

Figure 37 shows the peak clad temperature as found in the experiment and as calculated by RELAP5/MOD3. The temperature before and after the peak is in reasonable agreement and the duration of the peak is also. The time shift has been explained previously, but the magnitude of the peak is not in good agreement. As was noted in section 3.1, the upper parts of the core received some cooling from reflux water entering the core from the hot legs. The RELAP5/MOD3 model, due to its finite nodalization, spread this water over the entire cross-section of the core while in the experiment its effect was probably more 1 imited. Thus the experiment recorded more heatup in the central parts of the core than was shown by the averaged heatup in the calculation.

The behavior of loop seal clearing in loop 2 and loop 3 is shown by the value of the differential pressure on the downflow side of the loop seal as shown in Figures 38 and 39 respectively. With consideration of the time shifts, the agreement between the experiment and the ralculation is reasonable both for loop 2 which cleared and for loop 3 which did not clear. There is some confusion with regard to the initial value of the differential pressure plotted here. In the experimental data, loop 1 and 2 had an initial value of $15 \mathrm{kPa}$ while the loop 3 value was $18 \mathrm{kPa}$. In the calculation all three loops had the same value of approximately $18 \mathrm{kPa}$ in agreement with the loop 3 experimental value. The discrepancy appears to be in the experimental values reported for loop 1 and 2 . This discrepancy remains unexpiained but does not appear to persisi much beyonu the initiai value so it should have little bearing on the analysis results. The loop 


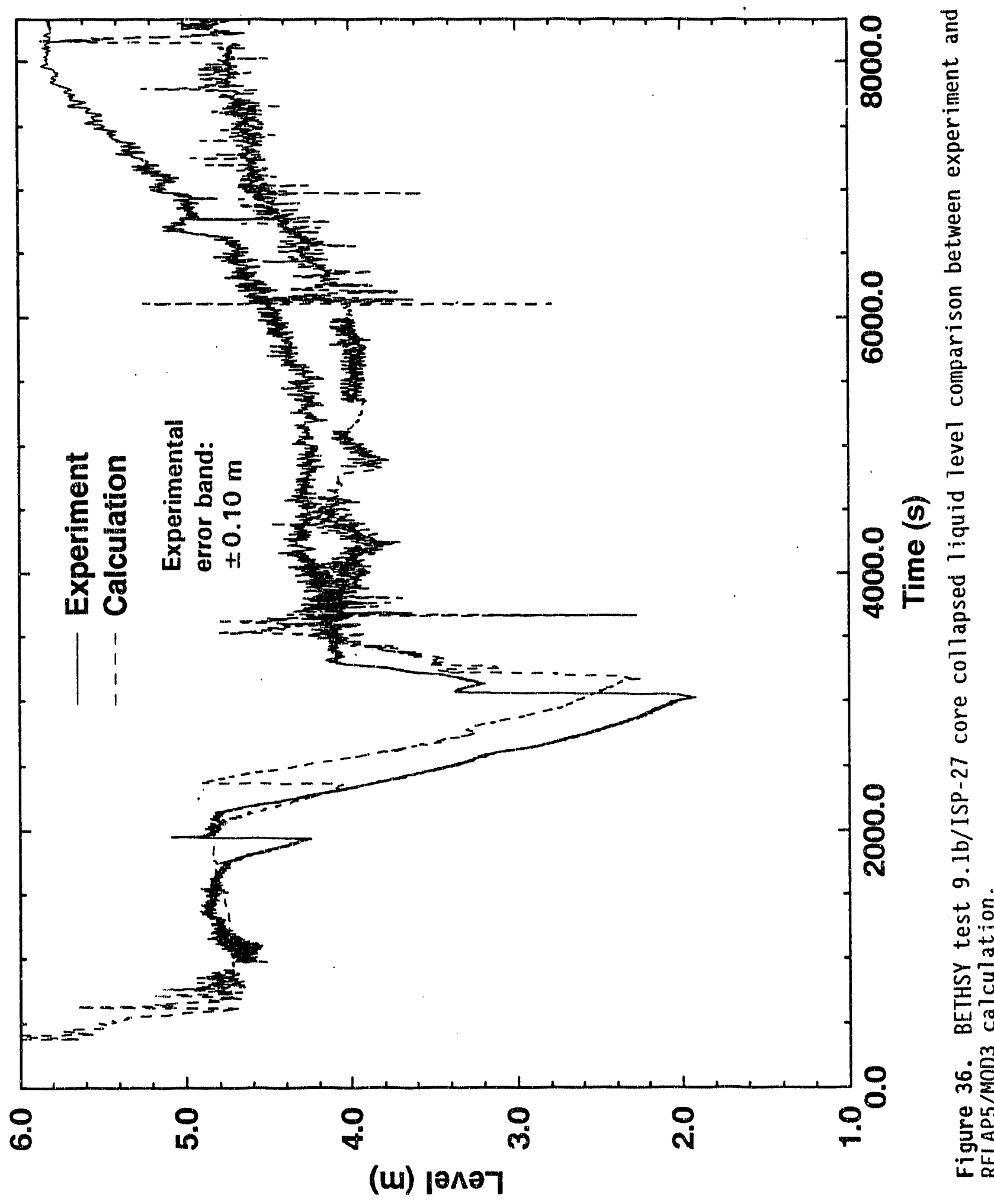




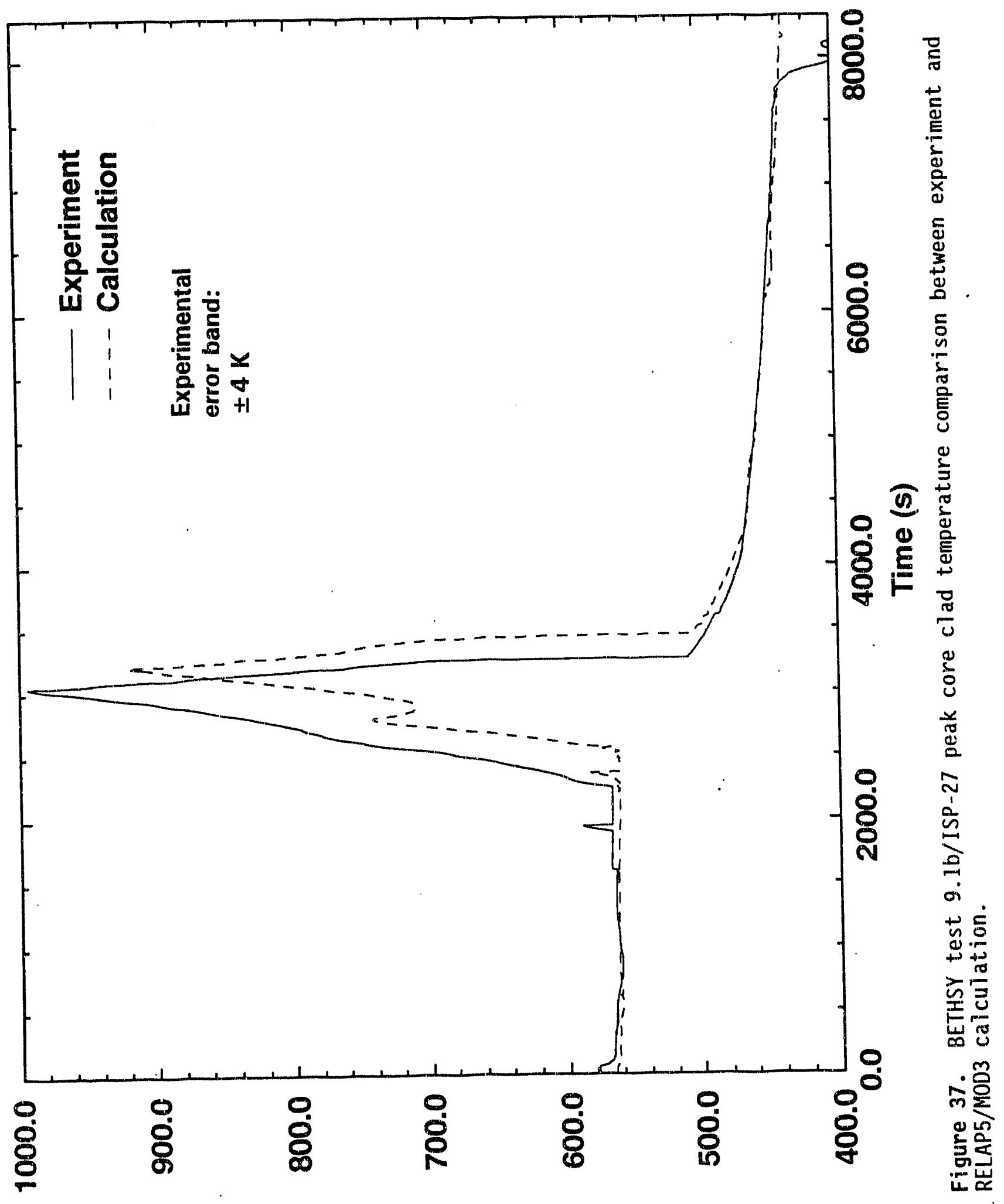

(y) ә.пฺеגəduə $\perp$ 


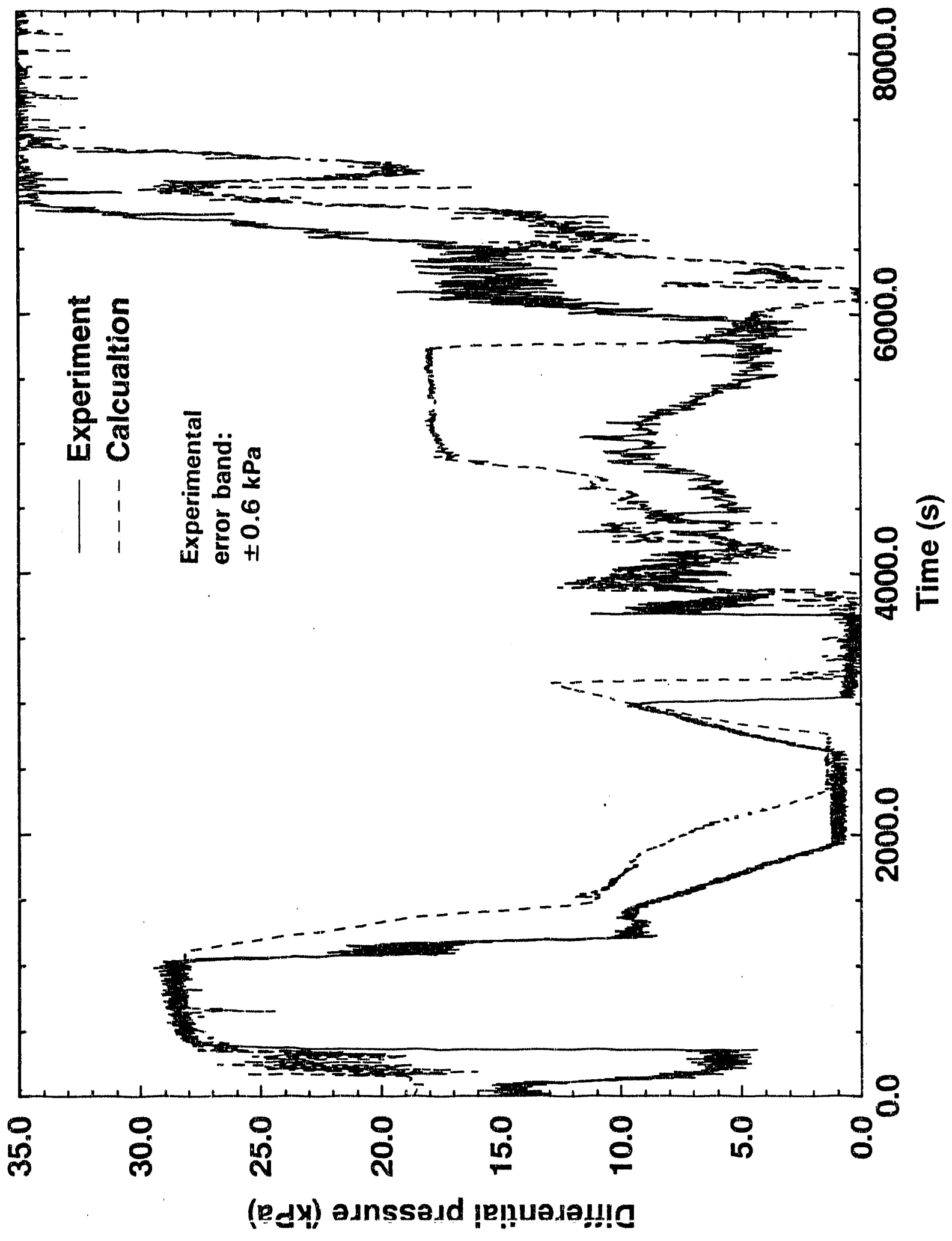

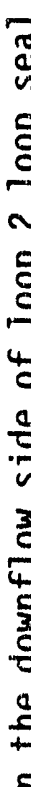

용

5.

ज范

प्⿱一兀)

-

ㅍํㅇ

잉ํㄹ

ปั

证

두뭄

i

岤

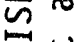

를

बं.

वे

范

过

บे

呈

崩范

$\infty$ 등

隽

\& 흘응 


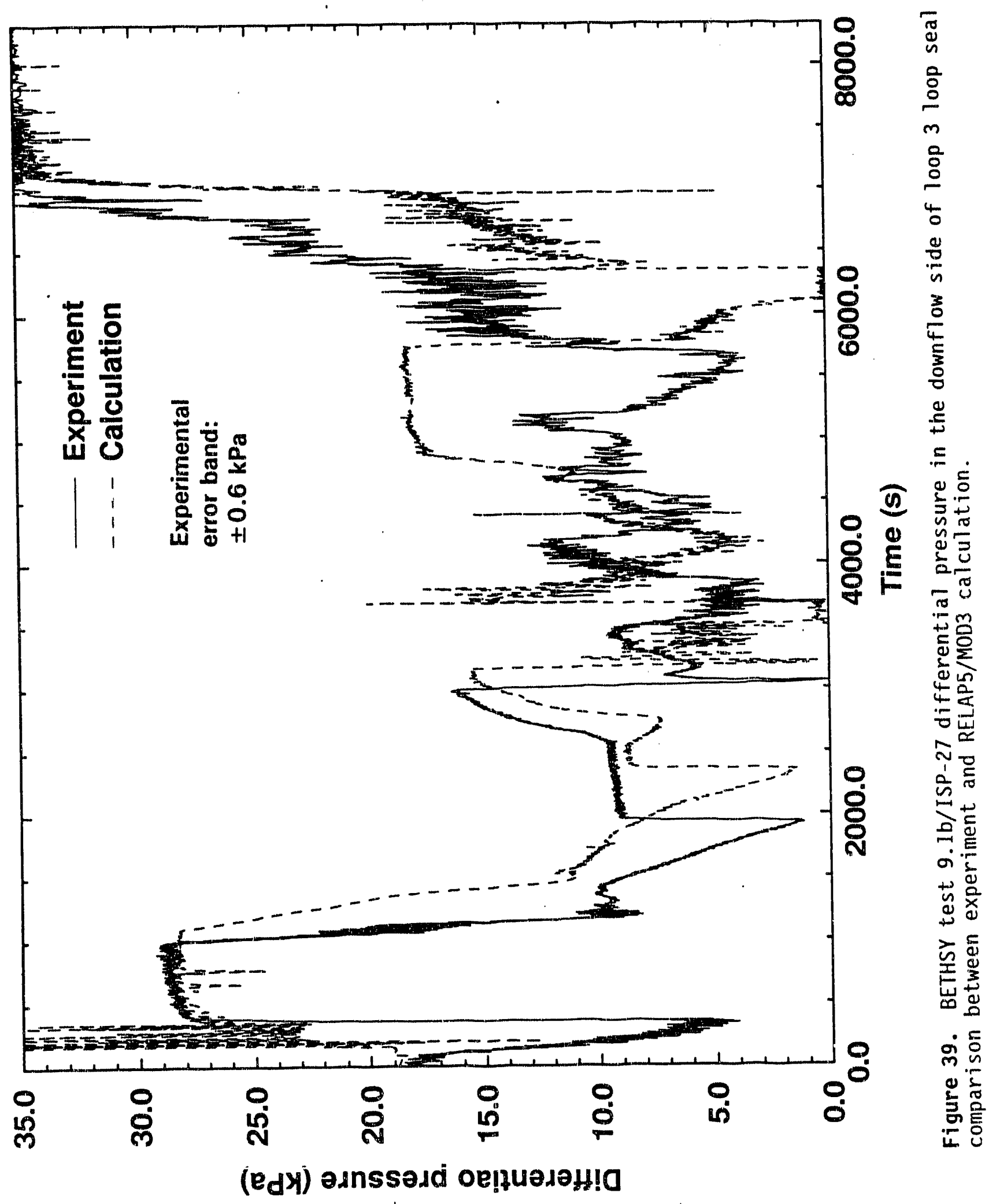


1 comparison plot (not shown) was the same as the plot for loop 3 with the exception of the initial experimental data offset.

Figure 40 shows the downcomer mass flow rate calculated by the code and found in the experiment. Agreement is reasonable with the exception of the time period between 150 and 400 seconds during which time the calculated values fell far below the experimental values. During this period the pumps were still on, but in the calculation, void had started to appear in them. The single phase input data used for the RELAP5/MOD3 pump mode1, were taken from data provided by the experimenters. However, the experimenters did not have complete two-phase data available and had only provided broad general estimates for much of the information. For this reason the input data for the pump two-phase multipliers and two-phase difference tables were taken from the Semiscale pump information. This hybrid pump input data may have acted alone or may have combined with some pump model problems to cause the discrepancy. However, this error appears to have no net effect on the overall outcome of the transient.

Figure 41 shows the performance of the vapor pull-through/liquid entrainment model in RELAP5/MOD3. The break was modeled as a connection to the middle of the side of the cold leg pipe. If a regular junction were used the junction void would always be the same as the void in the upstream cel1. If one only considered the water level in the pipe, one would expect the junction void to be zero until the upstream cell void exceeded 0.5 and then one would expect the junction void to be one. Using the vapor pullthrough/liquid entrainment model provides a compromise between these two extremes. The plot shows the void fraction in the cell feeding the break and the void of the fluid leaving the break. From analysis of Figure 41 it can be seen that for low upstream voids the break void was zero, but slightly higher voids upstream provided some void to the break even though the level was not yet down to the level of the break nozzle (vapor pullthrough). At higher voids, where the level in the upstream cell was below the break, the void in the break junction was less than one (1iquid entrainment). The actual observed values analyzed from the plot are summarized in Table 9 . These values appear to be physically realistic. The 


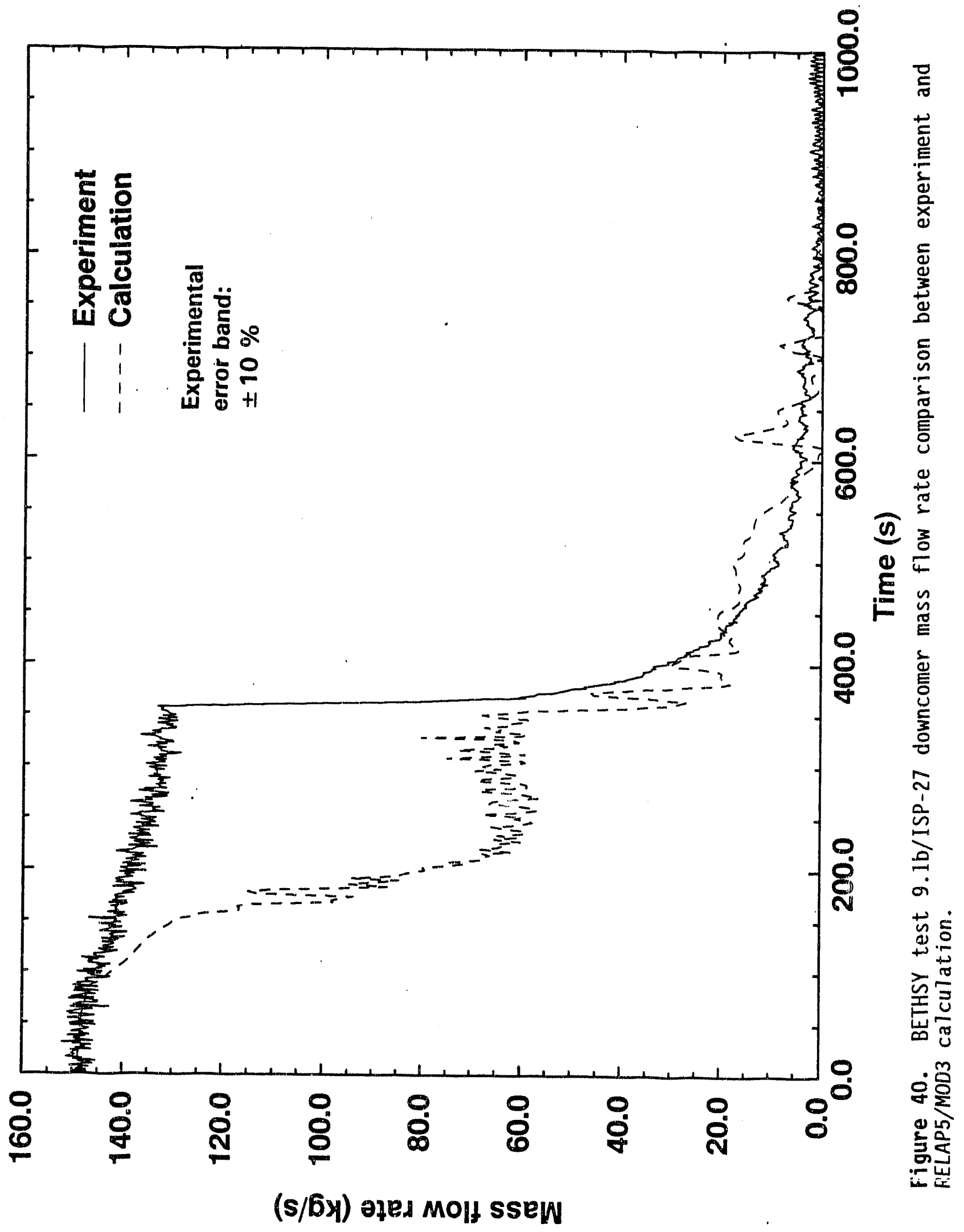




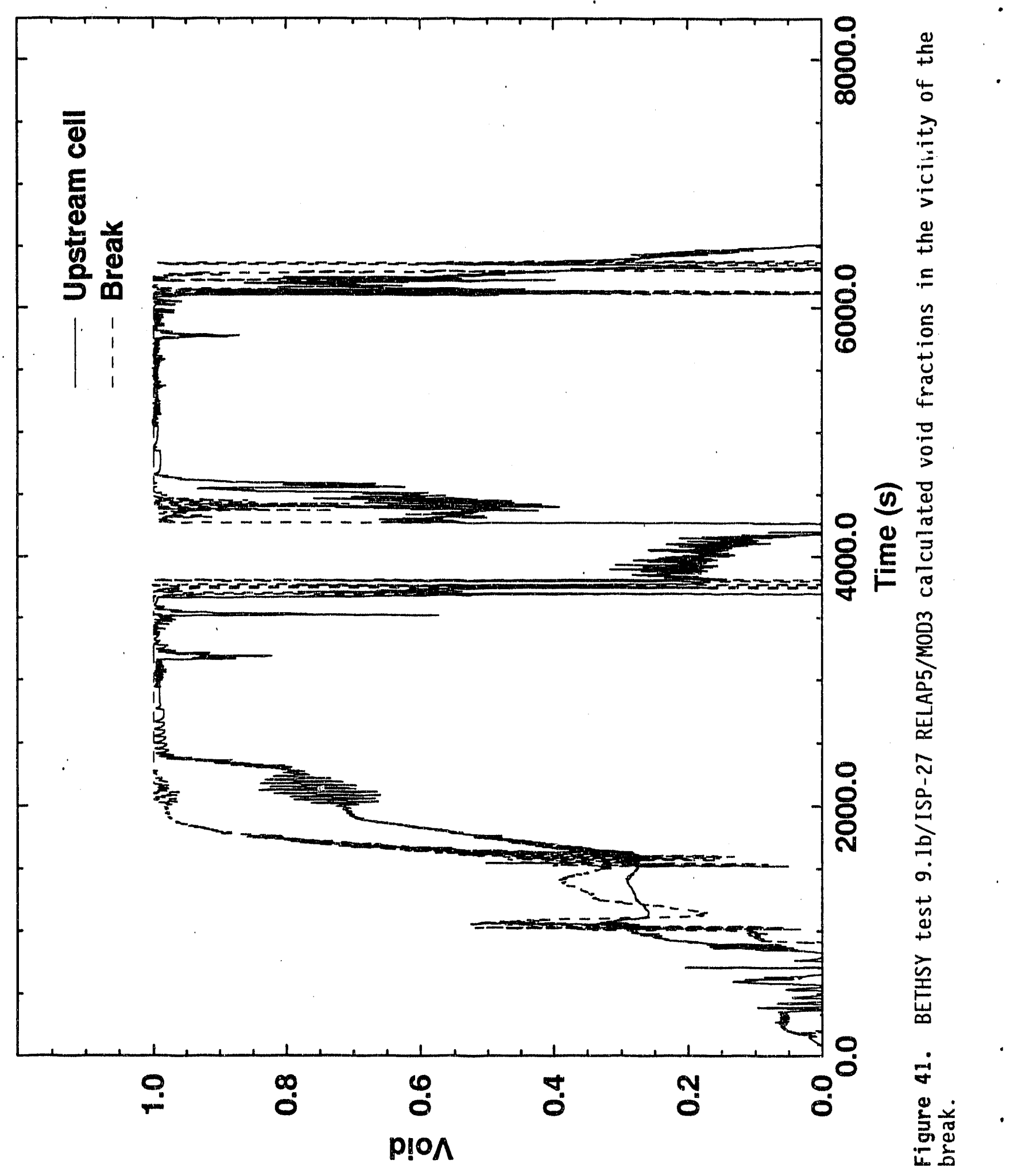


Table 9. Observed ranges for vapor pul1-through/liquid entrainment.

Upstream Cell Void Range

$0.00-0.19$

$0.19-0.27$

$0.27-0.80$

$0.80-1.00$
Break Void

0.0

above 0.0 but lower than upstream cell above upstream cell but under 1.0 1.0

vapor pull-through/liquid entrainment model is performing as expected. It would have been desirable to perform a direct comparison with experimental data to further verify this model but the ccld leg void fraction was measured too far from the break to make a good comparison.

\subsection{Test 6.2 TC Calculation versus}

\section{Experiment Comparison}

Table 10 shows the calculated and experimental initial conditions for test 6.2 TC. Most parameters were obtained within the experimental uncertainty range except the pressurizer level and steam generator differential pressures. The $3.5 \%$ deviation of the calculated pressurizer level from the measured value will not cause a noticeable difference in the outcome of the transient. Since the steam generator tubes do not uncover during the transient, the deviation in the initial steam generator secondary differential pressures will also have no effect.

Table 11 gives a summary of the major events and parameters as found in the experiment and in the calculation. The scram occurred slightly earlier in the calculation than in the experiment since the calculated break flow is slightly higher initially which lowers the pressure to the scram point more quickly. Otherwise, prior to the time when the primary pressure fell below the secondary pressure (ie. primary/secondary pressure reversal at about 170 seconds), the calculation showed good agreement with the experiment. Thereafter, because the calculated break flow was greater than the experimental value, the calculated events occurred earlier than in the experiment. 
Table 10. Comparison of experimental and calculated initial conditions for BETHSY test 6.2 TC

\begin{tabular}{lccc}
\hline \multicolumn{1}{c}{ Parameter } & Experimental & Calculated \\
Core power (kW) & $2863 \pm 30$ & 2863.0 \\
Pressurizer pressure (MPa) & $15.38 \pm 0.15$ & 15.38 \\
Pressurizer level (m) & $7.45 \pm 0.2$ & 7.19 \\
Pump speed (rpm) & $238 \pm 6$ & 238.0 \\
Core inlet temperature (K) & $557.15 \pm 4$ & 557.75 \\
Core outlet temperature (K) & $588.15 \pm 4$ & 588.75 \\
Primary system mass with & & \\
pressurizer (kg) & $1984 \pm 50$ & 1972.0 \\
Secondary system pressure (MPa) & $6.84 \pm 0.07$ & 6.81 \\
Secondary steam generator level (m) & $11.1 \pm 0.5$ & 11.2 \\
$\begin{array}{l}\text { Feed water temperature (K) } \\
\text { Feed water flow rate per steam }\end{array}$ & $523.15 \pm 4$ & 523.15 \\
generator (kg/s) & 0.55 & 0.55 \\
Bypass flow: downcomer to upper & & 0.28 & \\
head (\% of total loop flow) & 54.82 & 54.61 \\
Environmental heat loss (kW) & & \\
\hline
\end{tabular}

Table 11. Comparison of experimental and calculated chronology for BETHSY test 6.2 TC.

\section{Events}

Scram Signal (s)

SI Signal (s)

Loop Seal Clearing (s)

First Core Uncovery Start (s)

First Core Uncovery Minimum Level

- Minimum Collapsed Level (m)

- Maximum Rod Temperature Rise (K)

Primary/Secondary Pressure Reversal (s)

Second Core Uncovery Start (s)

Second Core Uncovery Minimum Leve

- Minimum Collapsed Level (m)

- Maximum Rod Temperature Rise (K)

Loop 2 Accumulator Injection (s)

Loop 3 Accumulator Injection (s)

End of test ( $s$ )
Experimental

\begin{tabular}{c} 
Base Cal. \\
\hline 5.34 \\
10.58 \\
137 \\
92 \\
134 \\
0.82 \\
$<1$ \\
161 \\
230 \\
335 \\
1.18 \\
48 \\
$294-701$ \\
$294-693$ \\
1800.3
\end{tabular}


The calculated and measured break mass flow rates are compared in Figure 42. The two values are usually within the $10 \%$ experimental error band even though the calculated value is generally above the measured value. The drop in break flow rate, which occurred at the time of loop seal clearing, occurred at the same time for both. In this case the break flow rate was enough higher than the measured value that it caused early event occurrence later in the transient.

Figure 43 shows the primary system pressure for the calculation and the experiment. The calculated primary depressurization rate was too high between 150 and 350 seconds. This is probably due to the slightly high calculated break mass flow rate during this time period.

Figure 44 shows the secondary system pressure. The initial pressure spike is lower in the calculation than in the experiment. Additional work is required to fully define the causes of this discrepancy. One of the contributors is the code's underprediction of the primary to secondary energy transfer. This problem is well known. Normally the code user compensates for the code's underprediction by adjusting the secondary hydraulic diameter to obtain the correct primary to secondary energy transfer rate at steady-state initial conditions. ${ }^{13}$ However the appropriate hydraulic diameter adjustment is a function of the power level. Thus, as the power level decreases, the hydraulic diameter value used at steady-state conditions should be modified but the code has no provisions for such an adjustment. ${ }^{14}$ Another of the potential contributors is less well defined. Past versions of the code, e.g. RELAP5/MOD2, have underpredicted the quantity of secondary inventory present for the steam generator normal operational level due to a deficiency in the interphase drag model. RELAP5/MOD3 will calculate less interphase drag under the same conditions as MOD2, but the total effect on the secondary inventory level for a given secondary level measurement has not been defined in assessments to date.

The secondary pressure spike observed in the data is a function of both the primary to secondary energy transfer and the secondary inventory leve1. These parameters are linked to the pressure spike by the change in boiling rate and the quantity of inventory that boils. Assessment of the code's secondary modelling capability is required. 


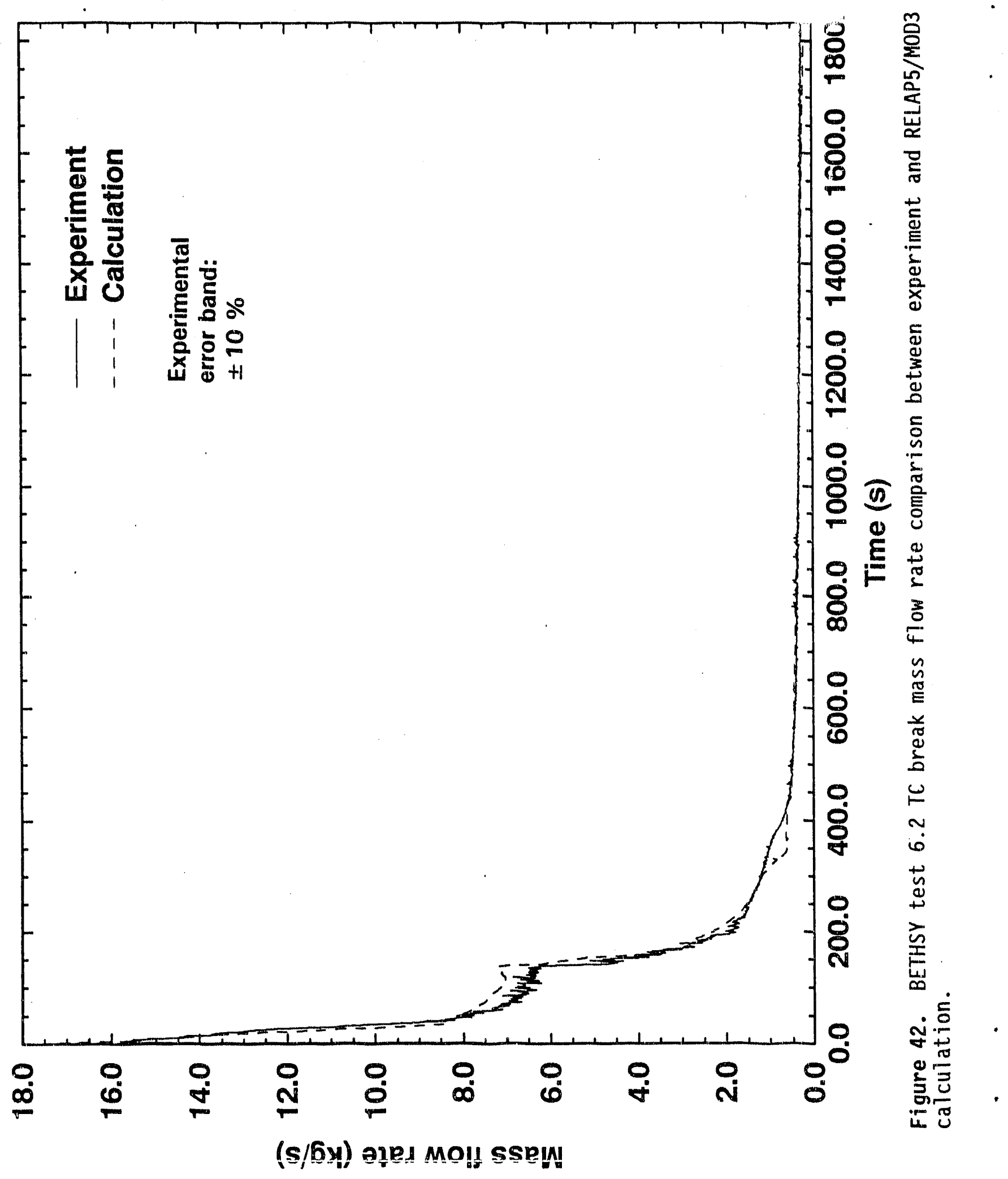




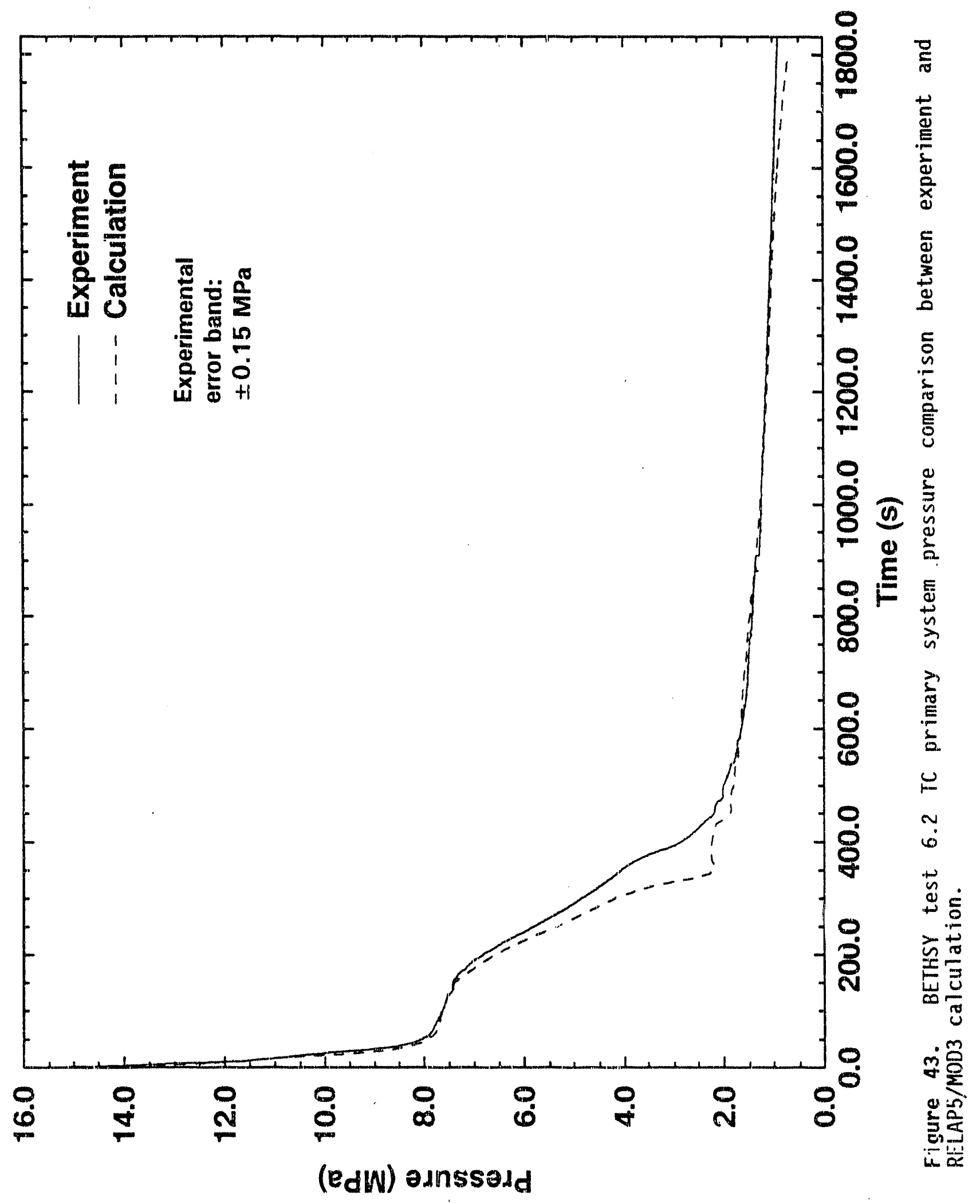




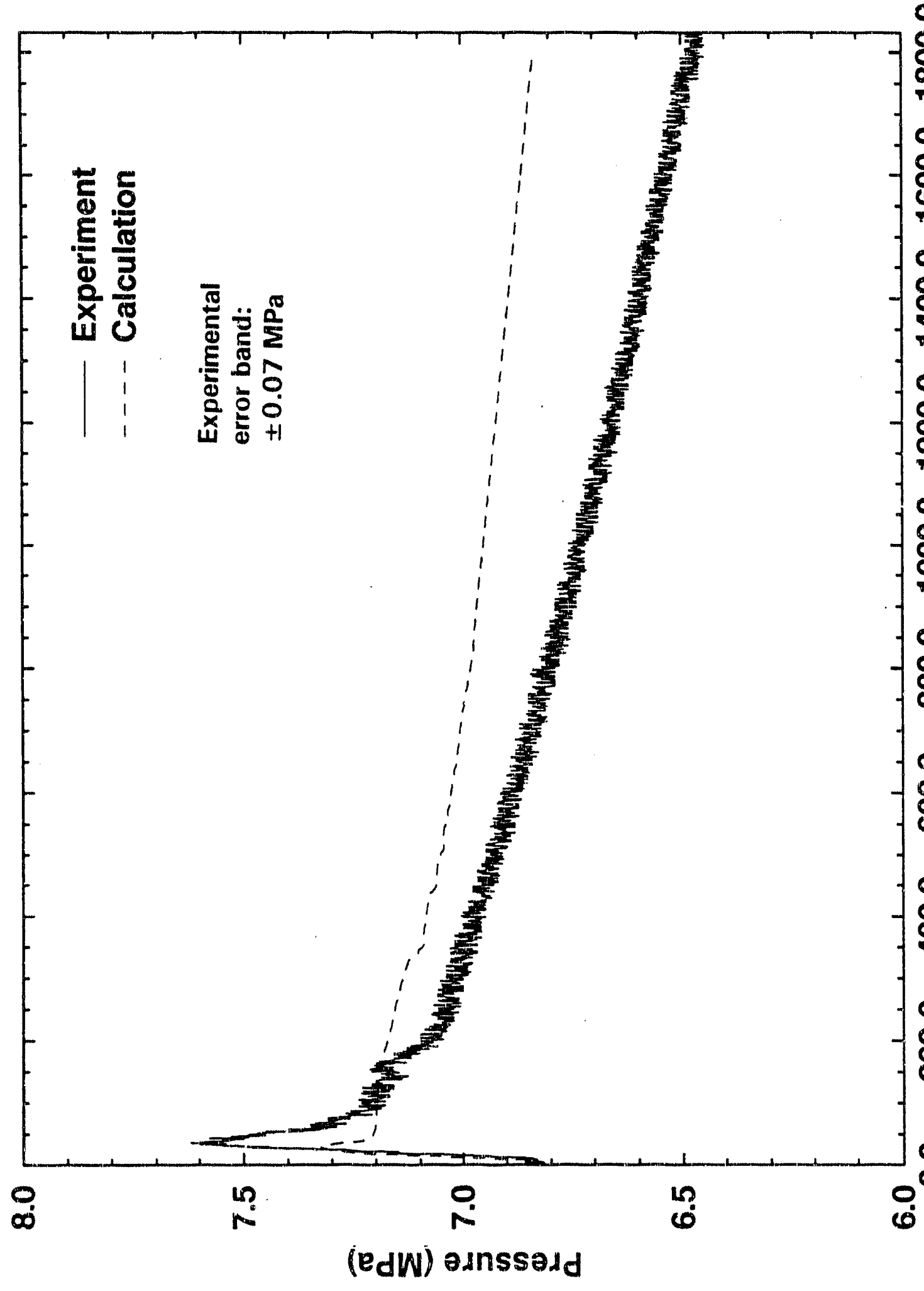

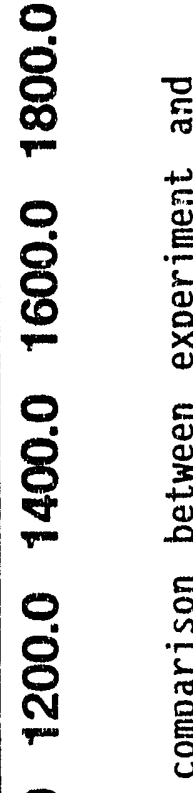

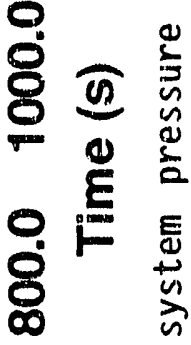

8 苋

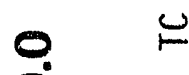

8

0 岕

8

o

ㄴำ

녹음

몬 
During the latter part of the transient the depressurization rate, shown in Figure 44, was higher in the experiment than in the calculation. This is due to an inaccuracy in modeling heat Tosses from the secondary but, since late in the transient the effect of the secondary on the primary is only to contribute a small amount of heat, this discrepancy will have little influence on primary performance.

The experimental and calculated values for the integrated mass injected by one of the accumulators are compared in Figure 45 . (Note: both accumulators behave the same.) The calculated injection is shifted to an earlier time due to the overestimation of the break flow rate which caused an early drop in mass inventory. The measured accumulator injection was continuous whereas the calculated accumulator injection was intermittent. The calculated periodic interruptions result from surges of vaporization in the core as the accumulator liquid is heated and boils. Whether this is a calculational inaccuracy caused by nodalization and/or the one dimensional nature of the calculation or a model deficiency, is beyond the scope of this analysis.

The rapid clearing of a typical loop seal is shown in the plot of the experimental and calculated differential pressure in the downtlow side of the loop saal (Figure 46). The timing of the calculation and experiment are in good agreement. There was an initial offset due to an input deck error which caused an inaccurate calculation of large values of this differential pressure. This error only occurred in the input for the analysis of test 6.2 TC.

The total calculated and measured primary fluid inventory history is plotted in Figure 47. The calculated and measured values show good agreement until loop seal clearance. Afterwaras, the calculated value decreased more rapidly than the experimental value until accumuiator injection. The divergence results from the difference in the break flow.

The calculated and measured core collapsed liquid levels are compared in Figure 48. As indicated in Table 11, the first level depression. Was well modeled in the calculation but the second depression occurred earty, was too deep and too long. After loop seal clearing, the calculated core level was usually lower than the measurec value. Figure 49 shows the differential 


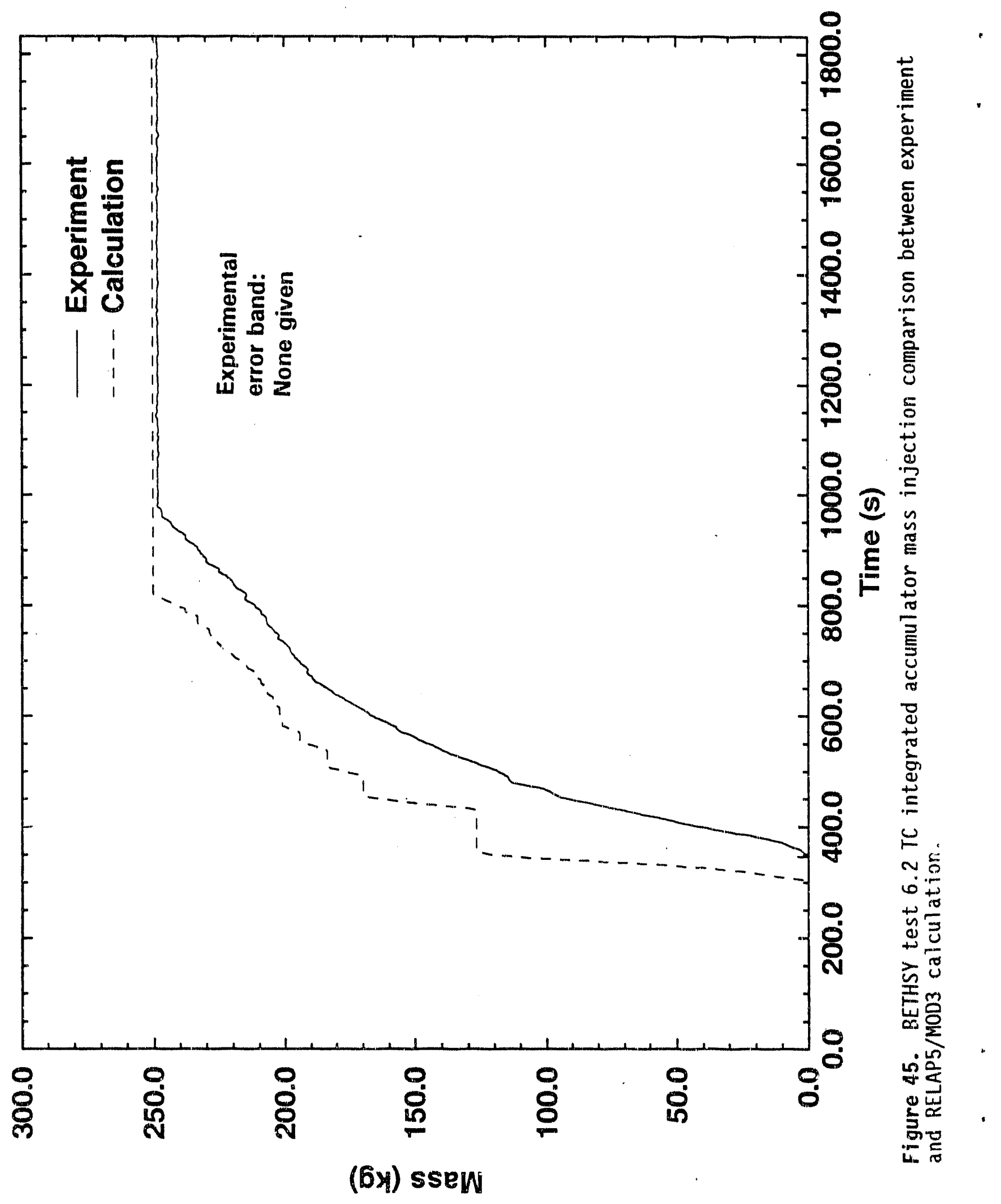




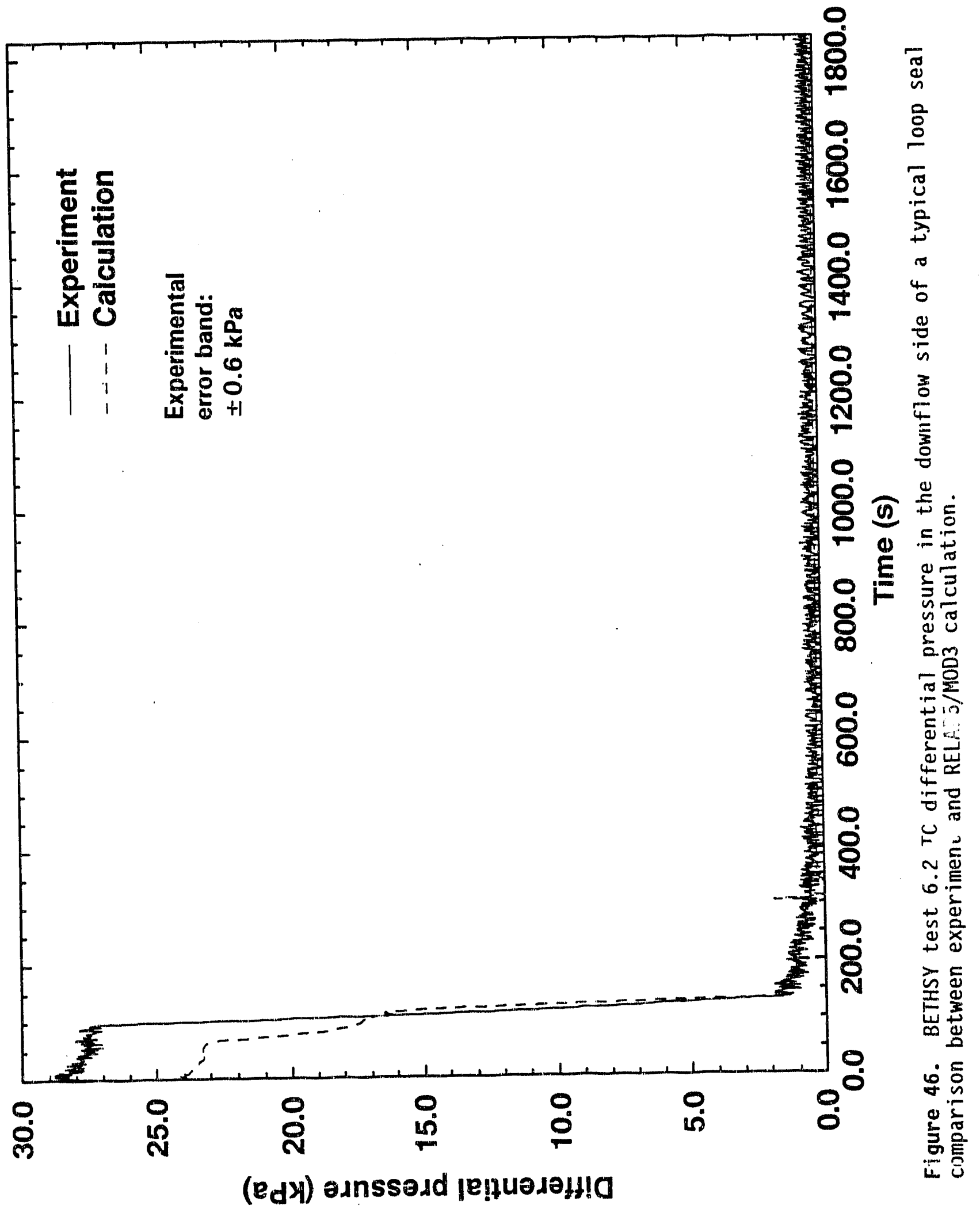




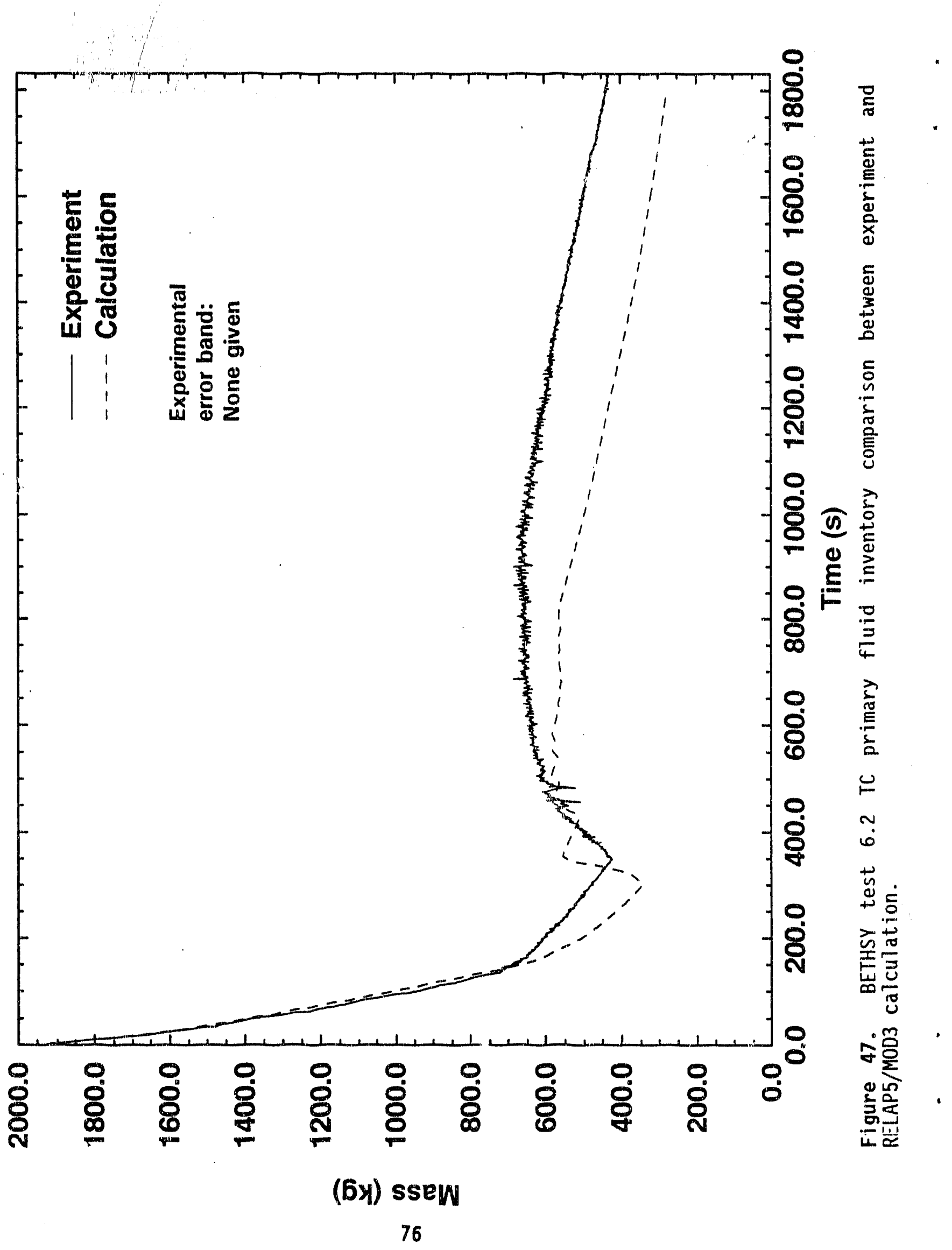




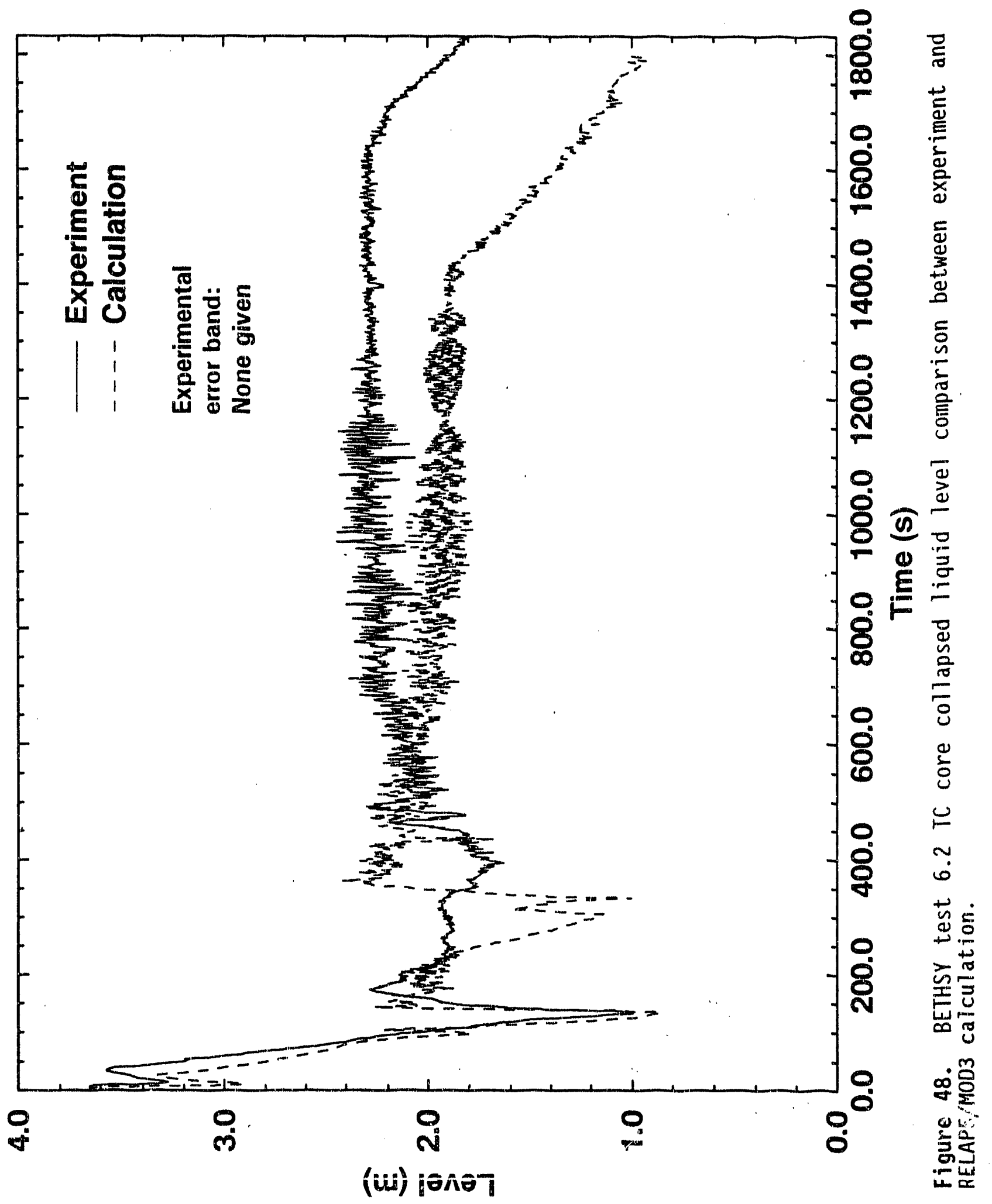




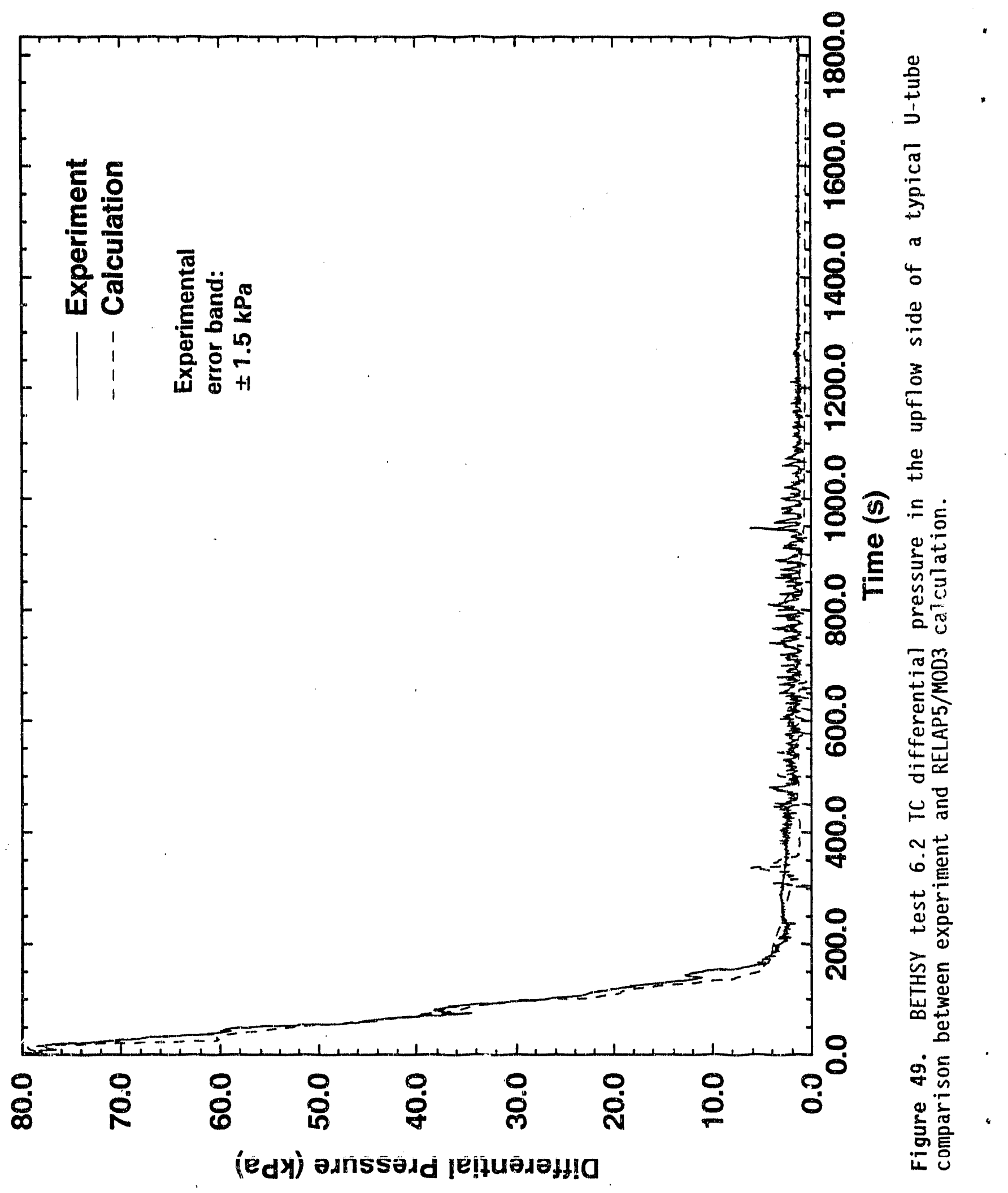


pressure in the upflow side of the steam generator $U$-tubes. Agreement is good except at the time of loop seal clearing (135-150 s) when, in the experiment, liquid was retained in the upflow side of the U-tubes. No evidence of liquid holdup not appeared in the calculation. Thus both the core and the $U$-tubes held less liquid in the calculation than in the experiment. This could have been caused by the cumulative effect of the high break flow rate on the overall primary system mass inventory.

Figures 50 and 51 show the rod $\mathrm{clad}$ temperatures at $1.628 \mathrm{~m}$ and 3.6 $m$ above the bottom of the core respectively. In each case the calculation underpredicted the temperature in general. This was due to the fact that the calculation values represent a regional average temperature while the experimental thermocouples, whose data are displayed, represent very localized values. The second core level depression which was calculated to be early, prolonged, and deeper than measured (see Figure 48) is shown in Figure 51 to cause a heatup which is earlier and larger than in the experiment. The core heatup at the end of the transient was early in the calculation because the core level was underpredicted. The root cause of all of these discrepancies could be the low calculated inventory due to high calculated break flow.

Results from the vapor pull-through/liquid entrainment model are not shown here because, since this is a fairly large break, the level in the cold leg only spends a very short period of time in the region where the model would take effect. The calculation data sampling frequency was not high enough to obtain a significant number of points while the model was functioning.

A sensitivity calculation was performed with a slightly modified input deck which utilized the ECCMIX component in the cold leg at the point of accumulator injection and applied the CCFL model at the tube sheet in the primary piping. The results, discussed below, were largely similar to the results found in the base case calculation. Thus the use of the ECCMIX component and the CCFL model are not important for the calculation of this transient.

The condensation rates at the accumulator injection point for the base case and sensitivity calculations are shown as a negative vaporization rates 


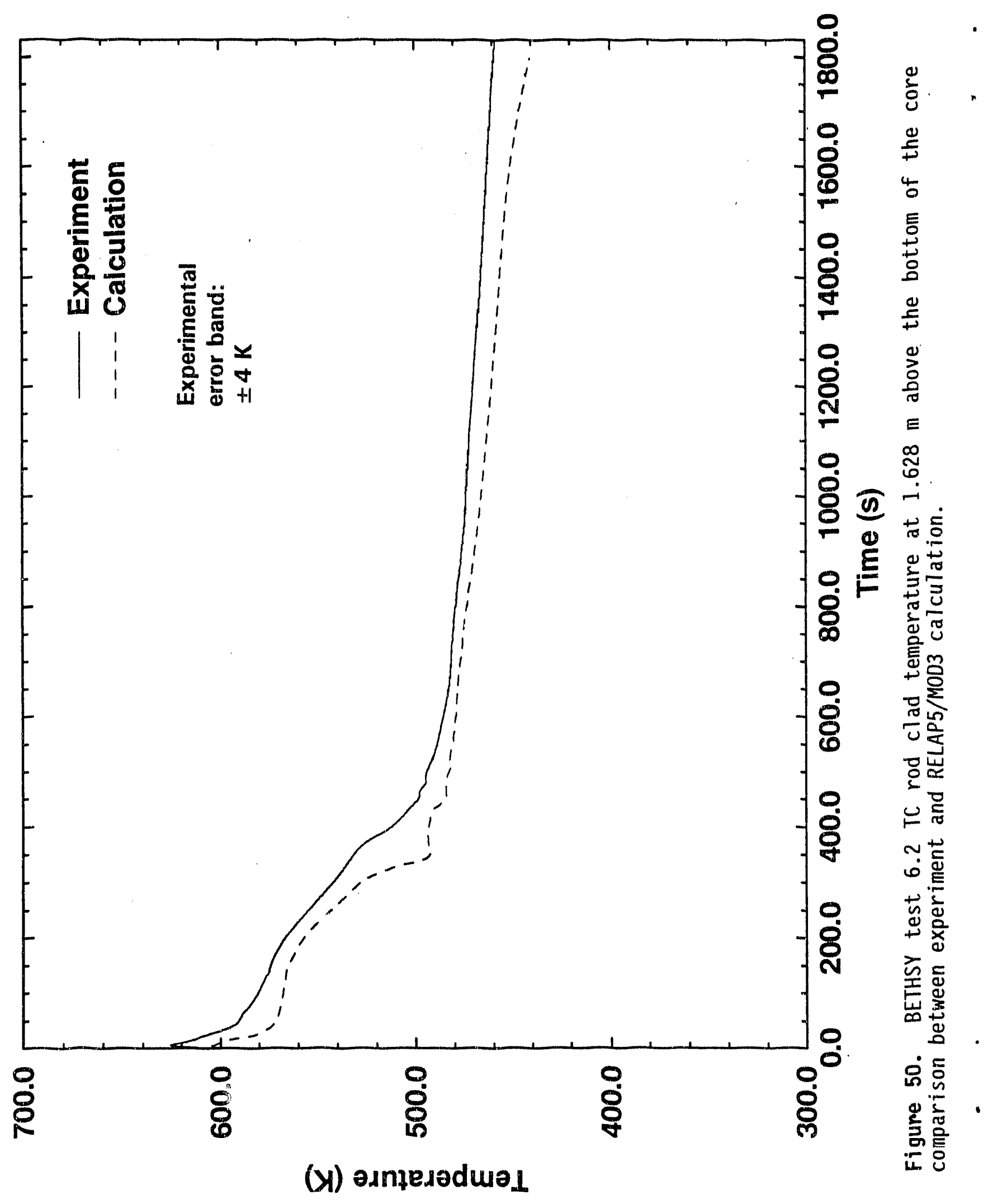




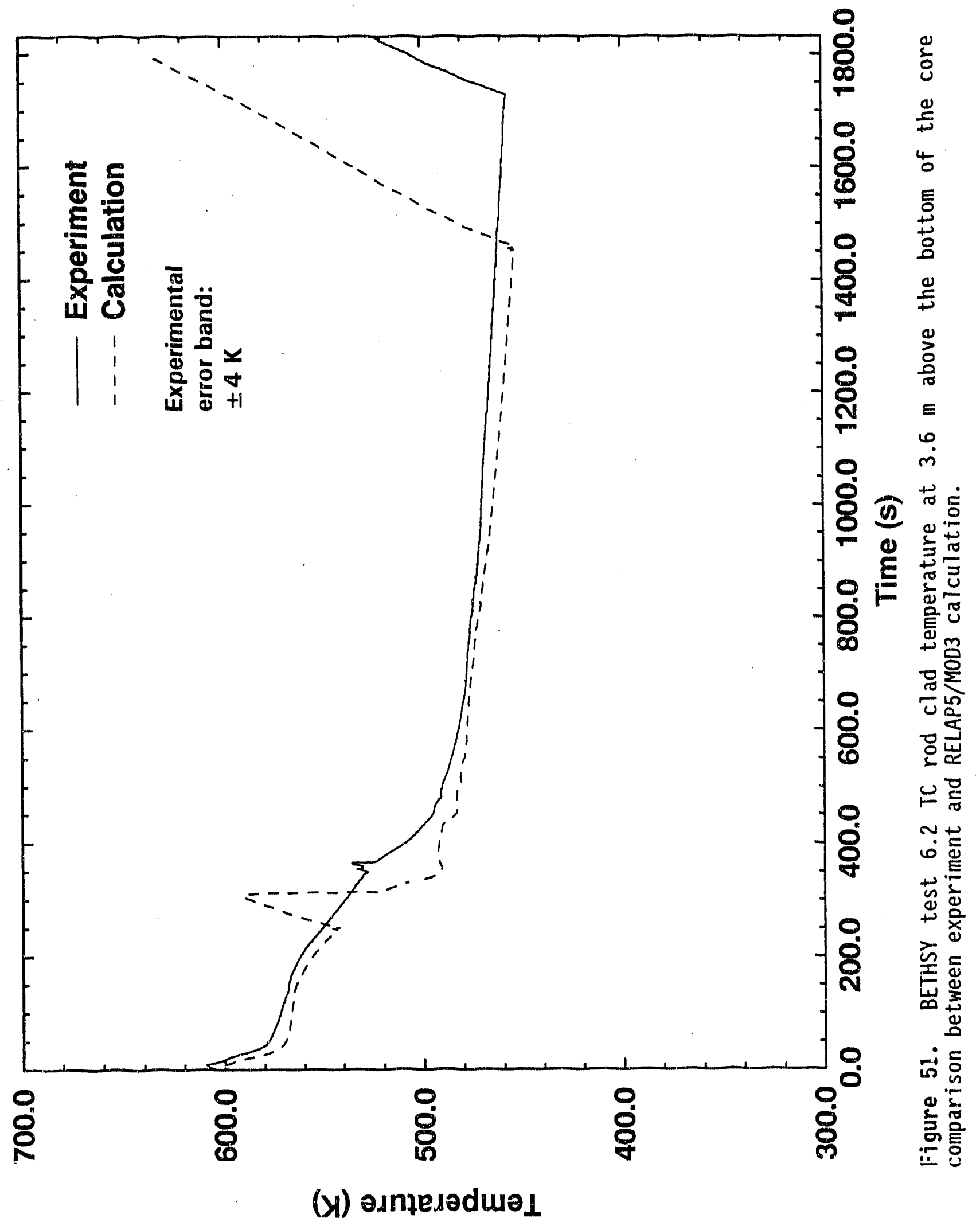


in Figure 52. There is no significant difference. Thus for this test, with a larger break than in test $9.1 \mathrm{~b} /$ ISP-27, the ECCMIX component could be used without causing difficulty. However, it probably would not improve the quality of the results either.

Figure 53 shows the core collapsed liquid level around the time of the first level depression (130 seconds) for the experiment and the two calculations. The sensitivity calculation shows a much lower level in the core at that time. This difference between the two calculations is due to a larger liquid holdup in the steam generator $U$-tubes since the sensitivity calculation implemented the CCFL correlation.

The CCFL model performance can be evaluated using Figure 54 which plots the square root of the dimensionless liquid flux $\left(H_{4}\right)$ versus the square root of the dimensionless vapor flux $\left(H_{0}\right)$.

$$
\begin{aligned}
& H_{g}=j_{g}\left[\frac{\rho_{g}}{D_{f}\left(\rho_{f}-\rho_{g}\right)}\right]^{\frac{1}{2}} \\
& H_{f}=j_{f}\left[\frac{\rho_{f}}{D_{j}\left(\rho_{f}-\rho_{g}\right)}\right]^{\frac{1}{2}}
\end{aligned}
$$

where $j_{0}$ is the gas superficial velocity $\left(a_{0} v_{0}\right), j_{f}$ is the liquid superficial velocity $\left(a_{1} v_{f}\right), \rho_{a}$ is the gas density, $\rho_{f}$ is the liquid density, $a_{0}$ is the gas volume fraction, $a_{f}$ is the liquid volume fraction, $g$ is the gravitational acceleration and $D_{i}$ is the junction hydraulic diameter. The CCFL limit line imposed in the model is shown. Some of the calculated points are marked on the plot by a plus sign. If the CCFL model were working properly, points would only be allowed to exist in the region

'Note: the work describer below, regarding iche errors in the CCFL model for RELAP5/MOD3 version 7 , was instrumental in defining the code problem. Since then modifications have been made in the CCFL model which should correct the probiem. These modifications wiil appear in the nexi reiease version of the code. 


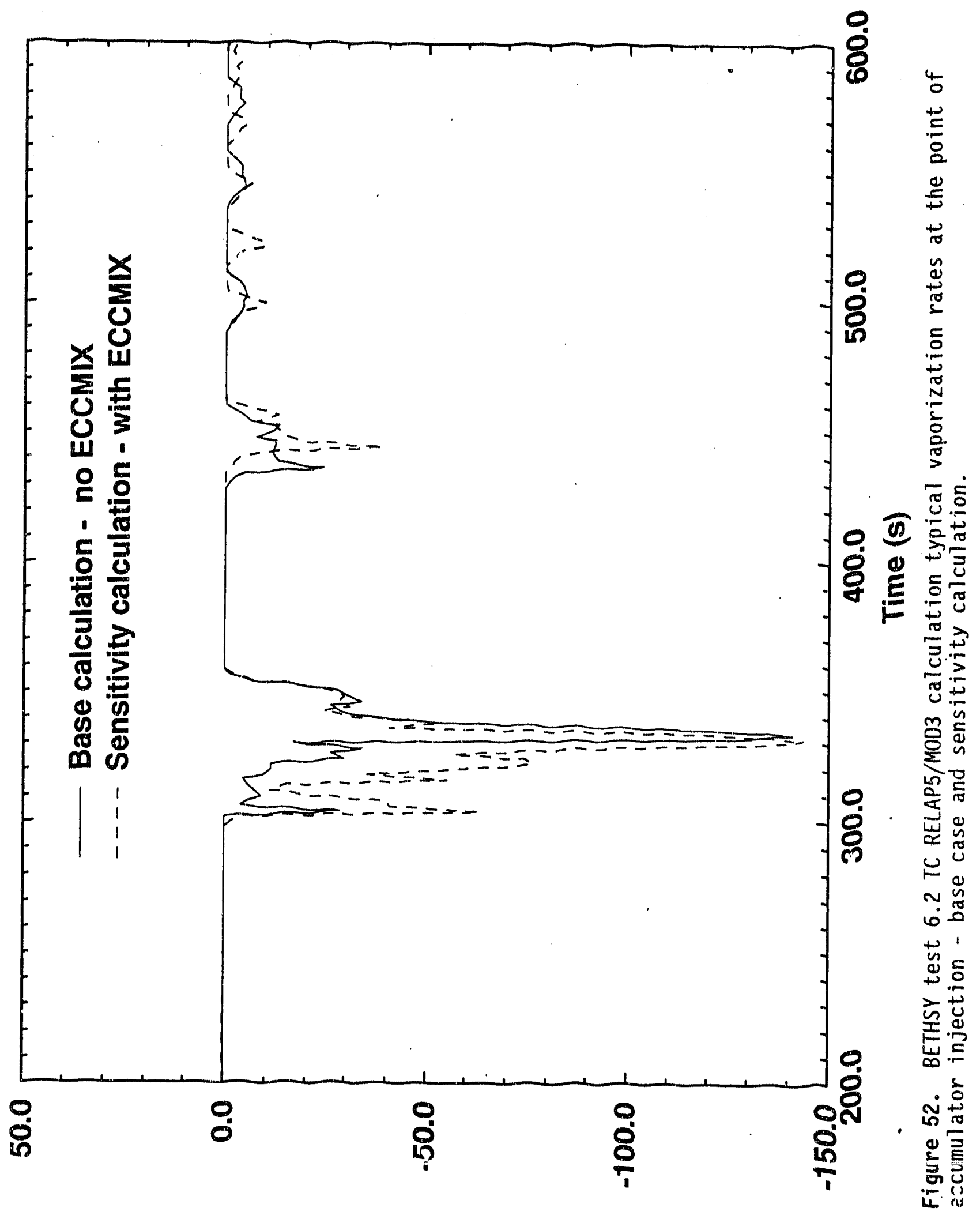

(s/u o!qno/6y) әңeג uo!̣ez!lode 


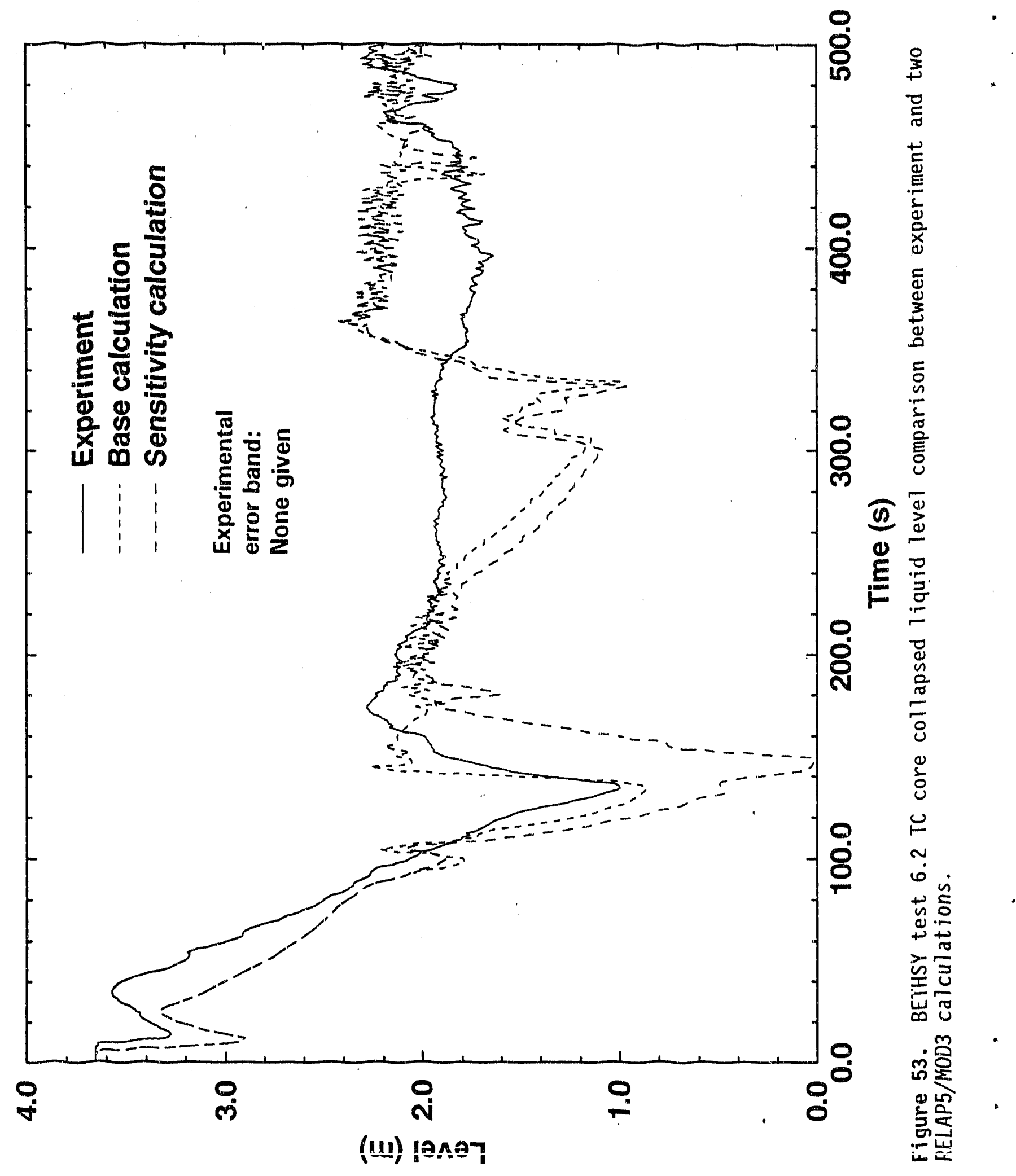




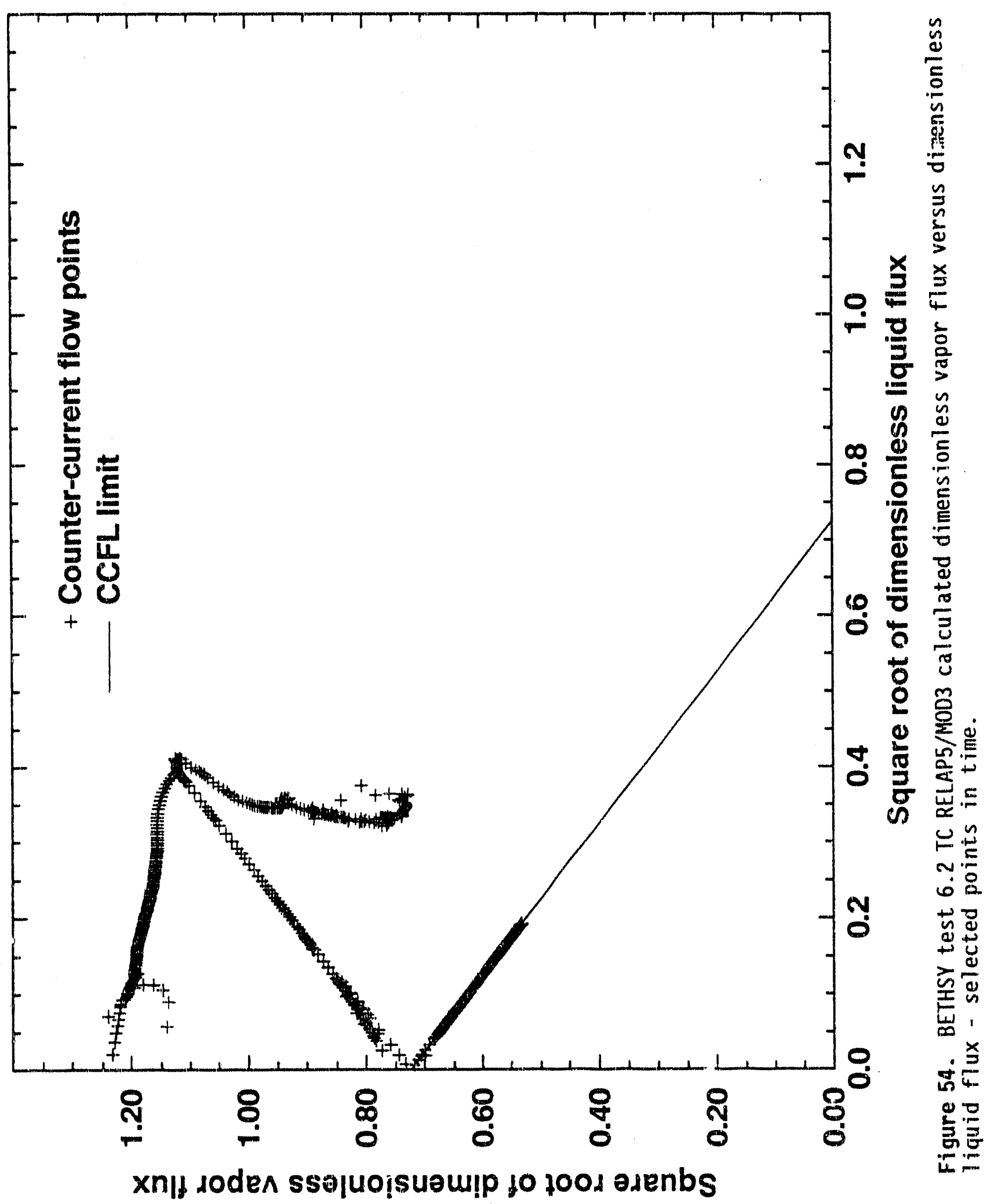


between the origin and the CCFL limit line or on the axes beyoir the intercepts with the limiting line. The figure shows that there are some valid points on the CCFL limit line, but there are a large number of points in the forbidden region. The points which violate the CCFL limit all occur during the time period from 100 to 160 seconds. All the points in the forbidden region have a square root of dimensionless vapor flux greater than 7.25 (the $y$-intercept), thus the CCFL model should have acted to limit the square root of the dimensionless liquid flux to be zero. If the calcuiation were performed with this CCFL model error corrected, there would be more liquid holdup in the U-tubes. This would improve the match with the differential pressure data in Figure 49 but it would make the core level depression in the sensitivity calculation even deeper. 


\section{OBSERVATIONS AND CONCLUSIONS}

Based on the code assessment results and data analysis discussed in the previous sections, the following conclusions and observations are in order:

1. Although some code deficiencies were evident, all trends in BETHSY tests $9.1 \mathrm{~b} / \mathrm{ISP}-27$ and 6.2 TC were qualitatively calculated by RELAP5/MOD3. The code's performance is judged as reasonable.

2. The model used for interphase drag may be deficient. This is indicated by the mismatch between the calculated and measured primary inventory distributions in the $U$-tubes, the cold leg, and the core during the latter part of both analyzed transients.

3. The CCFL model used in RELAP5/MOD3 version 7 contains an error and does not properly represent the limiting phenomena for high vapor flow conditions (specifically when the square root of the dimensionless vapor flux is greater than the value of the intercept of the CCFL limiting line). These results were instrumental in correcting the CCFL mode 1 and producing RELAP5/MOD3 version 8.

4. Further assessment is required to define the accuracy of RELAP5/MOD3 models related to secondary inventory and heat transfer.

5. The ECCMIX component should not be used when modelling the accumulator connection to the cold leg during a SBLOCA but can be used when modelling larger break sizes. 
6. The technique of using a single volume with choking junctions at each end and a correct length-todiameter ratio to model the large aspect ratio break nozzles used in the BETHSY facility is effective. 


\section{REFERENCES}

1. K. E. Carlson, et a1., RELAP5/MO03 Code Manual (Draft), NUREG/CR5535, EGG-2596, June, 1990 .

2. Guidel ines and Procedures for the International Code Assessment and Applications Program, NUREG-1271, U.S. Nuclear Regulatory Commission, Apri1, 1987.

3. BETHSY General Description, Centre d'Etudes Nucleaires de Grenoble, Note SETh/LES/90-97, Avri1, 1990.

4. T. Chataing and P. Clement, BETHSY Preparatory Workshop for International Standard Problem 27, 2" Cold Leg Break without HPS I and with Delayed UTtimate Procedure, Centre d'Etudes Nucleaires de Grenoble, Note SETh/LES/90-104, June, 1990.

5. T. Chataing and P. Clement, BETHSY Preliminary Data Comparison Report. for International Standard Problem 27, 2" cold Leq Break without HPSI and with Delayed UTtimate Procedure, Centre d'Etudes Nucleaires de Crenoble, Note SETh/LES/91-48, Novembre, 1991.

6. D. Juhel and G. Briday, BETHSY Test 6.2 TC, 6 Inch Cold Leq Side B. eak Comparative Test, Test Report, Centre d'Etudes Nucleaires de Grenoble, Note SETh/LES/90-112, September, 1990.

7. G. Briday and D. Juhel, BETHSY Test 6.2 TC, 6 Inch Cold Leq Break Counterpart Test, Test Analys is Report, Centre d'Etudes Nucleaires de Grenoble, Note SETh/LES/91-034, 0ctobre, 1991.

8. C. D. Fletcher and C. M. Kullberg, Break Spectrum Analyses for Small Break Loss of Coolant Accidents in a RESAR-3s PTant, NUREG/CR-4384, EGG-2416, March, 1986.

9. P. A. Roth and R. R. Schultz, Analysis of Reduced Primary and Secondary Coolant Level Experiments in the BETHSY Facility Using RELAP5/MOD3, Idaho National Engineering Laboratory, EGG-EAST-9251, JuTy, 1991.

10. "BETHSY - The French Integral Test Facility for PWR Safety Studies," Thermohydraulic Laboratory, SETh/LES, Centre d"Etudes Nucleaires de Grenoble.

11. P. Bazin, BETHSY: Data Base, Note SETh/LES/87-28, Centre d'Etudes Nucleaires de Grenoble, March, 1988.

12. International Standard Problem 27. Selected Results from Characterization Tests of the BETHSY Break Nozzles (2", 6") conducted on the Super Moby-Dick Facility, Centre d'Etudes Nucieaires de Grenoble, Addendum to Note SETh/L.ES/90-104.

13. C. D. Fletcher and R. R. Schultz, RELAP5/MOD3 Code Manual, User's Guidel ines, Volume 5, NUREG/CR-5535, January, 1.992. 
14. R. J. Preece and J. M. Putney, Pre? iminary Assessment of PWR Steam Generator Modelling in RELAP5/MOD3, National Power, Great Britain, TEC/L/0539/R91, PWR/THSG/T(91)38, November, 1991. 

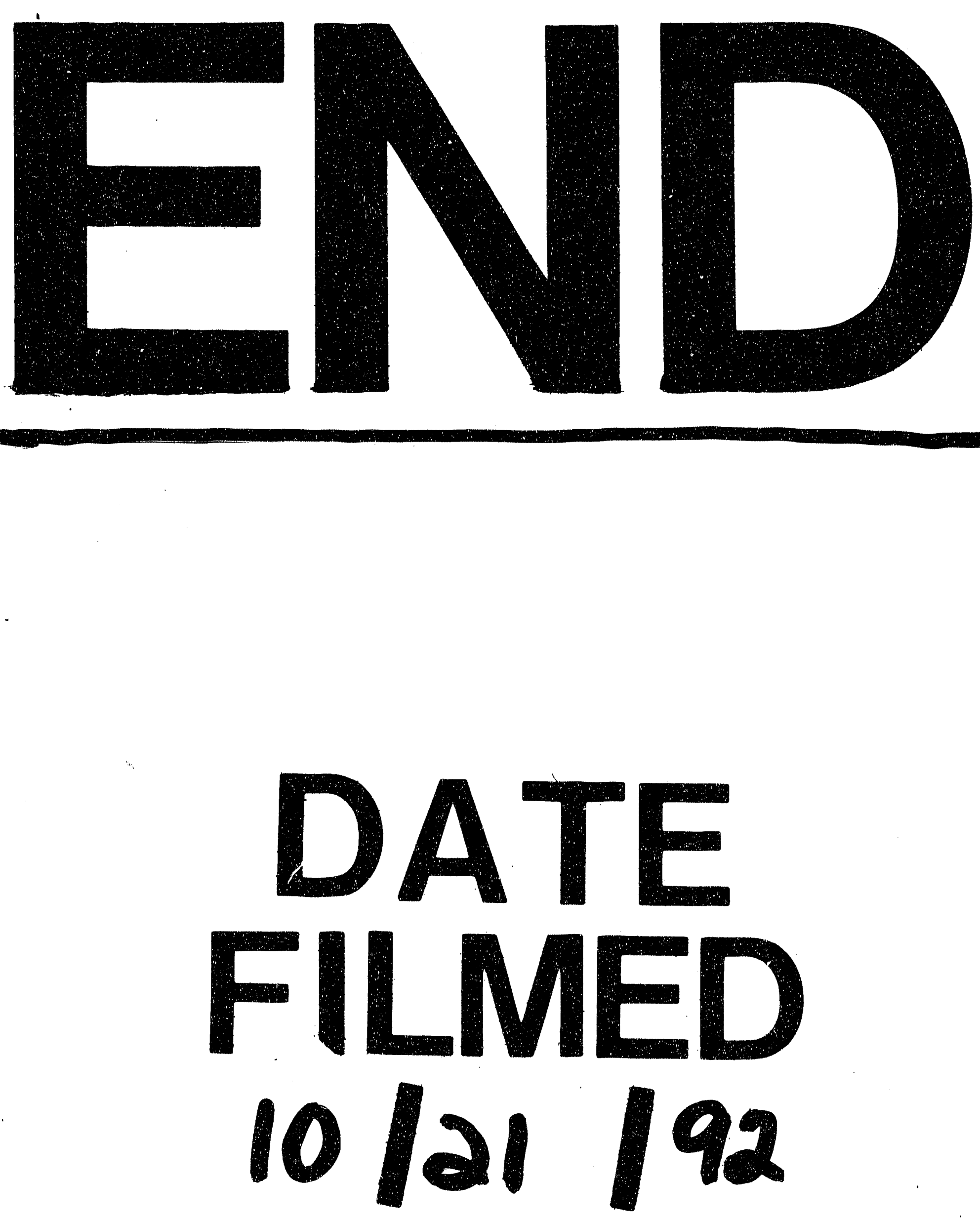
